$$
\text { IHE VEGETABIE GARDEN }
$$

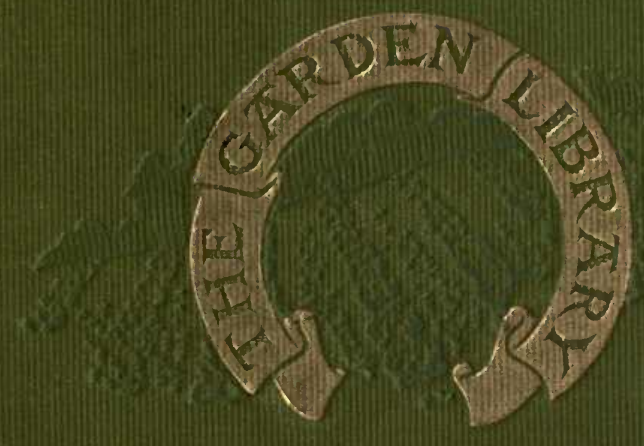




\section{LIBRARIAN'S FLiWi}

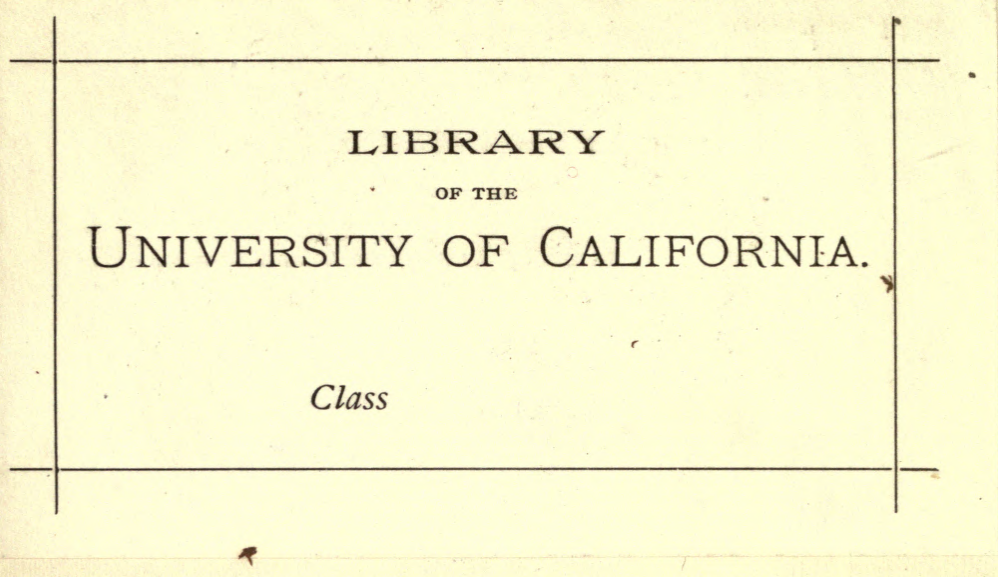









\section{THE VEGETABLE GARDEN}




\section{THE GARDEN LIBRARY}

Roses and How to Grow Them

By Many Experts

Ferns and How to Grow Them

By G. A. Woolson

Lawns and How to Make Them

By LEONARD BARRON

Daffodils-Narcissus and How to Grow Them By A. M. KIRBY

Water-Lilies and How to Grow Them

By H. S. Conard and Henri Hus

Orchard and Fruit Garden

By E. P. POWELL

The Flower Garden

By IDA D. BennetT 


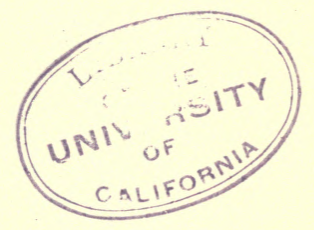




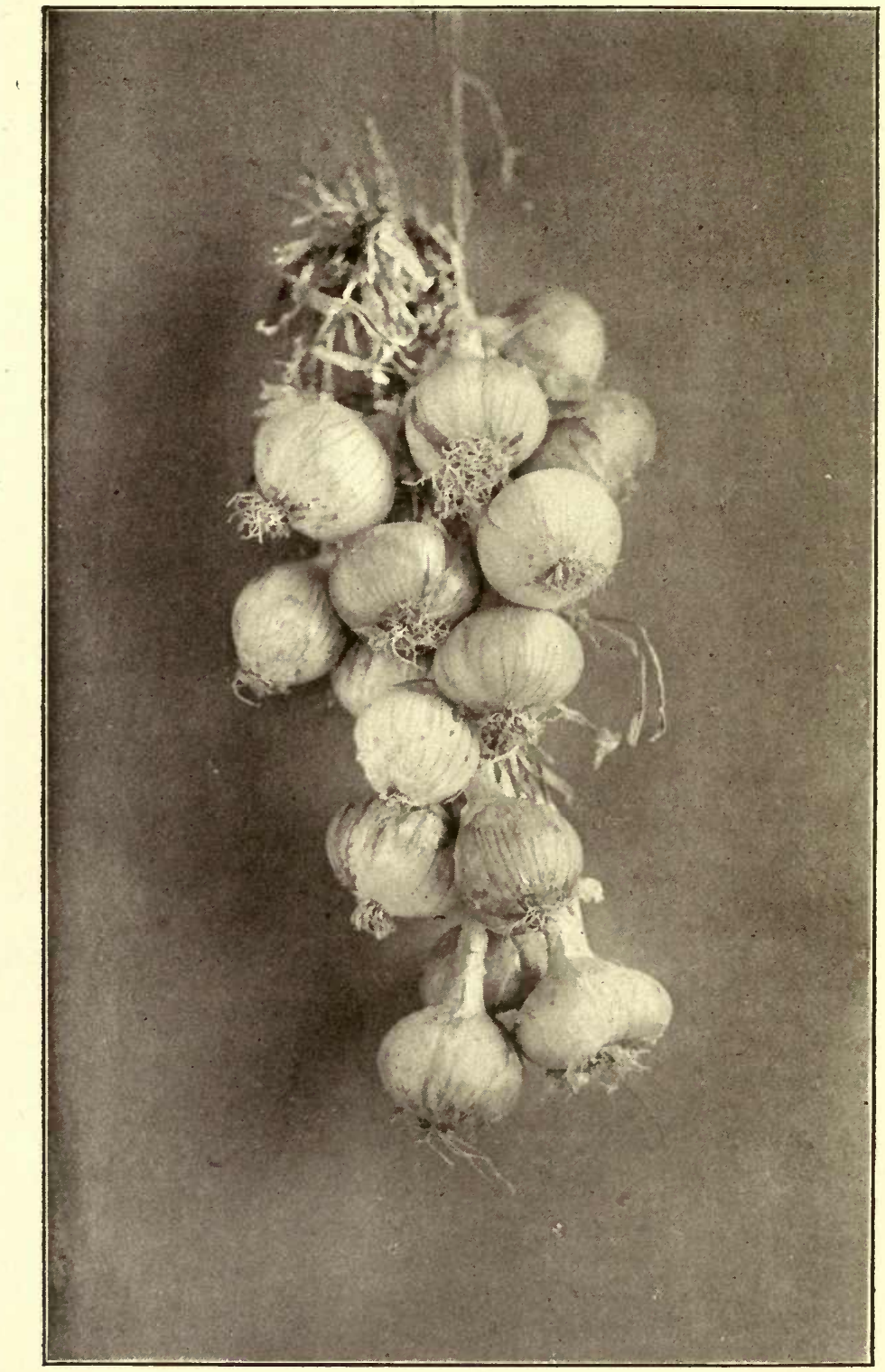

GIBRALTAR ONIONS, ONE OF THE BEST FOR THE HOME GARDEN 


\title{
The Vegetable Garden
}

A MANUAL FOR THE

AMATEUR VEGETABLE GARDENER.

\author{
By \\ IDA D. BENNETT \\ b)
}

ILLUSTRATED
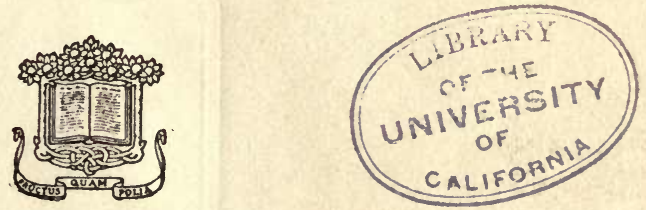

NEW YORK

DOUBLEDAY, PAGE \& COMPANY 1909 


$$
\begin{aligned}
& S B 321 \\
& B 5
\end{aligned}
$$

Copyright, I908, by The McClure Company

\section{LIBRARIAII'S FHID}

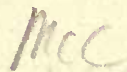




\section{A NOTE}

The author desires to acknowledge valuable assistance received from Dr. E. Porter Felt and William C. McCollom in the preparation of the chapter on Spraying; from Parker Thayer Barnes in the preparation of the chapter on Fertilising and the chapter on Garden Tools. She also wishes to express her indebtedness to Prof. Samuel T. Maynard for his careful revision of the text of the entire work. 


\section{CONTENTS}

CHAPTER

I. The Sanitary and Economic Value of the Kitchen Garden

PAGE

II. The Location of the Garden

III. Planning the Garden

IV. How to Maintain Fertility

V. The Construction and Care of Hotbeds, Coldframes, and Pits

VI. ON the Sowing of Seed

VII. Transplanting

VIII. Tools which Make Gardening Easy

IX. On the Growing of Various Vegetables

X. Root Vegetables

XI. Vine Vegetables and Fruits

XII. Greens and Salad Vegetables

XiII. Perennial Vegetables

XIV. Storing Vegetables in Winter

XV. The Garden's Enemies 



\section{II.LUSTRATIONS}

Gibraltar Onions, One of the Best for the Home GARDEN

Frontispiece

PAGE

A Garden Plan $\quad$ • $\quad$ • $\quad$ - $\quad$ - $\quad$ - 28

Liquid Manure is One of the Best-Acting Fer-

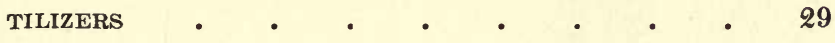

A Single but Serviceable Hotbed . • • • 48

Temporary Hotbeds in a City Back Yard • $\quad 49$

Straw Ḿrat for Use in Very Cold Weather • . 64

Showing Vegetables Growing in Hotbed • $\quad 65$

The Wheel Hoe is the Handiest Garden Tool 96

The Easiest-Running Wheel Hoe Valuable for

Marntaining a Dust Mulch $\quad$ • $\quad$ • 96

Paper Collar to Protect Plant from Cut-Worms . 97

A Home-Made Dibble $\quad$ • $\quad$ • $\quad$ • $\quad$ • 97

A Scuffle Mounted on Wheels . $\quad$. 112

The Scuffle Hoe Is Easier to Work than the

Ordinary Hoe $. \quad . \quad . \quad . \quad . \quad . \quad 112$

A Good Collection of Home-Grown Vegetables . 113

Letwuce Maturing in Home-Made Coldframe • 113

[ix ] 


\section{L L U S T R A T I O N S}

Japanese Chimbing Cucumber Nearly Six Feet from THE GROUND $\quad$ • $\quad$ • $\quad$ • 192 Well-Grown Cucumbers .

A Perfectly Grown Muskmelon • • • • 193 Fordhook Early Watermelons - • • • 193 Celery Banked with Earth to Blanch It $\quad$ • 208 Spraying with a Barkel Pump $\quad$ • $\quad$ • 209 Spraying with a Bucket Pump $\quad$ • $\quad$ • 209 A Practical Planting Table . $\quad$ • $\quad$ • 256 
THE VEGETABLE GARDEN 



\section{CHAPTER ONE}

THE SANITARY AND ECONOMIC VALUE OF THE KITCHEN GARDEN

$R_{\text {ECENT legislation has focused public atten- }}$ tion in no small degree upon the subject of pure food. Just what goes into the composition of the food we eat is becoming more and more a matter of inquiry by the consumer. It is doubtful, however, if the law requiring the constituents of tinned goods and sealed packages to be printed on the outside of the packages meets the full requirements of the case. It is probable that quite as much adulterated food is sold as at any time previous to the passage of the law. Many manufacturers rely upon the proneness of people to accept a thing as a fact without the trouble of personal investigation. Few people, it may be supposed, take the trouble to read the labels on the goods they buy, at least not until they are delivered at the house, and it is doubtful if the few who do take the precaution are much wiser for their pains. The bo- 
tanical and scientific names of the various adulterants convey little or no meaning to the average consumer. Still, anything in tin that has come through the government inspections and the wide publicity given the unsavoury details by the press of the country, is looked upon with a certain amount of suspicion by the general public.

The result of this suspicion has been to increase, in no small degree, the consumption of fresh fruits and vegetables by all classes. One naturally has confidence in anything which comes to her in its original form. It does not seem possible for anything to be other than it seems, and of this class of products the most inexperienced housewife feels confident to judge. If a cabbage is clean and bright-the outer leaves green and fresh, the inside fresh and crisp-what more could one ask? Well, to the initiated there does sometimes arise a question as to how all this immaculate crispness and freedom from the trail of the worm was attained. After even a few years' experience in the growing of cabbages and allied plants, one comes to know that their growing on any large scale, especially on old land, is not the simple or always the cleanly thing it seems. 
It is safe to assume that the average farmer and market gardener who raises cabbages for market is fairly conscientious in his methods. But this is not true of all, and it is not an unknown thing to hear of isolated cases where Paris green has been used freely after the heads are set on both cabbage and cauliflowers.

The use of Paris green on potatoes is an established practice, unavoidably so on plantings of any extent. All the products of the vine-cucumbers, squash, and melons-are subject to more or less "doping" at the hands of the professional, and currants, gooseberries, and grapes do not always escape their share of the death-dealing chemicals. Now there is little doubt that much of the applications used are, when applied early in the growth of the plant, ere yet it has set its fruit or formed a head, is harmless, but after a plant has made advanced growth, it is certainly the part of wisdom to keep it as near harmless to the human digestive tract as possible.

Anyone who has watched the action of the various insecticides, which may be plant poisons that kill the plants on which they are sprayed by entering into the circulation and destroying root and 
all, cannot but wonder how far the usual insecticides, especially the arsenates, may go in the circulation of the plants to which they are applied. There are certain plant-poisons-herbicides-on the market which it is claimed will kill out scrub oak, burdock, Canada thistle, and like persistent perennial growths; whether it does it or not, the fact remains that plants have the power of absorbing and carrying through the sap circulation to a limited degree foreign matter applied upon the surface.

It is considerations like this which make the growing of one's own kitchen vegetables so desirable, for though it may be practically necessary for the large grower to employ the aid of various poisons in order to produce a crop of any or many specific vegetables, on the restricted area of the home garden in many cases it is neither necessary nor desirable.

There is another point that has weight with the careful housewife-that of perfect cleanliness. If vegetables look clean and fresh one is apt to infer that they are fresh from the garden. This may be anything but the case. Market gardeners are not independent of time and seasons any more 
than the rest of mankind, and often find their crop ripening in advance of the market; especially is this the case in small cities or country towns, and the vegetables bought as fresh may have lain in the cellar of the gardener or green grocer for a week or more, and finally been sorted out from a heap of decaying matter and given a bath to make them presentable for offering for sale.

Much of the garden stuff offered in the open market or peddled from door to door was gathered the day before or even earlier and hauled long distances in an uncovered waggon over a dusty road, and we all know of what the dust of the road is composed, afterwards to lie exhibited on open stalls in markets or in front of stores, exposed to the flies or the attentions of every passing dog-and the benches are seldom above highwater mark - and the unspeakable dust and filth of the streets.

All this bids one pause when tempted to order one's daily supply of fresh vegetables from one's local grocer. Certainly it should, if one has a bit of land at command and the strength and ambition to work it or even the will to hire it worked, for there is profit, real and realisable profit, in the 
growing of one's own vegetables. Profit of health and of pocket for the expense of a small kitchen garden, properly managed, is light, the returns certain and enjoyable.

There are no vegetables like those which come wet with the morning dew from one's own garden to grace the breakfast table with the toothsome crispness of the scarlet radish or the fresh coolness of lettuce. Sweet corn, when detached from the parent stalk and has felt the heat of the day, loses half its sweetness; and peas have a delicate flavour easily impaired by lying in heaps, even though in a cool place.

To my mind there is nothing more disheartening on a marketing expedition than the sight of the limp vegetables exposed for sale, and it must indeed be a dearth in the family larder which induces me to purchase.

As to the expense incurred in growing one's own vegetables, it will be found comprised for the main part in the fitting of the land for planting and the trifling outlay for seeds. All varieties of seed, with the exception of peas, are of small cost. The usual five- or ten-cent packets of most kinds will be found ample. Where more than this amount 


\section{VALUE OF THE KITCHEN GARDEN}

is required, it will be well to buy it by the ounce. By first measuring the ground and then studying those catalogues which give the quantity of seed required to plant a given area-as an hundred feet of drill-one can estimate very closely the exact amount required of any variety. Of course where this is done one must calculate on purchasing good seed of reliable dealers, planting it properly and giving the plants suitable culture after they are up. One must not sow it in any haphazard way and expect good results.

It is very rarely that one family will find use for all the products of a garden, be it ever so small, and, if one is so inclined, the surplus will find ready sale among one's neighbours. Especially is this the case with the early plants from the hotbeds. A very good plan, when one wishes a great variety of vegetables and has but a limited amount of room in which to grow them, is to arrange with a neighbour to co-operate in the garden work and each take certain things. His land, perhaps, may seem more suited for, or he have more knowledge of the culture of certain plants; then let him grow of these enough for both gardens, while you undertake those which he does not grow. This 
insures a great variety of vegetables at the minimum amount of work and outlay. Possibly your neighbour's land is a little wet and low and well adapted to the growing of cabbage and cauliflowers, while yours may be a warm, sandy loam, especially suited to grow melons, or you may have turned under a piece of sod land which is not sufficiently tractable for growing root crops or those needing close cultivation, but will do admirably for corn or potatoes, while his ground may have been in cultivation for years and in so fine a state of tilth as to answer admirably for onions, radishes; lettuce, and the like.

Again, your neighbour may have a horse and be able to do the greater part of his work with it, while your ground must be cultivated by hand; it will then pay best if he shall undertake the growing of larger crops, which may best be handled with a horse cultivator. Corn, cabbage, cauliflowers, potatoes, and such vegetables, which are usually planted three feet apart, may be worked to advantage this way, while the smaller vegetables - carrots, onions, peas, parsnips, and tomatoes, which sprawl so that it is difficult to work among them with a horse after they have made much [10] 
growth-are better handled with the hand cultivator or even with a hoe.

Again, it pays from a physical standpoint of view. Did we cultivate more assiduously our backyard gardens, those of us whose daily grind chains us fast to a bell or whistle or even an office clock, there would be fewer nervous breakdowns. It is curious how our cares drop away from our poor fagged minds when we get out in touch with the good brown earth. It must be a deep-seated trouble, indeed, which will not lift ever so little when the robin's song is in the air and the sweet, moist smell of the soil comes up after a rain. To possess the land and till it is the primal heritage of man. To delight in the work of his hands, the reward which beckons him. 


\section{CHAPTER TWO}

THE LOCATION OF THE GARDEN

$T_{\text {HIs is a point which admits of little discussion or }}$ advice, as, in the majority of cases, circumstances decide this arbitrarily. Especially is this the case where the only land at command is comprised in the narrow confines of a city back yard or the somewhat more generous area of a suburban lot.

But in the country, where land is abundant, the only restrictive condition is that it should be near the house, so that it may be easily worked and cared for, especially if much of this care must devolve upon the women of the family, as is often the case on the farm. Given here a measure of choice of location, it will be well to select a bit of land well drained and exposed to the sunshine the greater part of the day. The near presence of trees is to be avoided, as these not only furnish more shade than is desirable, but the roots-which extend in all directions over an area equal to the spread 
of tops-drain all the moisture and much of the nourishment from the soil, much to the detriment of any crop which may be planted in their immediate vicinity.

Low, wet land should be avoided unless it can be thoroughly drained, in which case it often makes excellent garden land. I have such a spot on my own land which for a number of years was too wet to work to advantage in any but very dry seasons, and in the spring thaws and after every hard summer rain was under water for a foot or more. Finally after losing a dozen fine Brahma fowls (which had been shut up in a temporary coop to break them of setting) by a sudden summer rain, which flooded all of that part of the premises, it was drained by the very simple and inexpensive expedient of digging a deep hole, six feet deep and five feet in diameter, and filling this up with all sorts of rubbish from about the placeold tins, broken crockery, and the like. This proved perfectly successful and no trouble has been experienced since, the ground being in shape to work but a few days later than the rest of the garden and not delaying cultivation to any extent at any time during the remainder of the summer. It has 
been found an excellent place for the growing of cabbage and cauliflowers, which have now been grown there several years in succession without any sign of club-foot or much of any damage from the cabbage worm.

Of course this bit of land is underlaid with gravel. With a clay subsoil it might be necessary to employ more scientific drainage, and the laying of porous tile be found necessary.

Clay land does not make an ideal garden soil. A good warm loam, well overlaid with humusdecayed vegetable matter-is the best soil in which to grow garden stuff, but a stiff clay soil may be made to produce good results by heavy manuring and underdraining, but will not warrant the expense if other and better soil is available. The point to be considered in selecting garden soil is to choose that which will grow the greatest variety of vegetables with the least expenditure of labor and fertilisers. There are very few vegetables but what may be grown to a point of perfection satisfactory for the home garden, though they might not produce in quantities to make them remunerative for a market garden where much more is expected of the soil than in private places. Certain 
soils, like well-drained marsh lands, are ideal for certain vegetables, such as celery, cabbage, and the like, but less valuable for general use.

On the small village lot one must, perforce, take what one has, and it is doubtful if there is any bit of land but what may be made, under careful management, to produce a fair amount of vegetation. The fertility of a small area of land is so easily increased that no plot of land need be considered hopeless on that score. The mechanical condition is more apt to cause trouble. When a piece of land has been used for a dumping heap for years, probably beginning with the erection of the house, when all the excavated subsoil was dumped upon the ground and levelled off instead of being carted away, as it should have been, and succeeding years have left their accumulation of ashes, rubbish, and old cans to further injure the soil, there does not seem to be much to do, especially if the first deposit consists, as it probably does, of gravel and hardpan, but to first remove all rubbish and then to dig up the surface dirt down to the original soil and have the refuse carted away. As there is always a demand for dirt for grading in a place of any size, the expense of digging up the 
dirt will usually be all that is entailed, as some one can always be found to haul it away for it.

There is one condition to be considered, however, in this method of restoring the soil, and that is the grade. If this is high enough to allow of the removal of any considerable amount of earth, well and good, but if not, fresh earth must be brought in to take its place. However, the ploughing and fertilising of the soil will raise the grade considerably, and land that at first may appear too low will, in the course of two or three years' cultivation, have quite recovered its usual grade.

The proneness of land to rise has been well demonstrated on my own place, where the house stands on a knoll, the ground sloping away in all directions, and should, for this reason, afford a perfectly dry house and cellar. The contrary, however, is true, owing to the fact that several years ago the sod was broken around the foundations of the house for the planting of vines and shrubbery. As the soil about foundations is never very suitable for the growing of plants, fresh earth was added from the compost heap and garden, much of the poor soil being first removed. Subsequent top dressings of soil and fertilisers has resulted in 
THE LOCATION OF THE GARDEN

so marked a rise in the grade of the ground as to permit the water to run in at the cellar windows during spring thaws and summer storms; as a result, we find it will be necessary to cut the sod in narrow strips and roll it back for a distance of twenty feet or more; lay aside the surface soil, and remove about six inches of the subsoil and replace the surface soil and the sod and roll it thoroughly with the lawn roller. This is the one serious objection to "base plantings" about the house or outbuildings - its tendency to raise the grade of the land.

It has been said that the near presence of trees is to be avoided in the garden, but the comfort and convenience of working it will be greatly enhanced by the presence of a shed or other building on the north side, where one can store the necessary tools, do much of the indoor work connected with gardening, cleaning vegetables, and the like, or take shelter in a sudden shower. Such a building will afford a suitable location for the construction of hotbeds and coldframes, as well as affording temporary quarters for vegetables, which may need to be gathered in advance of a sudden cold snap. It will also be found invaluable for drying and ripen- 
ing off such vegetables as are to be stored in the cellar for winter use. A scaffolding of lath, erected just out of the way of one's head, will be found invaluable for drying onions, and will double the capacity of the shed.

Another feature of moment in the selection of a garden site is the nearness and availability of the water supply. Where one has city water the problem is simple-the water may be carried to the garden; but where this does not exist the garden must be carried to the well or a home system of water established. This may be accomplished satisfactorily by the erection of a wind-mill operated through a three-way pump, which will convey water to any point in the ground. Even the mill may be dispensed with and water carried to a stand pipe supplied with a hose and nozzle, whence it may be distributed about the garden as needed. It is necessary, however, in installing a force pump of any make to know just what you are getting, and not find one's self encumbered with a pump which it is a punishment to work or one with insufficient force to throw a reasonable stream of water.

The presence of a shed and a water supply ad[18] 
jacent will be found of the greatest convenience to the housewife, who can there prepare the vegetables for the table, doing away with much dirt about the kitchen and the subsequent disposal of the tops, husks, and other refuse.

There is one more point to notice in connection with the kitchen garden, and that is that it should be as widely separated from the hennery as possible. The presence of a high fence of chicken netting as a dividing line is not sufficient, though it is a distinct gain on chickens running at large. But for perfect immunity from the encroachments of Mistress Biddy it is best to begin with the youngsters and, by keeping temptation out of their way, nip in the bud any embryo inclination to revel in one's softest garden beds. Where the hen park adjoins the garden the little chicks, which can easily pass through the meshes of the netting, form the habit of working there, and the first move they make in the morning will be through the fence into the garden. I do not think that at this stage they do any harm; sometimes I have thought their presence a benefit, so many are the bugs and worms they destroy, and they aid materially in the cultivation of the larger vegetables-cauli- 
flowers, cabbage, tomatoes, and the like-but are destructive, indeed, to the tender leaves of the lettuce, and as the garden advances and tomatoes and melons ripen, they can be trusted to peck everything as it ripens. Moreover, having formed the garden habit it is nearly impossible to break them of it, and fences that were considered chickentight apparently form no barrier to them. I have repeatedly seen Plymouth Rocks and American Reds climb up a wire netting by hooking their claws into the meshes, balance a moment on the top wire, and fly triumphantly down into the forbidden land. Chickens which have never been allowed in the garden seldom make serious trouble in confinement.

The past summer I have been greatly puzzled to learn how certain half-grown American Reds gained access to the garden, past a six-foot board fence and a five-foot wire netting, but the mystery was solved when I found that they were climbing from branch to branch of a mulberry tree on the park side of the fence, until they had reached a sufficiently high altitude, when they flew down on, or over, the fence.

A flock of Buff Rocks, which came of stock
$[20]$ 
THE LOCATION OF THE GARDEN

which had always been confined, have evinced not the slightest inclination to stray, but stay contentedly in their park, coming up en masse each night to be fed. Yet I feel not a shadow of a doubt that had their parents been brought up on my own premises their offspring would have proven as predatory as the descendants of my own hens.

This may seem a far call from the subject, but it is a point which is likely to be called to the attention of the gardener in a very forcible manner any fine summer day, when he finds, as I did the past summer, his bed of prize lettuce, or other product of his tender care, practically exterminated by a few moments' visit of a flock of chickens. However, I can assure him he will not feel half as bad about it as he would had they been his neighbours' chickens. 


\section{CHAPTER THREE \\ PLANNING THE GARDEN}

THE work of planning the garden-inasmuch as it consists in deciding what and how much we shall plant and where we shall plant it-may very well be done long in advance of the season of active operations. Indeed, it is a distinct and pleasurable advantage to make the long winter evenings supplement the long summer days by devoting a portion of them to the seed catalogues and other garden literature.

The selection of varieties of vegetables to grow should be largely influenced by those which form one's daily fare throughout the season. Vegetables which are seldom purchased-unless it be because of their high price or scarcity-may not profitably be cultivated in the home garden. But in the case of high-priced products, then the home garden demonstrates its economic value as enabling one to indulge in otherwise unattainable luxuries. Plainly, 
then, one should grow in abundance those things of which most consumption is made. There will be a demand for those vegetables which come earliest in spring-rhubarb, asparagus, radishes, lettuce, and such quick-growing things; and for vegetables which may be stored in the cellar to increase the none-too-generous variety of the winter larder - potatoes, parsnips, carrots, squash, and the like. Sweet corn, beans, peas, and beets, especially those for early greens, cabbage, cauliflower, and tomatoes, will be indispensable summer products which must be provided for.

A little study of the catalogues or of the instructions under the heading of various vegetables will show the height of these, the period at which they are in season, and the distance apart they should be planted, and this data will furnish the necessary information as to quantity of seed or number of plants required for a given area.

If the land devoted to the kitchen garden is comprised in the boundaries of a city lot the arrangement will, necessarily, be somewhat different than that which would prevail in the country, where the garden occupies more ground and is more or less retired from observation. On the city 
lot it is always, to the family, at least, in evidence, and should be made as attractive as possible. This may best be achieved by planting the more ornamental vegetables in front and relegating the tallest and the least ornamental to the rear.

On the limited area of a village lot it will not be expedient to grow vegetables which require so large an amount of room as pumpkins, squash, and melons, but room should be found for a hill or two of cucumbers in order that one may possess these appetising fruits at their best. I have grown very good cucumbers-and melons, too, by the way-on the hen-park fence, thus not only producing a crop from a strip of land not readily available for other purposes but affording some useful shade for the poultry yard. A post or two set anywhere convenient, with a length of netting stretched from post to post, may take the place of the fence, or they may be grown against the side of a building.

The growing of this class of vegetables on netting is perfectly rational; Nature has provided the vines with clinging tendrils and evidently intended them to be used. The stems of all of this class of plants are quite strong enough to support the fruit [24] 
until it is perfectly ripe, when it drops of its own accord, and thus furnishes a sure guide for its harvest. Moreover, melons and cucumbers grown on netting are far more attractive in appearance than when grown on the ground, as they are not soiled, stained, discoloured, or rotted by contact with the earth. The difference in appearance between pickles grown on netting and those grown on the ground is marked indeed, the former being beautifully green and bright, and if they were grown in sufficient quantities to be marketed, there would nothing sell against them. I do not think they bear quite as freely as when grown on the ground, but then I have never given them the extra culture that would produce the highest results. If well cultivated throughout the season, and watered and supplied with weekly doses of liquid manure, the returns would doubtless be highly satisfactory, and this extra labour would be far less than that involved in gathering the fruit from the ground.

The back-yard fence of an ordinary lot will furnish sufficient room for the growing of all the vegetables of this sort needed by a small family, and a strip about three feet wide should be spaded 
along the fence and thoroughly manured; afterwards it will be well to mix a large spadeful of manure and a spoonful of phosphate in each hill prepared for cucumbers, melons, or squash. Between these hills, which will be from four to six feet apart, beets for early greens, radishes, lettuce, string beans, early peas, onions for use green, corn salad, mustard, endive, spinach, parsley, and any herbs may be planted, as most of these things are of quick growth and are usually planted for a succession throughout the summer at intervals of a few weeks, and where the space does not admit of but two or three varieties, those which mature early should be planted first, and when they have been used the ground may be cleared and a fall crop started.

By planning to use such available space for these early things, they are gotten out of the way of the main crop and the garden proper left for things which require the entire season to mature.

A good broad path will be advisable down through the centre of the garden for convenience in working, and a narrower one along the sides, if this part is to be planted as suggested. It will be more convenient in cultivating if the lines of vege- 
tables run straight across the garden. This is especially to be advised if an attempt to use a horse in caring for it is to be made, and even where the work is to be done with a hand cultivator this will be the most economical arrangement of space and labour.

If the land runs east and west the taller plantings should be on the north, so that the light will not be shut off from the lower growing vegetables. Corn grows so much taller than anything else cultivated that it should, if possible, be placed in the rear. In front of it the few hills of early potatoes which it is possible to grow on a city lot may be planted, as they are the least ornamental of vegetables.

Cabbage and cauliflowers grow of corresponding height, and may be planted side by side and given the same treatment. Tomatoes may follow the potatoes, and so on in the order of height until the front of the garden is reached, and such ornamental vegetables as remain may be placed.

The accompanying diagram will be of assistance, and is quite possible for an ordinary lot of twelve rods by four, allowing eight rods of the rear of the lot for the growing of vegetables.

It is not intended, however, that any one should 
THE VEGETABLE GARDEN

follow this chart arbitrarily; it is merely suggestive, and many of the vegetables indicated may be discarded and more of others planted to take their place, or a rod or two at the rear may be devoted to the growing of small fruit-red and blackcap raspberries, or currants, gooseberries, or even a small strawberry bed. 


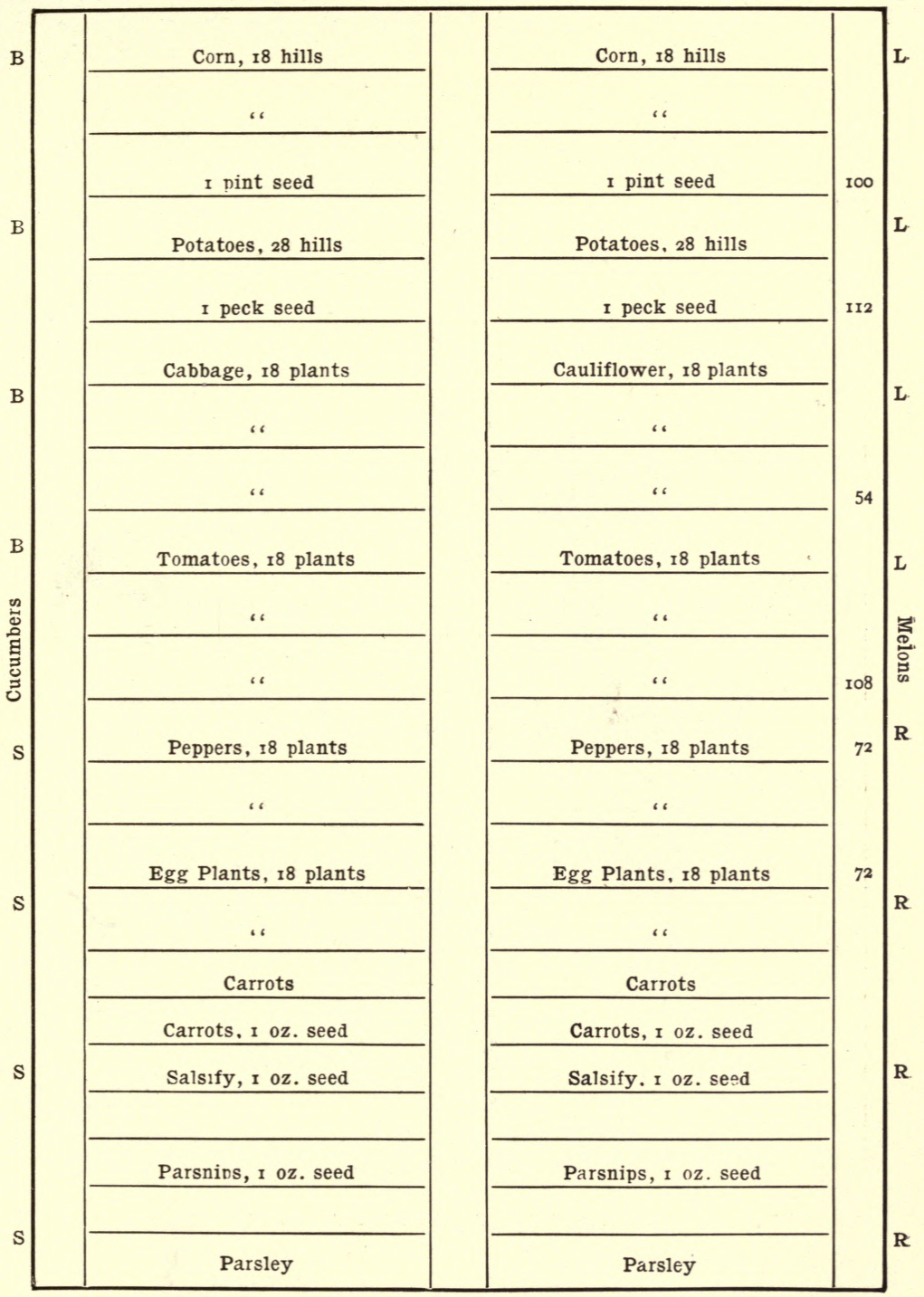

This leaves room for several rows of fruit and a generous asparagus bed in the rear. 


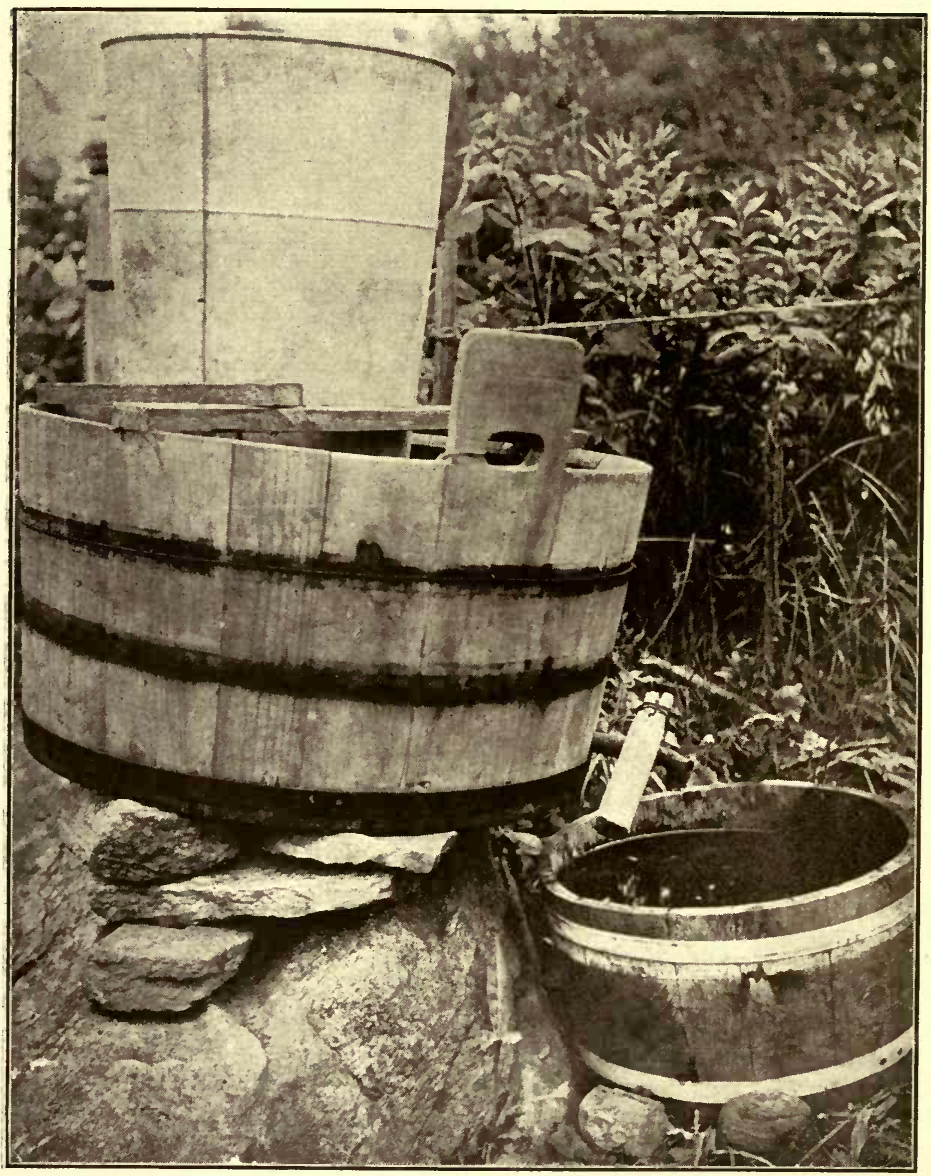

LIQUTD MANURE IS ONE OF THE BEST ACTING FERTILISERS 


\section{CHAPTER FOUR}

\section{HOW TO MAINTAIN FERTILITY}

THE soil is a working laboratory in which chemical reactions are constantly going on, making the various elements available as plant food. In order that a piece of land shall produce a profitable crop, as much depends upon the mechanical condition of the soil as upon the various chemical elements that it contains which go to make up the structure of the plants grown upon it. Soil is made up of disintegrated rock and decayed vegetable matter, but if it were rock alone it could not support plant life, at least the highly organised plant life upon which we depend for food. In order to support plant life it must have humus, decayed vegetable, and animal matter. Virgin soil contains enough humus to make possible all the necessary chemical changes to produce sufficient plant food, but unless the soil is carefully cultivated and attention paid to the replenishing of it the supply of 
humus is in great danger of becoming exhausted, and the soil is then said to be "worn out."

Humus is the black or brown material which gives the dark colour to the top ten or twelve inches of soil. Added to the soil, humus increases its water-holding capacity, thereby insuring a more constant soil moisture. It aids in the decomposition of the mineral matter by harbouring bacteria which convert unavailable forms into a condition in which it can be assimilated by plants. It fixes the ammonia, which contains nitrogen, in the soil, so that it is not leached out by rains, and it improves the mechanical condition of the soil by keeping it loose and free, permitting aëration.

The natural supply of humus comes from the decaying leaves and wood of the forest, but as soon as the forests are removed and the land cultivated this supply is cut off. It can be renewed, however, by giving the land periodical dressings of stable manure, green manure, or peat or swamp-muck. These last two are not always available, and when they are, it is doubtful if they can be economically applied to land on account of the cost of hauling and spreading.

Stable manure is undoubtedly the best form in [30] 
which to supply humus, because the soil is receiving at the same time nitrogen, phosphoric acid, and potash, the three most important elements in plant foods. It is vegetable matter that has been partly digested by animals and is in a condition to be more quickly assimilated by plants than is a green manure.

Green manure is supplied by growing a crop of clover, or other leguminous plants, or rye, and turning it under. I have seen comparatively unproductive sandy soils from which nitrogen was leached out by rains as fast as it could be supplied, brought into good tilth and produce large crops by its use. In the small garden, where one cannot afford to lose the time necessary to do this, as it is done in large farming operations, rye or clover can be sown in the fall as soon as the vegetable crops have been removed, or between the rows at the last cultivation of such crops as corn, and whatever growth has been turned under at the time of spring ploughing. I have seen this done with good results on small areas.

The clovers and other leguminous crops are the best green manures because of their ability to absorb and fix free atmospheric nitrogen. If you 
were to dig up carefully a clover plant and wash away the soil you would find many little nodules on the roots. These little bunches contain bacteria, and it is these little bacteria which collect and convert the free atmospheric nitrogen into an available form for plants to use. Long before the value of these little nodules was recognised it was a known fact that good crops of beans could be produced on land that could not grow a profitable crop of anything else. These bacteria made it possible. In the North the common red clover and rye are the best crops to grow for green manure. The rye is not a legume and cannot fix atmospheric nitrogen, but it makes a heavy growth of foliage, producing when turned under a good amount of humus. From New Jersey south to Georgia the crimson clover will make a good stand and survive the winter. It can be sown any time from July to September; the earlier date is for the northern portion of this territory. The vetches and cow peas have also proven to be valuable green manures.

With the exception of corn and potatoes, crops do not usually do well on land which has just had a green crop turned under, because of the acidity produced by the fermentation. Let the land lay 
for about six weeks before planting and frequently harrow it to compact the soil.

There are fourteen different chemical elements that are necessary for plant growth-namely, carbon, hydrogen, oxygen, nitrogen, phosphorus, sulphur, chlorine, silicon, calcium, iron, potassium, sodium, magnesium, and manganese. The first four are derived either directly or indirectly from the air, the remaining ten are derived from the soil. Virgin soil contains all these soil-derived elements in available forms and in sufficient quantities for plant growth, and it has the ability to absorb the air-derived elements, but our methods of agriculture rob the soil of some of its elements faster than it can convert them into available form for the plants. Therefore we must supply these elements in order to produce good crops.

The best way of renewing these necessary elements is by dressings of stable manure-the droppings from horses, cows, and other domestic animals. Soil enriched by barn-yard manure will yield better crops than soil which has been given chemical fertilisers containing an equal amount of plant food. Whether the manure shall be fresh or well rotted depends upon the conditions. The fertil- 
ising constituents of well-decayed manure are more quickly available to the plants than are those in fresh manure, but, on the other hand, fresh manure soon rots and the fermentation of decay assists in rendering soluble hitherto insoluble fertilising constituents of the soil. If the chief object of applying the manure is to improve the mechanical condition of the soil, the greatest benefit will be had by giving fresh manure to heavy clay loams and well-decayed manure to light, sandy loams. On the other hand, if quick action is wanted, greater benefit will be received under ordinary conditions from fresh manure on light soil than on heavy clay loam. On heavy soil decomposition takes place slowly, so it is some time before the plant food becomes available. Often there is no immediate effect the first year. In light soil, unless the season is very dry, the fertilising constituents of fresh manure become available about as fast as the plant is in need of them. There is danger of leaching away of the nitrogen before it can be used by the plants if well-decayed manure is applied to sandy loams. On clay loams there is no danger of this, because of their ability to absorb and retain large quantities of plant food. 
The amount to apply varies with the crop grown, but for ordinary garden crops as much as twenty tons per acre, or about one two-horse load to a $25 \times 100$-foot plot, can be used; one-half to two-thirds of this amount will give fair results, however, and larger amounts are often used by "truck" growers. This must be thoroughly mixed with the soil by ploughing under and harrowing before the crop is planted.

It is often the case that the soil does not need a complete fertiliser, for only one of the three important plant foods-nitrogen, phosphoric acid and potash-is lacking. If such is the case, it can be easily supplied by one of the various chemical fertilisers on the market.

Before applying these highly concentrated chemical fertilisers I would strongly advise your testing the soil to find out just what is needed. To do it divide the garden into strips, say ten feet wide, and on every other strip apply these special fertilisers, one to a strip, in various quantities and watch the results. One test will probably be sufficient to give the information desired.

Nitrogen is the most expensive of the three essential elements required by plants. It can be had 
in three different forms, organic nitrogen, as ammonia, and in nitrates. The most valuable sources of organic nitrogen are dried blood and tankage, which are by-products of slaughter houses, dried fish, and refuse from fish canneries and oil factories, and cotton-seed meal. These contain in every one hundred pounds of bulk the following amount (approximately) of nitrogen: dried blood, ten to fifteen; tankage, seven to nine; dried fish, seven to eight; cotton-seed meal, six to seven. All these substances decay rapidly upon being put in the soil, but not so quickly but that they can be made use of by the plant as soon as they become available. They are particularly valuable on light soils, from which nitrogen in the form of ammonia or nitrates are rapidly leached, and they have the further advantage of making available during the process of fermentation insoluble forms of phosphoric acid and potash. They also furnish small quantities of phosphoric acid. Cotton seed or cotton-seed meal is not used in the North to any extent as a fertiliser, but in the South it is a cheap form of nitrogen. It can be applied alone or in combination with chemical fertilisers. It contains about seven per cent of nitrogen and three per cent of phosphoric acid [36] 
and two per cent of potash. About sixty bushels per acre of the green seed or its equivalent of meal, together with about one thousand pounds of a complete fertiliser, will be a good dressing for the garden.

Nitrogen in the form of ammonia is derived almost exclusively from sulphate of ammonia, the commercial product containing about twenty per cent. This form of nitrogen is easily converted in the soil to nitrate, the form in which it is used by plants, but before being converted it will readily combine with the soil becoming fixed, so that there is no danger of its leaching. This quality makes it very valuable for light, sandy loams and for use in wet seasons, when nitrate of soda would leach from the soil rapidly.

The commonest form of commercial nitrogen is nitrate of soda, which contains about 15.5 per cent of nitrogen. Nitrate of soda dissolves at once upon being put in the soil; it has a strong affinity for water. In this form the nitrogen is at once available to the plants. As it is so soluble, there is danger of its being leached from the soils, especially sandy soils, if more is given than the plants can use in a short time. 
Phosphorus is used by plants in the form of phosphoric acid, and there are several forms in which it can be had. The organic forms of nitrogen, which I have mentioned, contain a little phosphoric acid. The most common and most highly concentrated form of phosphoric acid on the market now is superphosphates, or soluble phosphates. These are derived from the phosphate rock secured in South Carolina, Florida, and Tennessee. They are seldom used in their natural state, because but little of the phosphoric acid in them is available as plant food. It is made available by grinding and treating with sulphuric acid. These treated phosphate rocks contain twenty-five to thirty per cent of available phosphoric acid.

Thomas slag, a by-product in the manufacture of steel, has been used frequently as a source of phosphoric acid, but as the supply is limited it cannot always be obtained. It contains about nineteen or twenty per cent of available phosphoric acid and six or seven per cent which is insoluble in soil water.

Bone contains a great deal of phosphoric acidabout twenty-two per cent-and it also contains about four per cent of nitrogen. Bone can be se- 
cured in several different forms, such as raw, boiled or steamed, and fine bone. Upon its condition when applied to the land will depend the rapidity with which it will become available to the plants. All the phosphoric acid in raw, broken bone will not become available and used up by the plants in less than four years, because the fat retards decay. For this reason the bone is steamed and ground, and in this condition all the phosphoric acid will have become available in about two years. In steamed bone there is less nitrogen, however, because some of the organic material containing it is removed by the process.

Other forms of bone which are sometimes used as fertilisers are bone-black and bone-ash. They are much less valuable, because in their preparation by burning all the organic matter is driven off, therefore they contain no nitrogen, and it lessens the amount of phosphoric acid somewhat.

Tankage is the only other material containing phosphoric acid which is sufficiently common in the trade to warrant consideration. The fertilising content of tankage varies according to what it is made from; the higher its percentage of phosphoric acid the less nitrogen it contains and vice 
versa. At present there are five different grades on the market containing anywhere from seven to nineteen or twenty per cent of phosphoric acid. Its price also varies according to its contents.

When soluble phosphoric acid is added to the soil it becomes "fixed" or insoluble by combining with lime, making lime phosphate, or by uniting with iron or alumina. The former is the most desirable form, as the phosphoric acid in lime phosphate is more readily reconverted into available forms for plant use by the fermentation of organic material in the soil than are the phosphates of iron and alumina. Therefore, to insure the formation of lime phosphate, it is necessary that the soil should be well supplied with lime and humus.

The other element, potash, which it is necessary to add to the soil is derived mainly from muriate or chloride of potash, sulphate of potash, and unleached hardwood ashes. Most of the potash, other than the ashes, comes from mines in Germany. Sulphate of potash is a much better form to use because the chlorides in muriate of potash seem to have an unfavourable effect on crops. This is particularly true of tobacco and potatoes. Kainit is frequently offered and sold by dealers. 
Its potash is in the form of sulphates, but as it contains large quantities of chlorides mixed with it, it has the same general effect on plants as muriate of potash.

High-grade sulphate of potash contains fortyeight to fifty-one per cent of potash, low grade twenty-eight to thirty per cent, kainit twelve to fourteen per cent, muriate of potash (eighty to eighty-five per cent pure), fifty to fifty-three per cent, and unleached wood ashes four to eight per cent. Never use leached-wood ashes as a direct fertiliser, as they usually contain but a small percentage of potash.

When muriate of potash is used the chlorides combine with the lime, forming chloride of lime, which is very soluble and leaches away rapidly, a distinct disadvantage, and it makes applications of lime necessary. Further, the presence of large quantities of chloride of lime in soil is apt to be detrimental to plants.

Greater effect is had from the use of these potash fertilisers on light, sandy soils, humus soils, or those containing lime, than on heavy clay loams. On the light soils, to get the full value of the potash applied, there should be in it considerable 
lime. Without the lime the soluble potash leaches out rapidly.

I have described these different fertilising elements at some length in order that if the reader desires to mix his own fertilisers he will know what each contains. Unless one uses only a small quantity of these commercial fertilisers it is a distinct advantage in point of cost to do the mixing at home rather than to buy the ready-mixed materials. Not only is it necessary to pay the manufacturer for mixing them, but you also pay freight on earth, which is always added to these ready-made fertilisers as fillers. Another distinct advantage of home-mixed fertilisers is that the ingredients can be varied according to the needs of plants grown and the condition of the soil.

For an average soil, on which the ordinary garden crops-beets, cabbage, cucumbers, celery, tomatoes, etc.-are being grown, a fertiliser compounded as follows will give good results:

Nitrate of soda........ 50 pounds

Sulphate of ammonia..... 100 pounds

Dried blood............ 150 pounds

Acid phosphate........ 550 pounds

Muriate of potash....... 150 pounds 
An equal amount of sulphate of potash can be supplemented for the muriate of potash if that form is best for the crop.

This is enough for the spring application to one acre, but it should be supplemented by two or three dressings of nitrate of soda at intervals during the season, giving about one hundred to two hundred pounds each time.

The formula just given reduced to amounts for a small area, say a $25 \times 100$-foot plot, would be

Nitrate of soda....... 21/2 pounds

Sulphate of ammonia.... 5 pounds

Dried blood......... $71 / 2$ pounds

Acid phosphate....... 271/2 pounds

Muriate of potash...... $71 \frac{1}{2}$ pounds

and the subsequent dressings of nitrate of soda would be five to ten pounds each.

The ingredients of this formula may be changed; for instance, if bone meal is more accessible, an equal amount can be substituted for the acid phosphate, but the phosphoric acid will not be so quickly available.

When mixing fertilisers great care must be taken to evenly distribute all the ingredients 
through the mixture. This is best done by putting them in a pile in layers and then throwing them into another pile. Always shovel from the bottom of the pile, throwing the material on the top of the second pile. Three or four turnings will be necessary to thoroughly incorporate all the ingredients.

All these substances which I have mentioned are direct fertilisers, but there are soils from which the full value of these cannot be had without the use of a stimulant or indirect fertiliser. Lime and land plaster or gypsum are used for this purpose.

The reasons for the liming land are: First, that sour or acid soils must be neutralised or made slightly alkaline, because the bacteria which convert the organic forms of nitrogen into the forms of nitrates cannot thrive in acid soils. Second, used in small quantities, it will bind loose, sandy soils. Third, it will flocculate stiff clayey soils, making the passage of water through them easier, lessening the tendency to wash, and permitting better aëration. Fourth, in holding the potash compounds, as already described, and overcoming the bad effect of potash salts containing chlorides.

There are other lesser reasons which it is not [44] 
necessary to discuss here. Gypsum is just as good as lime for all these reasons excepting the correction of soil acidity.

To determine if the soil is sour, one of two methods can be used.

Take a fair sample of the soil and mix enough water with it to make the mass the consistency of thin mortar, then embed in it a strip of blue litmus paper. Allow it to stand half an hour or more, and then, if the paper has turned pink, you will know that the soil is in need of lime.

Another way is to place a tablespoonful of soil in a glassful of water and a teaspoonful of weak ammonia. If, after standing several hours, the liquid becomes dark-brown or black, it is an indication of soil acidity.

The amount of lime necessary will vary according to the soil. Light, sandy loams will not need more than 500 pounds per acre, twenty-five pounds for a plot $25 \times 100$ feet, but when applied to heavy clay loams, as much as 5,000 or 6,000 pounds can be used, 250 to 300 pounds on a $25 \times 100$-foot plot. These applications of lime do not need to be made oftener than once in five to seven years. 
For heavy, mucky soils, like freshly drained marshes, fresh-burnt lime may be used to good advantage, but in most cases slacked lime, which has been exposed to the weather for some time, is better. A common way in some parts of the country is to bury the lime in soil in the fall and distribute it the following spring. The lime must be evenly distributed and then harrowed in. This should take place several weeks before planting the crop, for if done immediately before seeding, the seeds are very apt to be injured.

Wood ashes contain about thirty-four per cent of lime. These can be used to good effect on sandy or acid soils. 


\section{CHAPTER FIVE}

THE CONSTRUCTION AND CARE OF HOTBEDS, COLDFRAMES, AND PITS

To attempt to garden without the aid of a wellequipped and constructed hotbed is to put one at a disadvantage in the beginning of the season-a disadvantage which strenuous effort and the most favourable of seasons will rarely compensate one for, as a well-stocked and successful hotbed will supply the garden with an immense amount of plants of the most desirable varieties at the minimum of cost and at just the season that they will be needed.

The possession of a hotbed greatly advances the garden season, as the seed may be planted and the plants brought to a suitable size for planting out by the time that, lacking this convenience, the seed would be going into the open ground. This advances the season some six weeks, and makes an appreciable difference in the maturing of plants and vegetables. 
There has long been a feeling among the uninitiated that hotbeds, coldframes, and the like are conveniences reserved for the professional florist, the fortunate few who possess a gardener, or are otherwise favoured by fortune. Nothing could be more mistaken than this idea. The construction and care of the hotbed is so simple and, in its simpler forms, so inexpensive as to be within the reach of the gardener whose little plot of land comprises but a few square yards of ground, while at the same time its capacity may be extended to meet the requirements of the most extensive estate or commercial plant.

Primarily, it consists of a receptacle where bottom heat can be supplied and plants grown at a time when the weather is too cold for the carrying on of gardening operations in the open ground; where protection may be supplied against the elements and the conditions governing plant growth held in control.

The manner in which this is done will depend largely upon the length of the purse, the results will be the same whether it be a small hotbed or a large one.

There is so much questionable information floating around in the magazines and papers anent the 


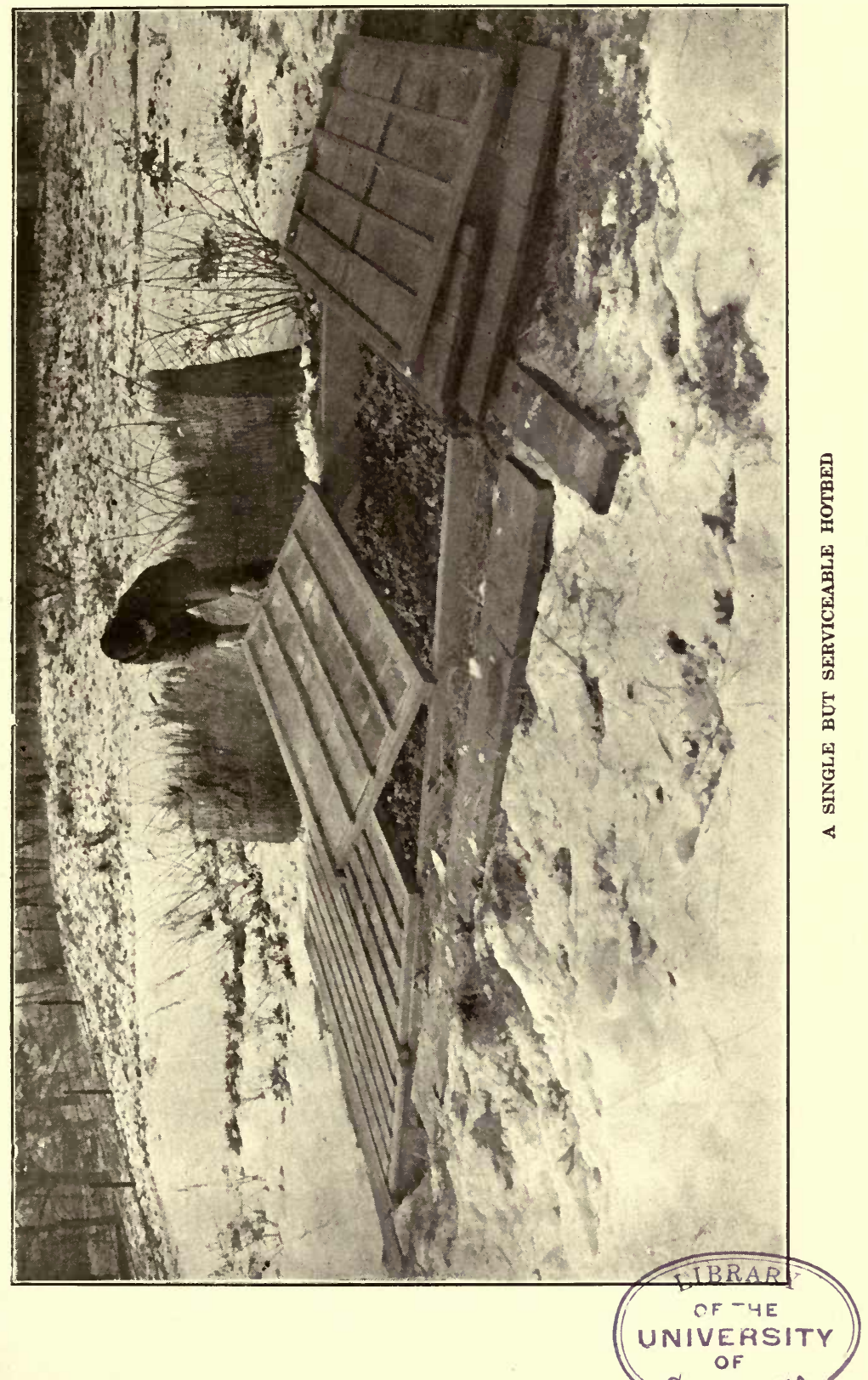




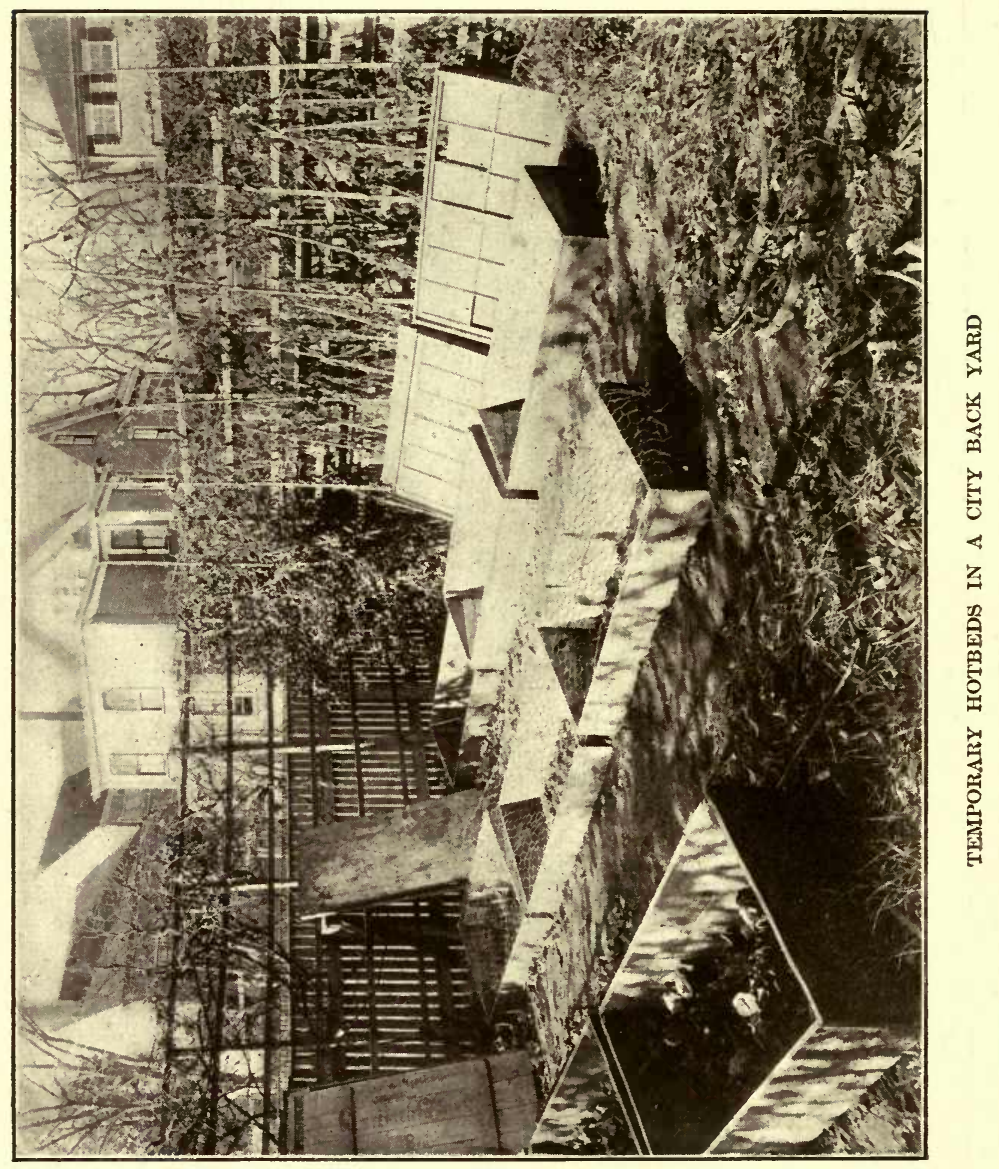


proper time for starting the hotbed that a little discussion on this point may not be amiss at this time. I noticed an article recently in which it was stated that the middle of February was the proper time in which to start the hotbed. I have no doubt that there are certain sections of the country in which the hotbed may, with advantage, be started as early as February, but they will not be found in the vicinity of New York, Chicago, Detroit, or anywhere much north of Philadelphia. There is no amount of heating material which may be put into a hotbed pit, or any devised covering which will keep the frost out of a hotbed when the temperature is loafing around in the vicinity of zero for a stretch of several days at a time, as it is prone to do in February at the North. Nor would there be any practical reason for this early starting of the beds were it possible for them to be kept free from frost and the plants in a growing condition, which the necessity of covering with rags and things which shut out air and light for days at a time, would render impossible.

The prime object in the use of a hotbed is to have plants ready for setting out in the open ground as soon as the weather is favourable; this 
will not be, in the case of most plants, until all danger of frost is passed. This period varies according to location; in the vicinity of Detroit and Chicago it may be generally calculated as from April 1st to about May 20th, and throughout the country at large it may be generally accepted as the average "corn-planting time." Such seeds as radishes, beets, onions for transplanting, celery, etc., should be planted as soon as April 1st, and plants of cabbage, lettuce, etc., should be ready to go into the open ground by April 20th. It will then be seen that it is necessary to start the hotbeds early enough to get the plants sufficiently advanced to plant out when the right season has come.

Seeds of some plants require much less time to germinate than do others, and such seeds may be planted nearer corn-planting time than the others. Generally speaking, about six weeks, or at the most two months, should be allowed for the development of the plant; so if we accept May 20th as a safe time for this operation, it will be seen that the first of March, and not much earlier, is a good and practical time for getting the hotbed in commission. And very satisfactory results may be se- 
cured by starting as late as the first or even the middle of April, as at that time the weather is mild enough for the sash to be raised a considerable part of the day, giving the plants abundance of fresh air, which makes for robust plants.

Plants which are left in the hotbeds even a few days longer than necessary are apt to be injured. For one thing, they become crowded and spindly and their roots penetrate below the soil into the crude, heated manure and are injured; they become matted and must be separated, and more or less injury results in the process, all of which would be avoided if the plants could go into the ground as soon as they are ready.

Next in importance in the starting of the hotbed is the location; this will depend largely upon the arrangement of the grounds and buildings, and I can only point out the most desirable conditions.

The location should be the warmest at command and one which will receive the greatest amount of sunshine. It should be on the south side of a building or high-board fence, and should have some protection from rough west winds if possible. It should be easily accessible from the house, [51] 
as the beds will require frequent and often sudden attention.

The lay of the land should afford good drainage, so that the water will not settle back against the beds; this is of special importance where the beds are to be used as coldframes for the carrying of plants through the winter.

Where the drainage is at all faulty it will be well to construct a drain in one corner of the beds by digging a hole and setting a porous tile therein, or filling with broken crocks, gravel, or other rough material. The opening should be flush with the surface of the soil, or slightly lower, and be covered with sphagnum moss or a piece of sod, laid grass-side down, to prevent the soil working in and filling the drain. This will carry off any surface water that might accidentally find its way into the beds.

But where the hotbeds are to be used the year round and may be considered permanent constructions, it will be well to begin right by draining the land in the immediate vicinity, if low, or by hauling on sufficient earth to raise the grade above the danger line. Considerable more soil will be thrown out in the first excavation of the pits than will be 
returned when the beds are made. All the subsoil removed may be used to raise the grade of the land if necessary, and where the same site is used for the beds from year to year, the handling of the soil as it is thrown in each year will aid in raising the soil in the vicinity of the beds, until in time a good natural drainage is established.

The construction of the hotbed may be of any building material, ranging from the inexpensive frame contrived from the waste lumber about the place and old window sash to florist's sash and walls of concrete, brick, and cement blocks, the last three being permanent and highly satisfactory. These permanent frames are the cheapest in the end.

For the temporary home or the small city lot, where it is desired to use the ground for other purposes, once the hotbed has served its purpose, the frame construction will be preferable; in the latter case it may consist merely of a frame set on the surface of the ground and removed when its usefulness is past; this forms the cheapest and also the least satisfactory of beds, for, while it answers the practical purposes of a hotbed, there is nothing below the surface of the ground to protect 
the beds from the incursions of vermin of various kinds-as mice and moles, two mischievious enemies of the hotbed and coldframe.

The size of the beds will depend upon the size of the sash used. If the frame is to be of plank and the sash discarded window sash, which, by the way, is by no means to be despised, the beds will be of a size to correspond. It will always be found an advantage in constructing hotbeds, especially if the beds are set against a building and are only to be approached from one side, to have them of a size that may be easily reached across, as nothing is more tiresome and unsatisfactory than to try to care for a bed too wide to be easily reached in all of its parts. Three feet will be as wide as can be conveniently handled, but the length may be as long as desired.

In excavating the pit for the frames it will be found a convenience, where there are several sash, for the pit to be in one long excavation, the necessary divisions being made by partitions in the frame itself, and which need not extend below the surface of the ground; these partitions, being removable, may be lifted in the spring, when the beds are to be made, leaving the full size of the

$$
\text { [54 ] }
$$


CONSTRUCTION AND CARE OF HOTBEDS

pit to work in, and will be found to require far less labour than to attempt the excavation of a number of small pits in restricted quarters.

The pit should be about four feet deep and of a size to readily receive the frame, and the sides of the pit should be as firm and even as may be practicable; the bottom, especially, should be level and hard, but no artificial bottom is required or should be made. In constructing the frame, four corner posts, of any rough stuff, two by four inches in diameter and long enough to reach from the top of the frame to the bottom of the pit, should be used, the posts for the back being six inches longer than those for the front. Upon these the planks, which should be of good size and of clear lumber that is free from knot-holes, or, if these cannot be avoided, they should be masked with pieces of tin nailed over them, so as to effectually shut out vermin of all kinds. The planks should extend below the surface of the ground two feet six inches according to the season, though, if preferred, they may extend to the bottom of the pit; but this is not really necessary, as moles, and especially mice, rarely enter beds at a lower depth.

The proper slant may be given the top by saw[55] 
ing a nine-inch board in two on the bias and using one section for an end, placing the boards with the sawn side down and nailing through the thin ends of the pieces into the boards below and also upon the corner posts. The frame should extend above the ground about a foot in the front and a foot and a half at the back. This gives the proper slant to shed rain, and also gathers the greatest possible amount of sunshine.

The back of the frame should be the thickness of the sash higher than the sides and front, if the beds are set close to a building or wall, in order that the sash may fit back snugly against the back of the frame, where they may be attached by hinges and so raised without removing. A notched stick should be fastened at the front or sides of the frames to hold the sash at any desired height when airing them. Where two or more sash are used and it may be desired to divide the bed with partitions in order that plants requiring different conditions of temperature, air, or moisture may be successfully grown, narrow strips of wood may be nailed to the back and front of the partitions at the point where the sash meet, and about an inch and a quarter apart; into these inch boards may [56] 
be slipped, their tops level with the sash and their lower sides extending slightly below the level of the ground; the top board will, of course, need to be sawed on the same slant as the ends of the frame. These not only serve the purpose of separating the several portions of the bed, but also furnish a firm support for the sides of the sash and of closing any cracks that may exist in the jointure of the sash.

All sash should be in a good water-tight condition, and no cracked glass or defective putty should be tolerated. It will be well if the amateur gardener acquaint himself with the use of putty, and so provide against the loss, by sudden breakage of glass by hail, carelessness, or other causes, of a valuable lot of plants. There are few things more prone to disaster than hotbed sash, and it might be helpful to know in this connection that broken glass is easily and quickly removed by the application of hot iron to the putty.

Where the ground is to be used for other purposes in the summer it will only be necessary to construct a frame about a foot high in front and eighteen inches at the back, with corner posts of equal height, as in this case the frame merely rests 
upon the surface of the ground, or only six inches or a foot below it, the soil and manure being piled about the frame to exclude cold. Such frames are very handy to protect beds of tender roses and other plants during winter, as they may be readily moved about from place to place, or if only wanted for spring use, they may be fastened together with pegs or hooks, and so taken apart and piled away like boards until wanted again another spring.

In constructing permanent beds with brick walls, the pit should be dug four inches larger all around to allow for the laying of the brick. Four inchesthe width of the brick-will be sufficient for these walls, except where frost works into it, and secondclass brick may be used; it should be laid with cement and given a finishing coat of one to three cement all over. In laying brick or cement walls it will be well to mortise in a strip of wood on the top for the sash to rest upon, also the cleats of wood for the partitions to slide in, and a shoulder may be left in the cement for strips of wood to extend across the beds under the jointure of the sash, to rest in, where partitions are not to be run through the beds and but two sash are to be used. Where window sash is used, it may be hinged to [58] 
CONSTRUCTION AND CARE OF HOTBEDS

the strips of wood on top of the walls, as is done on wooden frames.

Concrete makes a very substantial and comparatively cheap wall. These should be somewhat thicker than the brick, and are laid up by the aid of a square wooden frame or form the size of the inside dimension of the pit, the excavation being about eight inches larger all around. In laying the wall, a rough concrete of sharp sand and gravel, in the proportion of one part of cement to six or seven parts of sand and gravel, is used. This is placed in the space between the frame and wall and tamped down firmly and until the moisture rises to the surface; all four walls may be laid at once to a height of one foot and then allowed to harden before adding the succeeding foot; always wet the last course of cement before adding fresh concrete. After the wall is built up to the desired height, a frame of narrow strips of wood should be fitted to the top, as in the case of the brick wall. Such a wall is very economical, warm, and durable.

Having constructed the hotbed of the chosen material, all that remains to do is to put it in commission. To accomplish this, fresh horse manure sufficient to fill the beds quite to the top will be re[59] 
quired. This should be procured before frozen from that which has accumulated over night from young, grain-fed horses. It should be mixed with straw or, better still, with leaves - an amount equal in bulk to the manure. This admixture of leaves or straw is very important, as this furnishes heat by the fermentation or heating of the manure and insures the permanency of the heat; were only manure used, the heat would be intense at the start, but soon die out for lack of fuel.

The manure and leaves should be thoroughly mixed, and may be piled at once in the pits, packing it down lightly that all parts of the pit may be filled, or it may be allowed to get well heated before filling the frames. Should the manure be very dry it may be sprinkled with hot water. Place the sash on the beds and leave the manure to heat, which will begin almost at once if the manure is all right. The temperature of the mass may be tested by a thermometer thrust into it, or if a pitchfork is thrust into the manure and allowed to remain a few moments and then withdrawn, it will show at once if the mass is heating. When the heat has penetrated every part of the mass, especially the corners, it may be tramped down. Pro[60] 
CONSTRUCTION AND CARE OF HOTBEDS

fessional gardeners put the manure in a pile and turn it over once or twice as it heats before placing it in the pits, but they handle so large a quantity that it is not possible to get sufficient at one time for all the beds, so older manure is used and allowed to heat in piles. For the home garden, however, I have found this way, more satisfactory and far less work. Occasionally, when not able to get sufficient fresh manure for all my beds, I have supplemented it with manure from the heap at the barn, which had begun to heat, and have found it answered very well.

When the temperature has risen to a hundred degrees or more the mass should be tramped down as firmly and evenly as possible and an inch or two of old manure, made very fine, placed on top of it. Over this place four or five inches of good soil, composed of garden loam, leaf mould, and a little sharp sand well mixed. The surface soil should be entirely free from all rough matter, stones, roots, and the like, and to secure this condition, it will be well to pass it through a sand sieve or coalash sieve.

When the heat has begun to subside, so that the thermometer indicates ninety or less, the seed may 


\section{THE VEGETABLE GARDEN}

be sown. The soil should be moist, not wet or dry, and if for any reason it should be wet, it must be turned over and over and dried out until in a condition to use; if too dry, it may be watered with warm water from the sprinkler of the watering pot and then allowed to lie under the sash until the moisture is uniform. Soil which adheres to the trowel in working is too wet to plant. It should fall apart after being pressed in the hand, not form into a ball or lump.

Before sowing the various seeds it will be well to obtain a supply of narrow strips of wood, which may be used to divide the various plats of seed from each other, by sinking them half way into the ground between the different sowings of seed. This is of moment, especially where more than one variety of different kinds of plants are sown-as cauliflower, cabbage, or tomatoes. Where but one kind of seed is sown in a sash, or one cabbage and tomatoes, for instance, in which there can be no difficulty in distinguishing them, it will not be necessary; still the presence of these little barriers prevents the washing of fine seed when the plats are watered, and defines the boundaries of the plats. When one lives in the vicinity of a 
box factory, long, thin, narrow strips of wood admirable for this purpose can be secured. These make excellent labels, also, and should be prepared in advance of the time of planting. Not only the name of the seed should appear on these, but also the date of sowing and, where known, the period of germination. It is also well, where seeds of different seedsmen are used, to put the name or initials of the seedsman on the label. In this way one can judge of the relative value of the seeds, particularly if one is buying in large quantities.

In planting the seed, it is necessary to consider carefully the requirements of the various plants, and give those requiring a considerable amount of heat a sash by themselves, which the partitions under each sash will make possible, and place those requiring less heat and more air by themselves.

In gardening on a large scale, separate hotbeds should be used, and they should be started at different times to accommodate the requirements of the different plants; but in the small home garden this is not practicable, for even one small bed, three by six feet, may, by the use of a partition, be used to start a variety of vegetables at the same time with very fair success. 
Egg-plants, peppers, and tomatoes may be started under the same sash, the cabbage and cauliflowers occupying the other sash.

When the date at which the various seeds germinate is known, it will be well to plant those which germinate at the same time in the same part of the frame for convenience in handling. It is also well to plant those seeds which make the more robust plants in the rear of the beds, that they may not overshadow the remaining plants, though there is less danger of this in the vegetable frames than in the flower frames.

Before beginning the sowing it will be well to provide one's self with a thin piece of wood, with a handle on one side to be used for pressing the seed into the soil. This is better than to try to pack it down with the hand, as it leaves a uniform pressure and a level surface. The board may be of any convenient size, but one about a foot long and ten inches wide will be convenient.

It is immaterial whether the seeds be sown broadcast or in drills; broadcasting requires rather less room, but plants in drills are more easily lifted and transplanted, and, where there is sufficient room, by placing the drills three or four inches apart, it 


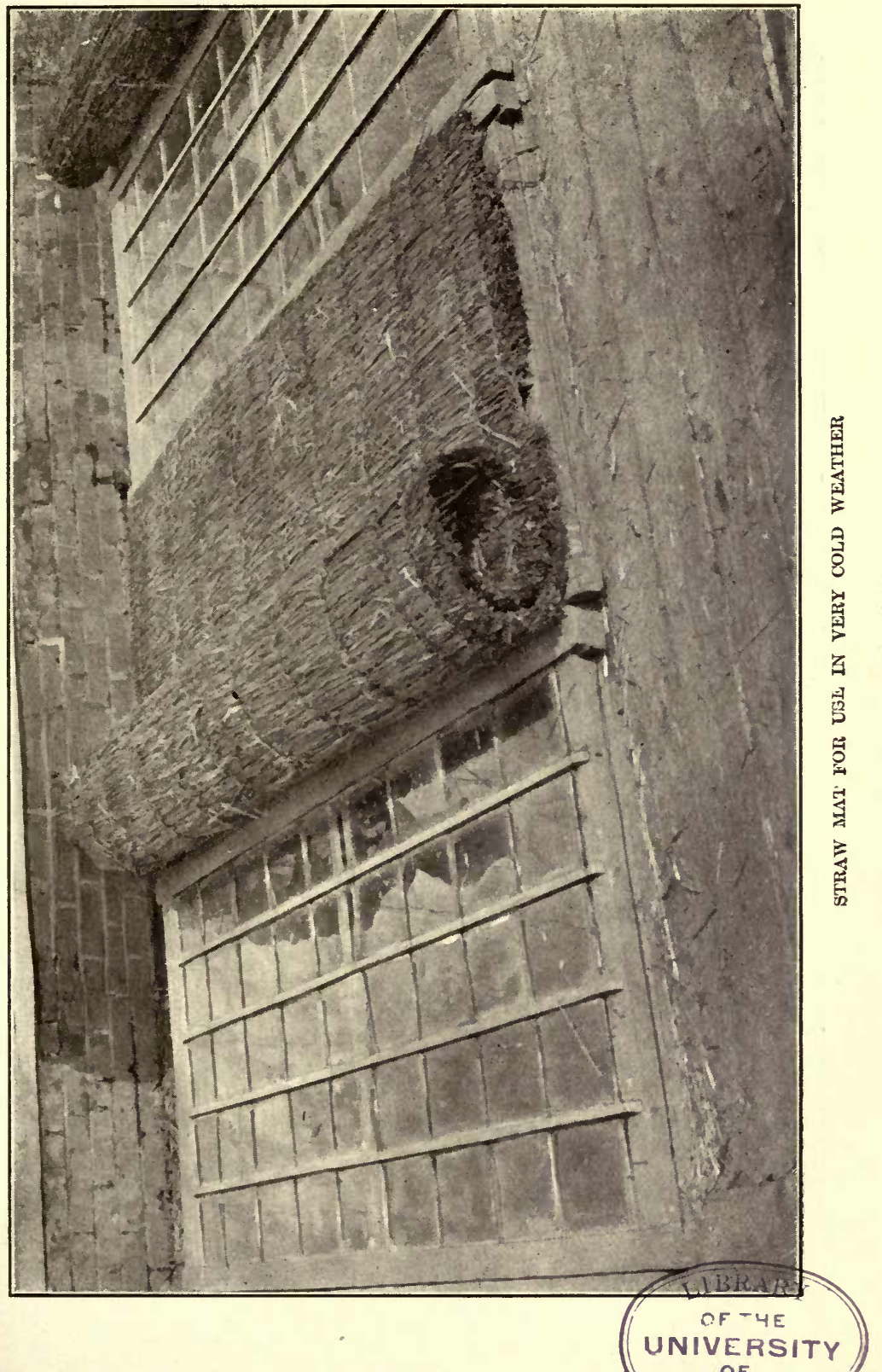




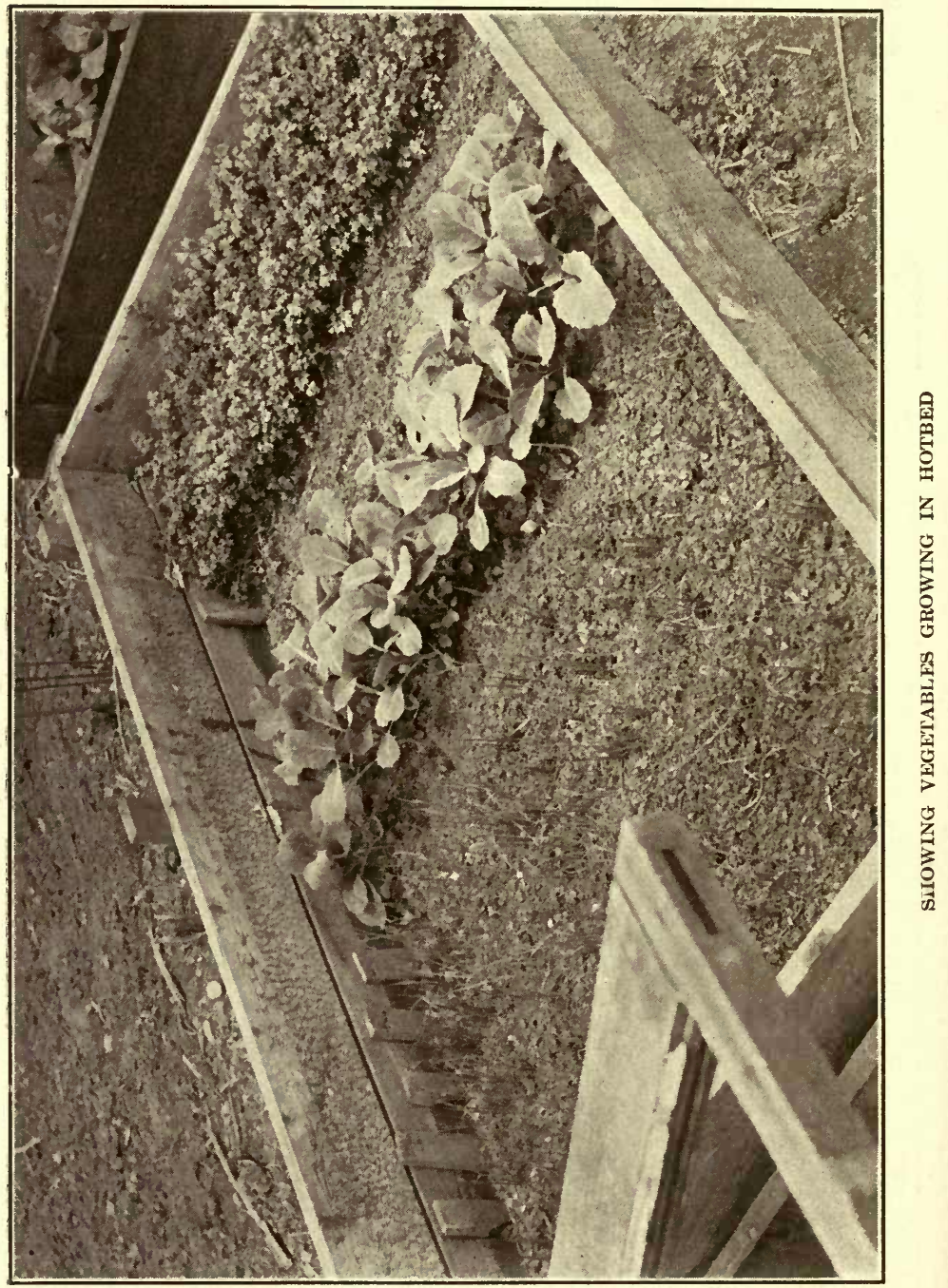


will be possible to transplant half of the plants in the drills into fresh rows between the drills, a process which will produce much better plants. However, it is easier to scatter seed thinly when sowing it broadcast than in drills, and there is not so much danger of crowding.

Seeds sown under the protecting care of the hotbed do not need to be covered as deeply as when sown in the open ground, as they are protected from all changes of the weather, drying winds, burning sun, and washing rains. If well covered and the soil pressed firmly over them, that will be all that is really necessary in the matter of planting. An eighth of an inch of covering will be as much as such seeds as tomatoes, cabbages, and cauliflowers require, providing they are never allowed to dry out. Egg-plants may be planted at the same time as peppers and tomatoes, but the same temperature required for these would be rather high for cabbage and cauliflower were it not for the fact that by careful airing and shading of the beds these last can be kept at a much lower temperature than the former.

Both egg-plants and peppers germinate very slowly. Especially is this the case when the tem[65] 
perature of the hotbed is not sufficiently high, and much care is required to so regulate the sash as to afford sufficient air without at the same time unduly lowering the temperature. When all the seeds are sown, pressed down, and labelled, the soil should be sprayed lightly with a rubber sprinkler or the fine rose of a watering pot, covered with newspapers, the sashes closed, and the seed left to germinate. The beds must be examined every day to note if the soil is becoming dry, in which case it must be watered carefully as before, or if too wet and moisture gathers on the glass, the sash must be raised a little to allow the excessive moisture to pass off.

When the first plat of seeds germinates and the tiny green leaves appear above the soil, the paper should be lifted from that much of the bed and placed on top of the glass, directly over the plat. This shields the plants from the direct rays of the sun, while allowing sufficient light to reach the plants indirectly for their proper growth at this stage.

Many seeds have a tendency to come into the world heels up, and unless this penchant is corrected by turning the youngsters over into the [66] 
CONSTRUCTION AND CARE OF HOTBEDS soil, by making a tiny depression in the soil beside them with the point of a pencil to receive them, they are quite likely to perish. For this reason it is necessary to keep a close watch on the seedlings during the period of germination. The same end may be accomplished by sifting a little fine sandy soil over the seeds when they begin to germinate.

It is doubtful if any portion of the summer gardening is of greater interest than this watching of the breaking of the earth crust and the appearance of the tiny, tender green heads, and if good seed has been used and the planting carefully done, each square will present a mosaic of vigorous growth from the start.

The hotbed must not be neglected during these early days of growth, as sudden changes of weather may cause untold disaster. The temperature in a closed bed, under the influence of a bright sun, rises rapidly and the beds dry out with amazing frequency, and it will be necessary to admit air and exclude, to some extent, the sun by placing papers over the glass and raising the sash a trifle for the escape of the surplus heat. If, however, there is also a wind, it will be necessary to guard the opening on the windward side by a bit of rug 
or old carpet that no chill wind may blow over the exposed plants. Should the sun go under a cloud when the sash is open and the temperature fall, the sash must be closed at once. It will also be best to keep the sash closed during rains and lowery weather.

One of the most serious difficulties which confront the gardener in the management of a hotbed arises from a spell of hot weather when the plants are yet in their seed leaf, or the first week or two of growth; when this occurs to the extent of necessitating the closing of the beds for days at a time, especially if it also becomes necessary to protect the beds from the cold with rugs, not only shutting out the air but the light as well, then the situation is indeed serious, as there is often much loss of plants from damping off. The only palliative treatment is to watch the weather and not water the beds, especially at night, when a spell of wet weather is imminent; if the beds go into bad weather in fairly dry condition they will come through in much better shape. It is, for this reason, always better to water early in the morning if conditions are favourable.

The beds should be well protected with rugs or [68 ] 
CONSTRUCTION AND CARE OF HOTBEDS

mats on cold and frosty nights; glass radiates heat very rapidly after the sun goes down, and should, for that reason, in the early days of spring, be covered while yet it retains the heat. Whatever covering is used should be brought down well over the sides of the beds, and in windy weather should be held in place with racks or strips of wood. Shutters or some waterproof covering is necessary over the rugs in wet weather, as wet rugs or frozen ones do not exclude cold, and for this reason should be kept dry.

As the weather grows warmer and the plants increase in size, more air and sun should be given and the sash may be partially raised throughout the warmer part of the day. If the sun is hot, newspapers should be placed over the sash or the glass whitewashed. Later the sash may be removed during the heat of the day and replaced with lath screens, and as the season for removing the plants to the open ground approaches, these, too, may be dispensed with and the plants given full exposure to harden them off and make the plants grow more stocky.

Where there is room for it, much benefit will be derived from transplanting the plants, when they 
have grown large enough to handle, into fresh rows or other hotbeds. Such plants as cabbage, cauliflower, and lettuce may be transplanted into coldframes or beds in the open ground, where they can be protected with canvas in case of sudden drop of temperature, and grown on until time for transferring to permanent positions in the garden.

\section{COLDFRAMES AND PITS}

The coldframe is simply a frame of boards provided with sash or other protective material, and differs from the hotbed principally in that it has no heating material or pit beneath it, but is set on the surface of the ground. It has many uses and is a valuable adjunct to the garden. In the small home garden it is most useful for starting early lettuce, for growing a few melons or cucumbers ahead of the outdoor crop, or for carrying lettuce and cauliflower through the winter in order to have an early crop of these. It is also useful for wintering plants of artichoke, which will not endure the winter in the open ground at the North. It is a very useful auxiliary of the hotbed when used for transplanting the plants from those beds in order to give more room to develop. A very 
small hotbed can be made to do service for a goodsized garden if supplemented by a coldframe.

The transplanting of any plant is a distinct advantage, as it not only allows of greater top development, but the root development is also much improved, as a new growth of roots is induced with each removal; and the greater the amount of roots carried by the plant when it goes into the open ground, the better will be its development and subsequent growth.

Any spent hotbed may be used as a coldframe through the summer and winter, and makes the best of places for the midsummer starting of pansy seeds and other flower perennials that are to be carried over the winter under sash.

It is well in constructing coldframes for winter use exclusively to build them so that they may be taken apart if necessary and stored away during summer. This may be done by making the four sides separately and fastening them together with pegs, hinges, or hooks; the joints should be a perfect fit, though, as the exclusion of cold is the first reason for their construction.

Where the coldframe is intended for the protection of any large number of plants, as in the [71] 
flower garden, where beds of roses, azaleas, rhododendrons, and the like are to be protected, the span-roofed frame is preferable. This, as its name indicates, has a double sash or roof of glass and glass ends, being built with a wooden base a foot high all around and a frame about two feet high in the centre on which the sash rests, the gable ends being filled with glass. This is much more pretentious than the common coldframe or hotbed and much more commodious. It is not necessarily prohibitively expensive, and will more than pay for itself in the protection it affords.

The permanent hotbeds may be made useful and attractive during the summer by using them for planting out tropical plants or those requiring an unusual amount of heat and nourishment, as their location in the sunniest position furnishes the one and the great amount of manure they contain the other. No better place could be found for growing banana plants, whose luxuriant growth requires just these conditions. It will also be found a convenience in applying water, as the frame and the lowness of the soil inside prevent all waste, and the soil can be kept wet under conditions that would be impossible in the open ground. 
CONSTRUCTION AND CARE OF HOTBEDS

The space back of and between the wall and hotbed may be utilised for the growing of vines, and so render beautiful what might otherwise prove barren and unsightly. This would be an excellent position in which to grow a vine or two of the Niagara grape, as the building would afford it the protection it needs and the position on the south wall the necessary amount of sunshine and heat.

In renewing hotbeds and pits, the old manure in the bottom should be separated from the soil and thrown in a pile by itself, and may be used as a top dressing for bulb-beds, shrubbery, and the like.

The plant pit is another very useful adjunct to the garden, especially in the Middle and Southern States, but is of little use at the North, where it is only available for the wintering of tender roses, carnations, and the like-plants which require to be kept dry more than to be protected from frost.

It is possible, however, to make use of the pit for the raising of winter lettuce, radishes, and the like, when it can be constructed in connection with the cellar, and so receive heat from the furnace or other source. When this is undertaken, an excavation should be made on a south wall, reaching down to the cellar bottom and having an entrance 
into the cellar. The sash should slant sharply toward the south, and the frame should be of stone, cement, or brick construction, and if this can be built with a hollow wall, so much the better. Hollow cement tile furnishes a good, solid construction, or concrete may be built hollow by the use of cores. The sash should be provided with heavy wooden shutters and mats of straw or rugs to protect the pit in severe weather; these should be removed during the day whenever the weather permits. If the pit opens out of a furnace cellar and receives a good amount of sunshine, considerable growth will be made during the winter. The pit should be provided with shelves, which will permit of the placing of such plants as are wanted for immediate use close to the glass. Plants which are to be merely carried through the winter may rest on the floor of the pit or be placed midway between the top and floor.

In a mild climate a shallow pit may be built against a south-cellar wall and access gained to it through a cellar window. This is a most inexpensive form of pit and affords an excellent place for the growing of violets. 


\section{CHAPTER SIX}

\section{ON THE SOWING OF SEED}

THERE is no part of the garden work which calls for such nice judgment and careful attention as the sowing of seed. Most of the failures originate right here, and a large share of the blame devoted to the seeds and seedsman, if traced back to its original source, would be found to rest on the ignorance or carelessnes of the gardener. In the first place, there is a tendency among a large class of people to get something for nothing or at least at a bargain. This results in the purchase of cheap seeds or premium seeds, or seeds are purchased of the local grocer or seedsman and may, probably, have lain on his shelves from the season before or an even earlier date.

Now, to have a successful garden one must start right by buying good seeds of reliable seedsmen and seeds of plants suited to one's own locality. If, in addition, the seeds have been grown in prac- 
tically the same latitude, so much the better; it insures a hardy constitution, acclimated to the conditions which prevail in your particular locality. Now, as a general thing, good seed means highpriced seeds or seeds for which one pays a reasonable amount. This is at it should be. One should not expect to raise premium vegetables from cheap, scrub seed, and there is as great a difference in the pedigree of seed as in that of animals.

Then one should not only see that they are securing the best seed that the market affords but they should secure it in time, not wait until they are ready to plant and then rush off an order, hurriedly prepared and half the things needed forgotten and most of the others wrong, and expect to receive them by return mail. The spring of the year is a busy time with the seedsman, and it is but fair to him, as well as just to yourself, to give him a reasonable time to fill your order by getting it in early. If Mr. Jones has ordered an ounce of silver-skin peppers and ruby-king parsnips, there ought to be time allowed for the seedsman to inquire what Mr. Jones really wants, and not be obliged to fill his order by guesswork. Of course he will readily understand that what is wanted is ruby- 
ON THE SOWING OF SEED

king peppers and silver-skin onions, but how about the parsnips?

Late in winter or early in spring one should go over their seeds which have been saved from the home garden and ascertain how far they meet the requirements of the coming year. Then a list of such seeds as are not on hand should be made and the catalogues consulted for prices and varieties. The list made up then may, probably will, need frequent revising, and by the time it is mailed to the seedsman may be trusted to supply just about the varieties and quantities wanted. And, speaking of quantity, it will be about as cheap, in a good many cases, to buy by the ounce as by the packet; especially is this the case with those seeds of which it may be necessary to make repeated sowings - as cucumbers, squashes, melons, beans, and the like. A cold, wet spring often entails much replanting, and sufficient seed should be on hand to enable one to replant at once when it is discovered that the first planting is for any reason abortive. Owing to the proneness of seeds of vine plants to rot in the ground if too wet or cold, a much greater quantity of seed is required. Generous planting of these seeds is also necessary on account of the rav- 
ages of the squash bug, which must be liberally fed to induce him to leave a plant or two for the garden.

Next in importance to the quality of the seeds is the time in which they are sown. There are a few seeds which may be gotten into the ground as early as it can be worked. Beets, cabbage, lettuce, onions, peas, salsify, spinach, and turnips are all planted for early crops as soon as the ground can be worked, but such early planting of corn, tomatoes, melons, cucumbers, and other heat-loving plants would simply result in the loss of both time and seed.

The condition of the soil, also, has a marked influence on the germination of the seed. When the ground is still wet from the frost in spring it is not in condition for successful sowing of seed; it is better to wait until it has dried sufficiently to be mellow and tractable before sowing any kind of seed. Too dry a soil is seldom a cause of complaint in early spring, but is a condition which sometimes gives trouble in the summer, when seed of various vegetables are sown for a succession-as late corn, turnips, and the like. As it is not expedient to wait for the rain at this time, the proper conditions are 
partially secured by tramping the seed down very firmly and watering the rows well after sowing. The thorough firming of the soil over the seed is of the utmost importance-this and the depth at which the seeds are planted-for in sowing seed in the open ground much greater depth is necessary than would be given the same seed in the hotbed.

A case in point occurred this last season in my own garden, when the planting of peas, for a succession, and lima beans was left to an assistant. The most careful directions were given as to the manner in which they were to be sown. "Plant these peas," I said, handing him a package of Nott's Excelsior, "four inches deep and scatter them thinly in the rows. Tramp the rows down firmly, and when you have finished, go over the surface of the rows very lightly with the lawn rake. Be very careful to only scrape the surface of the soil, so as to leave a light dust mulch, so that the soil will not dry out; and these," handing a packet of Dreer's Bush Limas, "are to be planted two inches deep, two inches apart, in the drills, and the soil tramped down over, but these being planted so much more shallow, you need not use the rake. Make the drills for each a foot apart for two drills, then leave two feet be- 
tween to cultivate through." "Yes'em, I understand." An hour later he reports for more work. "Well, how deep did you plant those peas?" "Four inches deep, tramped down the rows, and raked them over. Planted the beans two inches deep and two inches apart in the row and tramped them down," he answered glibly. Very good! A few days after a heavy rain and every pea on top of the ground, and all sprouted, but nowhere any beans. An investigation demonstrated that the beans were reposing four inches below the surface, all sprouted and decayed-result, the loss of both crops. He had simply " mixed those babies up." Had they been planted as directed, there would have been an excellent crop of semi-early peas and an abundant supply of beans.

The tramping down of the seed should never be omitted when the ground is in a dry condition. On very wet soil it is not necessary nor best, but on dry soil it is indispensable. The reason for it is obvious. If the soil is dry and lies loosely about the seed, there will not be sufficient moisture to cause the seed to germinate. Or, should it be able to do so, the contact with the soil will not be close enough to allow the tiny roots to take hold upon it, and 


\section{ON THE SOWING OF SEED}

without this immediate connection, the young sprout cannot grow, but will wither and die. Planted in loose soil, the seed may lie in a space between two particles of soil, very tiny, but to the little hair-like roots a veritable cavern, through which they will grope in vain for food and moisture. When the earth is pressed firmly about the seed it comes in immediate contact at every point, and can at once, when germination takes place, lay hold upon the earth and grow.

It is not well to plant seed, especially that which is only lightly covered, just before a hard rain, but a gentle rain is a distinct advantage. In the small home garden the delay of a day or two in the planting is not often the cause of serious loss, though it may well be of moment to the commercial gardener. It is much more important that it shall not be gotten into the ground too soon than that it shall not be planted too late. To be sure, if one has an abundance of seed and does not care for the labour involved, then the chances of getting an early crop by early planting may be worth while. But as a general thing, seed planted when the soil has become warm and the nights are warm, will make enough more rapid growth to more than [ 81 ] 
balance the difference in time, and can usually be trusted to overtake the earlier-planted seed plants.

In my early gardening experience I was very ambitious about getting things started at the earliest possible moment and to have things a little in advance of my neighbours, but several years of covering plants in the open ground to protect them from frost has quite cured me of any undue ambition; I am quite willing that my neighbour's tomatoes shall ripen a day or two ahead of mine if in return they will collect blankets, quilts, canvas, and other protective material and spend frosty hours spreading them over tender plants scattered over an acre or two of ground and trail around in the dew of the morning removing them, while I toast my toes by the fire and read my evening paper.

Unless the time and the condition of the ground is entirely favourable, it will be well to plant only a portion of the seed at a time, reserving enough for a second planting should the first fail to come up or the young plants be destroyed in any way. Should the seeds fail to come up in a reasonable time, do not be in too great haste to blame the seedsman, but go over the operation carefully in your mind and try and see if the fault may not 


\section{ON THE SOWING OF SEED}

have been in your management of the seed. I know that this is not an especially pleasant task, for, in the first heat of disappointment, it is a relief to be able to blame some one else for our misfortunes, but I can assure you that it is a very profitable process and one by which the amateur gardener learns and grows wise. 


\section{CHAPTER SEVEN \\ TRANSPLANTING}

$I_{\mathrm{T}}$ is a question whether the time at which tender plants shall go into the ground is a matter of prudence or of courage. If one has a good hotbed well stocked with plants on which to draw, then "he either fears his fate too much or his deserts are small. Who fears to put it to the touch, and win or lose it all," if the weather and soil are in a favourable condition for planting, for there is no question that one often gains two or three weeks by early planting. Nevertheless, the chances are against it, and it is not to be recommended where plants must be purchased, or all one's stock is put into the ground at once.

It may be accepted as a rule that warm weather early in March or April will be followed by a cold spell in early May, and that plants put into the ground ahead of this period will be apt to suffer, if, indeed, they do not perish outright. 
The kind and condition of the plants will have much importance in deciding the time at which they may be transferred to the open ground. If cabbage plants have been properly hardened off they may go into the ground much earlier than if very tender. For this reason plants which were started from seed sown in September of the previous year and carried through the winter in coldframes or those from seed in spring and well hardened can go into the ground as early as it can be worked in the spring, but tender plants from hotbeds, started the middle of March or first of April at the North, should not be set out before the first of May, and even then should have been well hardened off by exposure to the weather-nights as well as during the day-for a week or more. Cabbage plants which show a whitish-green shade are too tender for outdoor life, and it will be better to wait until they show a film of blue over the foliage. Tender plants, like peppers and egg-plants, should not go into the ground until settled warm weather, which at the North will be any time from the twentieth of May to the first of June.

Before commencing the transplanting of any vegetables the ground should be thoroughly pre- 
pared by ploughing and dragging-both waysand floating off, or if spading is necessary, it should be very thoroughly done, so that the soil is entirely broken up and pulverised, and the steel rake should be used to get the surface into as fine a condition as possible. The lines for the plants should be set and the distance apart the plants are to stand in the rows indicated. Market gardeners use a marker consisting of a long pole with a crosspiece at one end of the length of the distance apart of the rows and provided with a triangular piece of wood, as a marker or peg, at each end. This is drawn over the ground in each direction and a plant set at each intersection of the lines. It is very little more trouble to use a garden line and reel, and the result is much straighter lines. A garden tape, which has the feet marked in red numbers, is handy in this connection, and as a hundred-foot line is inexpensive, it will be found a very profitable thing to have about the garden.

It will much simplify the planting to have the rows marked out and the holes dug before any plants are lifted from the beds. The hotbeds should have been well watered the night before, and if the number of plants is not large, planting may be 
delayed until the late afternoon of the following day. Planting large numbers of plants in this way may be done in several days. Great care should be exercised in lifting the plants from the beds; they should not be grasped by the handful in the hand and pulled up like so many weeds-a process which leaves most of the roots in the ground-but should have the trowel passed well down below their roots and a section lifted carefully out, the plants being separated as they are set. The advantage of this method will be apparent if one will compare the roots of the carefully lifted plants with those pulled up in the usual haphazard way. The latter will have one long root, with a few fragments of side root adhering, while the carefully lifted and separated plant will show a fine mass of fibrous roots, which will at once take hold upon the soil in the new position and begin to feed the plant and produce growth, while the badly lifted plant must first replace the roots of which it was so ruthlessly bereft before it can give any nourishment or assistance to the top.

Only as many plants should be lifted at once as may be gotten into the ground before they wilt. Keeping the plants in good condition until they [87] 
are safely in the ground is half the battle in transplanting.

In setting the plants, the directions for the several kinds of vegetables as to distance apart of the rows and space between the plants in the row should be followed, but the same general principles must be followed in the transplanting.

A hole should be made for each plant, large enough and of sufficient depth to hold the roots in the same position they occupied in the hotbed and the roots placed so that the plant sets slightly lower than it did in the hotbed. Draw a portion of the soil about the roots and press it down firmly with the hands. If the soil is very dry, fill the hole with water, and when it has nearly soaked away draw up the remainder of the earth and settle this snugly, but not hard, about the plant; after all is done, go over the ground lightly with the trowel, so as to leave a fine dust mulch about the plant.

The work of planting will be much simplified where the plants are set in long rows by setting all the plants in the holes before applying the water; one can then go along the rows with a pail and dipper and fill the holes with water, and by the time the end of the row is reached, the first 
holes will be ready for filling, and by the time all are filled, any moisture which may work to the surface will have had time to appear and may be covered with a dust mulch. The planting should all be looked over carefully before leaving to see if any wet spots appear; when such is the case, they must be immediately covered with fresh, dry earth. No covering or protection of any kind need be given, except in case of frost. The dust mulch takes the place of shingles, paper, or anything used to protect from the sun. Properly planted, with the soil firmly pressed about the roots and well watered and the protecting dust mulch preventing the heating of the soil or evaporation of moisture, the tops exposed to the fresh air and sunshine, the plant is in the best possible condition to withstand the change of position; also, if it has been watered the night before and lifted in the morning before the sun has materially reduced its strength, the plant cells are full of water and will not need to call on the roots for a supply until a time they are in a position to respond.

There is no one fallacy I find so much trouble in overcoming in people I employ about my garden, or with whom I come in contact in gardening [89] 
matters, as that of the necessity of protecting newly set plants. I was brought up in the orthodox dogmas of gardening and taught to protect everything that went into the ground until it had taken root, and I remember the wearisome hours spent in placing shingles, paper caps, and the like between the plant and any possible rays of the sun; and I especially recall several hundred small plants which were once covered with the most "scientific" of paper caps, provided with an attached stick to thrust into the ground to hold them in place. I spent the leisure hours of several evenings fashioning these out of stiff paper, and I viewed with pride the little army of tents in orderly array that gleamed white in the morning sun. But my pride turned to humiliated dismay when the tents were lifted at eventide that the plants might have the benefit of the night air; fully fifty per cent of my plants lay wilted and dying. The water in the soil, unhindered by any protecting dust mulch, had, under the ardent rays of the sun, drawn to the surface and, confined within the narrow confines of the tents, was rapidly reduced to steam, and the poor plants, confined within a Turkish bath, were literally cooked to death. That ended 


\section{TRANSPLANTING}

my use of any kind of protection, and I have frequently, in the years that have intervened between that disastrous experience and to-day, set out plants of balsam a foot in height in the hottest sunshine without a sign of wilting - and few plants wilt more readily than these.

Having gotten the plants safely and rightly into the ground, let them alone. This is another much-mooted point. Almost everyone who sets out plants during the day is possessed to go puttering around at nightfall with a watering pot or pail and dipper with which to water the newly set plants. This is not only unnecessary but actually harmful if the plants have been properly set. It destroys the dust mulch and defeats the purpose of all the care in planting. Instead, then, of watering the plants, go over the rows late at night or early in the morning and restore the dust mulch to any part that shows wet.

Should rain occur in a day or two after planting, the ground must be gone over, as soon as it can be worked, with trowel, rake, or hoe, to create a fresh mulch of dust.

There is a prevalent prejudice in favour of planting just before a rain. That is, in certain con- 
ditions of the weather, a very good plan to follow. If the rain promises to be a long one, or what is known as a spell of wet weather, the plants may safely go into the ground, but if nothing more than a summer shower threatens, which is likely to be followed by bright sunshine, it will be well to wait until it clears. Bright, settled weather offers the best of conditions for planting, as then one can control conditions. A succession of showers, with bright sunshine, or hot, muggy weather, is the most unfavourable condition; the wet earth, under the influence of a hot sun, steams and cooks, and as there is no fresh wind to carry away the unwholesome vapours, the tender plants suffer as much as we do. Cloudy weather, on the contrary, following after a good rain, affords the very best condition for the establishing of the plant in the ground. As a usual thing the plants will not require watering for several days, but should any appear to suffer, a hole may be made by the side of the plant with trowel or dipper and this filled with water and the dry mulch restored.

In setting some plants in the soil, if of weak growth, it will be well to remove a portion of the top. This is universally done by Dutch gardeners, [92 ] 
who remove all but the top leaves of cabbage and cauliflowers, and these two they denude of the upper half of the leaves, and I have found it an advantage in my own practice. It not only relieves the roots of the care of the top to a great extent, but, by lightening the tops, the weight is removed from the stem, which is enabled to retain an upright position. Strip every other plant of its leaves and it will be standing upright when the full-leaved plants are bending weakly under the weight of their tops.

Tomato plants are often " drawn" from crowding and form what is known as a "knee" by bending downward towards the ground and then assuming an upright position at this point when roots form all along the horizontal part of the stem. In setting the plants in the ground, they may be set deep enough to cover this crooked part with advantage. Where the plants have become very crooked and drawn, it is a good plan to make the hole in the form of a shallow trench and lay the plant therein, leaving only the top exposed, first removing the leaves below this point. The exposed part will assume an upright position as soon as growth begins and make fine, stocky plants. 
All newly set plants are at the mercy of cutworms, and the rows must be gone over every morning early to see what, if any, damage has occurred over night. Wherever a plant is found cut off, immediate search must be made for the culprit. A moment's search will generally discover him just below the surface of the soil near the decapitated plant. Any loose dirt or rubbish will serve as a hiding place for him, and this tendency may be taken advantage of to trap him by laying pieces of board or chips on the ground near the plant, under which he may hide. But as he does not hide until he has had his meal, this is much like locking the stable door after the horse is stolen; but then, of course, his capture and execution will prevent his eating other plants.

Where the plantings are small, it pays to surround the plants with collars of stiff paper, three or four inches high. These should be pressed into the ground a half inch, and care should be taken to see that there are no worms inside the collar when it is placed. Old tin cans with the bottoms burned out are also a good protection, but the trouble with these is that they must all be gathered up in the fall and disposed of in some way. An[94] 


\section{TRANS PLANTING}

other remedy which leaves no after-work is to poison the worms, and this I have found very successful. Cut clover wet with sweetened water and Paris green is often used, but I prefer a mixture of corn meal and Paris green, made thin enough to run, and poured in a ring around the stem of the plant, a little way from it. The only objection to this is when chickens are about, but as no little chickens are likely to be abroad at this time of the year, and large ones should be in confinement, this is of little moment, and the first cultivation will turn it under the soil.

I usually find it necessary to go over the garden every morning for a week, and each time replace more or less of the plants before I am finally rid of the pests.

Cabbages, cauliflowers, and tomatoes are the plants most affected by the cut-worm, but his depredations do not stop in the vegetable garden, as he is equally destructive to the flower garden; and some vine plants can never be secure without an encircling collar of tin or other substance. 


\section{CHAPTER EIGHT}

TOOLS WHICH MAKE GARDENING EASY

THE number of tools which it is really necessary for one to have is not large; but if the amateur gardener tries to get along with a hoe, a rake, and a spade, he is sure to have long, tedious hours of hard work.

The tool which will be most used during the season is, of course, the hoe, for the weeds grow rapidly. By using a wheel-hoe you can save all that backaching work. I kept a three-fourths-acre vegetable garden in good shape all summer with one. Only a couple of hours were needed in which to stir the surface of the whole garden. This was done regularly once a week and after each rain.

The wheel-hoe is the handiest tool in the garden. It may be fitted with ploughs, rakes, cultivatorteeth, flat-hoes, which work like the scuffle-hoe, and seed-sowing attachments. They cost anywhere from $\$ 3.50$ up, according to the kind you get and the number of attachments that you wish.

[96] 


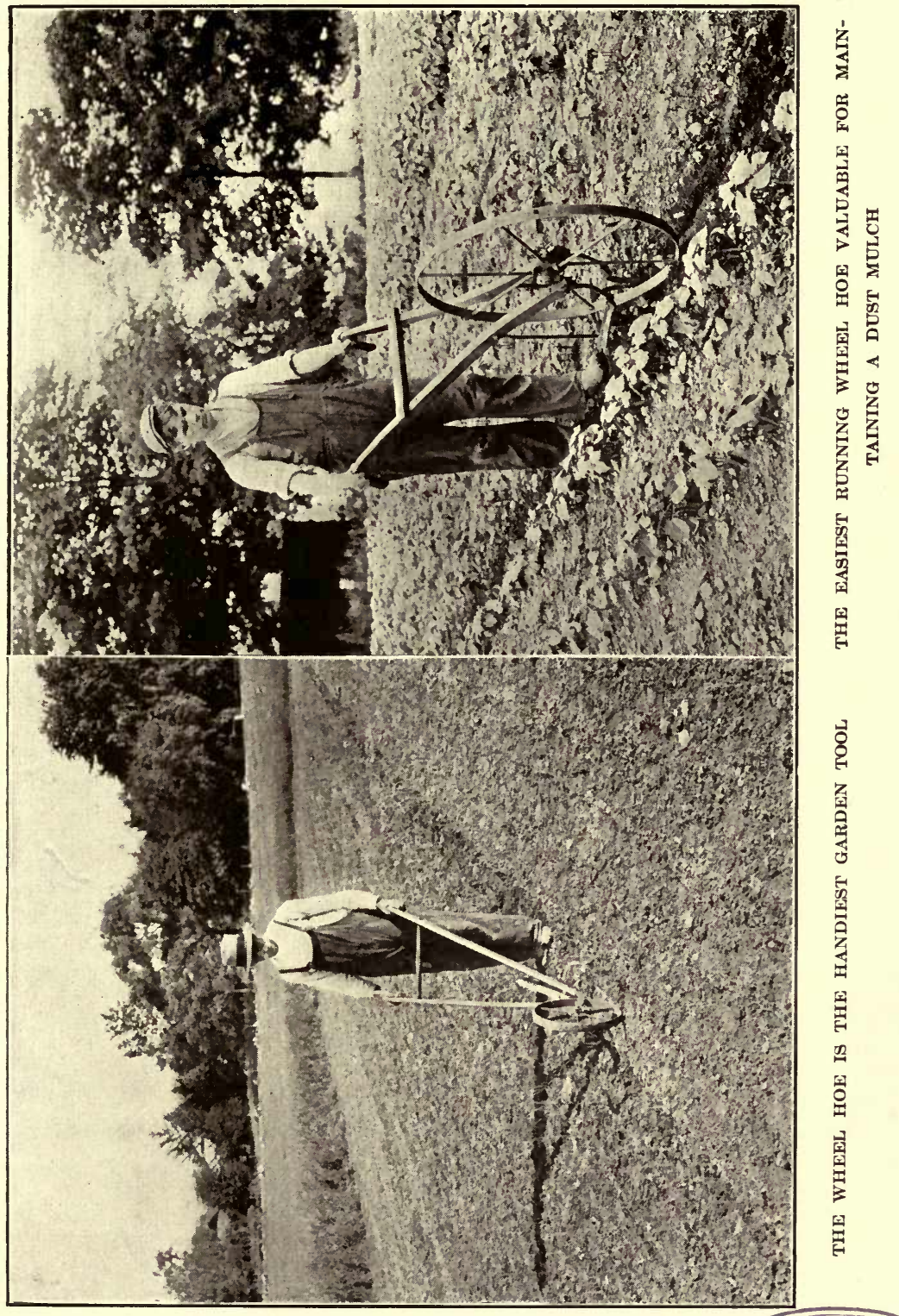

IIBRARY OF THE 


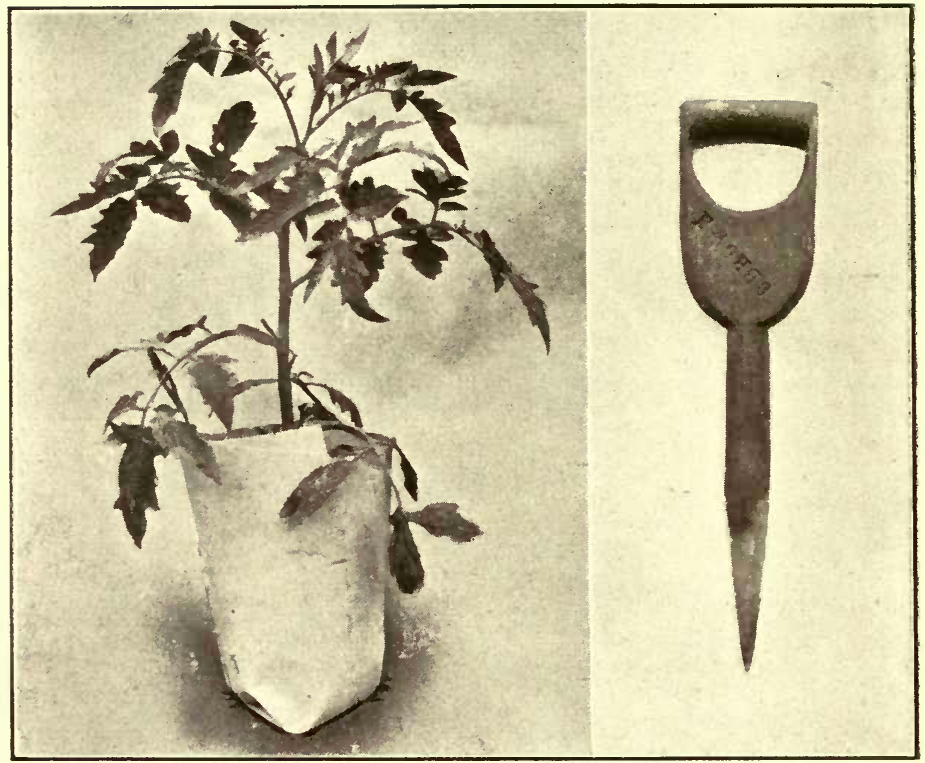

PAPER COLLAR TO PROTECT PLANT FROM CUT WORMS

A HOME-MADE DIBBLE 
TOOLS WHICH MAKE GARDENING EASY

There are single-wheeled and double-wheeled wheel-hoes. Some have small wheels and others large. It is the small-wheeled ones that have all the attachments.

In the spring, after your garden is ploughed or spaded, the rakes may be substituted for the hoes and the ground levelled. Then the little ploughshare is put on, and the drills in which the seeds are to be sown can be made-that is, if you are going to sow them by hand. It is easier, however, to have a seed-sowing attachment on the wheel-hoe. It costs about $\$ 7$, but I really believe that it is worth it. It saves one from getting down on his knees, or doubling up like a jack-knife, when sowing the seed, and, as the machine is regulated so that the seed may be sown any thickness desired and the work done much more evenly, a given quantity of seed will go farther than if sown by hand. As soon as the seed-leaves show above the ground, cultivating commences with the regular cultivator-teeth. And this should be continued all summer long, using scuffle-hoes to cut off the weeds, or the teeth of rakes to keep the dust mulch in good condition.

In selecting a wheel-hoe, it will be necessary to [97] 
consider the size of the pocket-book. I prefer the one with double wheels, for it can be used in most places to better advantage than the single-wheel hoe. It is an extremely handy tool to have late in May and early in June, when the weeds are growing fast. It is made to straddle the row. You should fit it with scuffle-hoes, which can be so nicely adjusted that all the weeds except those between the plants can be cut off. It is especially useful on such crops as onions.

The only large-wheeled hoe which I ever used was like the one shown in the illustration. It is easy to run-easier, I think, than the small-wheeled ones-but it has the big disadvantage of not having detachable tools. However, if the hoe is to be used only to maintain a dust mulch, it does equally as well as the small-wheeled one and involves less labour.

For the larger garden, which is to be cultivated by horse-power, there are several good makes of cultivators, which have changeable teeth and hoes. These cultivators have light, but strong, steel frames, so are easily handled. They have levers, by means of which the cultivator can be instantly. changed from one width to another, so that it can 
TOOLS WHICH MAKE GARDENING EASY

work in narrow or wide rows. Other levers regulate the angle at which the teeth are set. These horsecultivators can be used for making furrows, cultivating, hoeing, and covering hills and furrows. Many times have I made the furrows for my potatoes with this, and then followed the boy who dropped the seed with the same machine, but with other attachments to draw the soil in the row and firm it.

Where the amount of cultivating will warrant it, I would recommend buying a spike-tooth cultivator. For stirring the soil to create a dust mulch, it is better than the ordinary cultivator in that it does not leave the soil in ridges but perfectly flat and very fine.

Of the ordinary hoes there are a great variety. The common one is useful for straight hoeing, and, if kept sharp, does good work, but there are special hoes which are much better; they do the same work and do it more easily. There is a heartshaped hoe which is particularly useful for making furrows. There are hoes with scalloped edges, which, if kept sharp, will cut weeds with about onehalf the effort that is necessary to draw the ordinary straight-edged hoe through the ground. The [99] 
best hoe I ever used for hoeing corn looked a good deal like a rake, but the teeth were thin and half an inch broad.

One trouble with all these hoes is that the operator walks over the ground he has already worked, and treads the weeds which have just been cut off back into the earth, where they take root again. With a scuffle-hoe it is different. The best way to use this is for the operator to walk backward, so that the newly stirred ground shall not be walked on. Most of these scuffle-hoes have straight edges and are pushed, but there are $\mathrm{V}$-shaped ones which are made to pull, the ends of which are turned up, so that the possibility of cutting off a plant is removed. When using an ordinary hoe, one invariably bends his back. There is no necessity for doing so, but, somehow, nearly every one does it. With a scuffle-hoe this tendency is entirely obviated. You can pull or push a scuffle-hoe all day without getting a backache.

There is a scuffle-hoe made mounted on a wheel which is pushed "steady by jerks," as is the ordinary wheel-hoe. Although I have never used it, I like its appearance very much.

The spade is a necessary tool in the garden, for [100] 
there is always more or less digging to do. For digging celery, I have found a small spade to be much better than those of the standard size, but if one has only a little celery it would not be worth his while to get one. If it is necessary to spade the garden rather than plough it, by all means do it with a spading fork. It has four or five strong prongs. The difference in weight between this and a spade is considerable, so that by its use one saves himself from lifting a good many pounds while digging over the garden. Besides, it is much easier to push into the ground.

A good garden line is indispensable. Get a good linen line and keep it on a reel. One hundred feet of line and a first-class reel will cost about $\$ 1$. Keep it dry, or dry it out if it becomes wet, and it will last for years.

For weeding small plants like onions, radishes, and such like, a hand-weeder is useful. There are two types: one is like a hand with bent fingers and the other is a narrow band of iron bent at a right angle. I have used both with equal success.

A cart or wheel-barrow, or even both, will be found necessary. The best kind of a cart for the small garden is one which has a platform with a [101] 
detachable box; for whenever it is necessary to carry water in a barrel for spraying purposes, you can put the barrel and pump on it in place of the box.

Where large amounts of corn are to be planted, use a corn-planter. These are made in two general forms: one to thrust into the ground by main force where the corn is to grow and the other is on wheels, and by a mechanism attached to a driving wheel the corn is dropped at stated intervals into a furrow made by a share on the machine and covered by two wings. Both these types of machine carry the seed in a box or inside the machine, and are so regulated that the required number of kernels are dropped in each hill. The machines, which run on wheels, also have a fertiliser attachment which drops about a tablespoonful of commercial fertiliser in each hill. Either of these tools will prove handy and money savers where an acre or more of corn has to be planted.

For setting out plants, one can get a variety of trowels, curved, straight, and angled. I have found the angled trowel exceedingly useful in setting out such small plants as cabbage, cauliflower, and the like. 
TOOLS WHICH MAKE GARDENING EASY

Do you ever have any trouble in cutting asparagus? I did until I purchased an asparagus knife. There are several forms of these knives, but they are all made long, so that one can get down three or four inches under the surface of the soil to cut it and do less damage among the shoots which have started. 


\section{CHAPTER NINE}

ON THE GROWING OF VARIOUS VEGETABLES

T Here are several forms of vegetables which, while the culture is not specially dissimilar, may yet, for convenience, be divided into five classes: those the edible part of which is produced beneath the surface of the soil and are known as root vegetables; those which set fruit above ground; those whose fruit is produced on vines; such plants as are used entire, as lettuce and the various greens, and those perennial forms which include the asparagus, articholes, rhubarb and horse-radish, and the like.

We will first consider the general culture of the plants which produce heads, pods, ears, or other fruit, and which may be roughly designated as head or pod vegetables.

\section{BEANS}

Are a tender class of vegetables, and the seed of any varieties should not be planted out until the nights [104] 
THE GROWING OF VARIOUS VEGETABLES and soil are warm. Usually the middle of May, at the North, will be found to be quite early enough. In cold, wet soil the seed will decay instead of growing, while the opposite is true where the seed is given a warm location and a warm, sandy soil. The soil should be deeply prepared and well enriched with old manure.

The seed of bush varieties should be sown in drills, two feet apart, and the beans dropped two inches apart in the row and covered two inches deep, treading down the earth after planting.

If the beans are to be used for string beans or fresh shell beans, they may be planted every two weeks for a succession, but for dried beans to use with pork in winter, should be planted early and kept well cultivated and clean until the pods ripen in the fall.

Beans should not, for best results, be planted in a low, wet place or in too much shade. They must not be worked or handled when wet, as this will cause them to mildew. Therefore a warm, sunny position, where they will dry quickly in the morning, is best.

Bush Lima beans, so much preferred for succotash by many, are rapidly superseding the pole [105] 
Lima. These are planted the same as other bush beans and given the same culture. They come fairly true from seed and are heavy producers. They make an excellent dry bean for winter use. They come quite true from seed, but occasionally a plant will show a disposition to run, and when this is noticed, it will be well to pull it up, as it will tangle up the other plants and interfere with their cultivation and gathering.

One quart of bean seed will plant a hundred feet of drill and give sufficient beans for a goodsized family. They may be planted for a succession of string beans up to the fifteenth of August. Pole varieties yield much larger crops than the bush forms, and by training to strings, wire netting, etc., may be planted close up to the gardenfence or the poultry-yard, or serve as a screen to hide outbuildings or parts of the garden if desired. The expense of poles is, however, avoided by planting only the bush varieties.

The varieties most generally cultivated are the following:

$$
\begin{aligned}
\text { Wax string beans. } & \left\{\begin{array}{l}
\text { Dwarf Golden Wax. } \\
\text { Yellow-eyed Golden Podded. } \\
\text { Black Wax. }
\end{array}\right. \\
& {[106] }
\end{aligned}
$$


THE GROWING OF VARIOUS VEGETABLES

Green string beans. $\quad\left\{\begin{array}{l}\text { Early Valentine. } \\ \text { Early Six Weeks. }\end{array}\right.$

Green shell beans. $\left\{\begin{array}{l}\text { Dwarf Horticultural. } \\ \text { Burpee's Dwarf Lima. }\end{array}\right.$

Field or winter beans. $\left\{\begin{array}{l}\text { Small Pea. } \\ \text { White Marrow. } \\ \text { Red-eyed Field. }\end{array}\right.$

DIRECTIONS FOR COOKING BEANS

\section{STRING BEANS}

Break off the end that grew upon the vine, drawing off at the same time the string upon the edge; repeat the same process upon the other edge; cut them with a sharp knife into pieces half an inch long and boil them in just enough water to cover them. They usually require about an hour in which to cook tender, but this depends upon their age and freshness, beans which are at all wilted taking much longer.

After they have cooked tender and the water has very nearly cooked away, add pepper and salt, a tablespoonful of butter, and half a cup of cream; if no cream is available, use milk and a little more butter. 


\section{LIMA AND KIDNEY BEANS}

These beans should be put into boiling watera little more than enough to cover them-and boiled till tender, about half an hour if young and fresh, but as much as two hours may be required if old and somewhat wilted. Season with butter, pepper, and salt.

\section{SUCCOTASH}

Take a pint of fresh-shelled Lima beans, or any large, fresh beans; put them in a pot with enough cold water to a little more than cover them. Scrape the kernels from twelve ears of young, sweet corn, first carefully removing every particle of silk; put the cobs in with the beans, boiling from a half to three-quarters of an hour. Then take out the cobs and put in the corn, boiling fifteen minutes. Season with salt and pepper to taste, a lump of butter the size of an egg, and half a cup of cream. Serve hot.

\section{BEAN SALAD}

String young beans; break into half-inch pieces or leave whole; wash, and cook soft in salt water; drain well; add finely chopped onions, pepper, salt, [ 108 ] 
THE GROWING OF VARIOUS VEGETABLES and vinegar; when cool, add olive oil or melted butter.

\section{PORK AND BEANS}

Take two quarts of white beans, pick them over the night before, and put them to soak in cold water; in the morning put them in fresh water and let them scald, then turn off the water and put on more, hot; put to cook with them a piece of fresh salt pork, as large as desired (sufficient for serving sliced when cold is desirable), or the pork may be boiled separately and added to the beans when put in the oven; this is less greasy and more appetising. Boil slowly till soft (not mashed), then add a tablespoonful of molasses, half a teaspoonful of soda, and a teaspoonful of made mustard; stir in well and put in a deep pan to bake, first placing in the centre of the bottom of the pan a mediumsized raw onion and over this the square of pork, pouring the beans around the pork, not over it. Bake one hour and a half.

\section{CABBA GE}

At the North cabbages are usually started in coldframes or hotbeds early in March and planted out as soon as danger of killing frosts is passed. They [109] 
succeed best in a deep, rich soil, heavily manured, and in some localities cannot be grown successfully on the same ground year after year; in other sections this does not seem to make any difference, and in my own garden they have grown in the same spot for several successive seasons.

They should be well cultivated and kept free from weeds. The cabbage worm is very troublesome in some sections, but in the private garden need not make any serious trouble. As soon as the little white butterflies appear, the plants should be watched for the presence of eggs, and when these are found and removed, the worms are disposed of; the eggs will be found in a small yellow patch on the underside of the leaves; they are quite conspicuous, and easily removed.

Early cabbage is sometimes given to cracking as soon as ripe, and must be used at once, as the new growth commences then. To prevent this, the roots may be cut off on one side of the plant as soon as the head has attained its growth and the plant tipped over on its side; this checks growth, and the head will then keep for some time.

For late cabbage, seed is sown in the open ground from April to June, and the plants transplanted 
THE GROWING OF VARIOUS VEGETABLES

into permanent rows early in July, setting the plants in rows two and a half feet apart and two feet apart in the rows, which is the space allowed the early cabbage. The cabbage fly is likely to trouble the young seedling cabbage plants, and they should be dusted with wood ashes, air-slacked lime, tobacco dust, or road dust, as soon as the plants are above ground; this should be done while yet the plants are wet with dew in the morning.

The Early Jersey Wakefield is one of the best early cabbages, being very solid and hard and of conical shape. For those who prefer a looser head, the Flat Dutch varieties are excellent.

\section{DIRECTIONS FOR COOKING CABBAGE}

\section{BOILED CABBAGE}

It is best boiled with corned beef, and should be cooked whole or divided in halves or quarters according to the size of the head. It should be very carefully washed and looked over before adding to the meat, as worms and other undesirable tenants are sometimes inclosed within its leaves. The large Drumhead cabbages require an hour to boil, while the green, Savoy cabbage will cook in a half-hour, 
so that they should be added to the meat the necessary length of time before the former will be done. Over-cooking must be avoided, as it makes the cabbage watery.

Pepper vinegar is a delicious condiment to serve with boiled cabbage, and is made by putting an ounce of the seed of cayenne peppers in a quart bottle and filling up with white-wine vinegar; this is corked and allowed to remain for several weeks, or until the strength of the pepper seeds is all extracted, when it should be turned off carefully into vinegar cruets.

\section{WARM SLAW}

To prepare this delicious dish of cabbage, slice the cabbage fine with a sharp knife or slaw-cutter and put over the stove in a skillet, with a little butter or fry-grease. Have ready a half cup of cream and the yolk of two eggs, well beaten together, and seasoned with salt and pepper and sharp vinegar to taste. Turn this over the cabbage and allow it to come to the boil, but not to cook, and serve at once. 


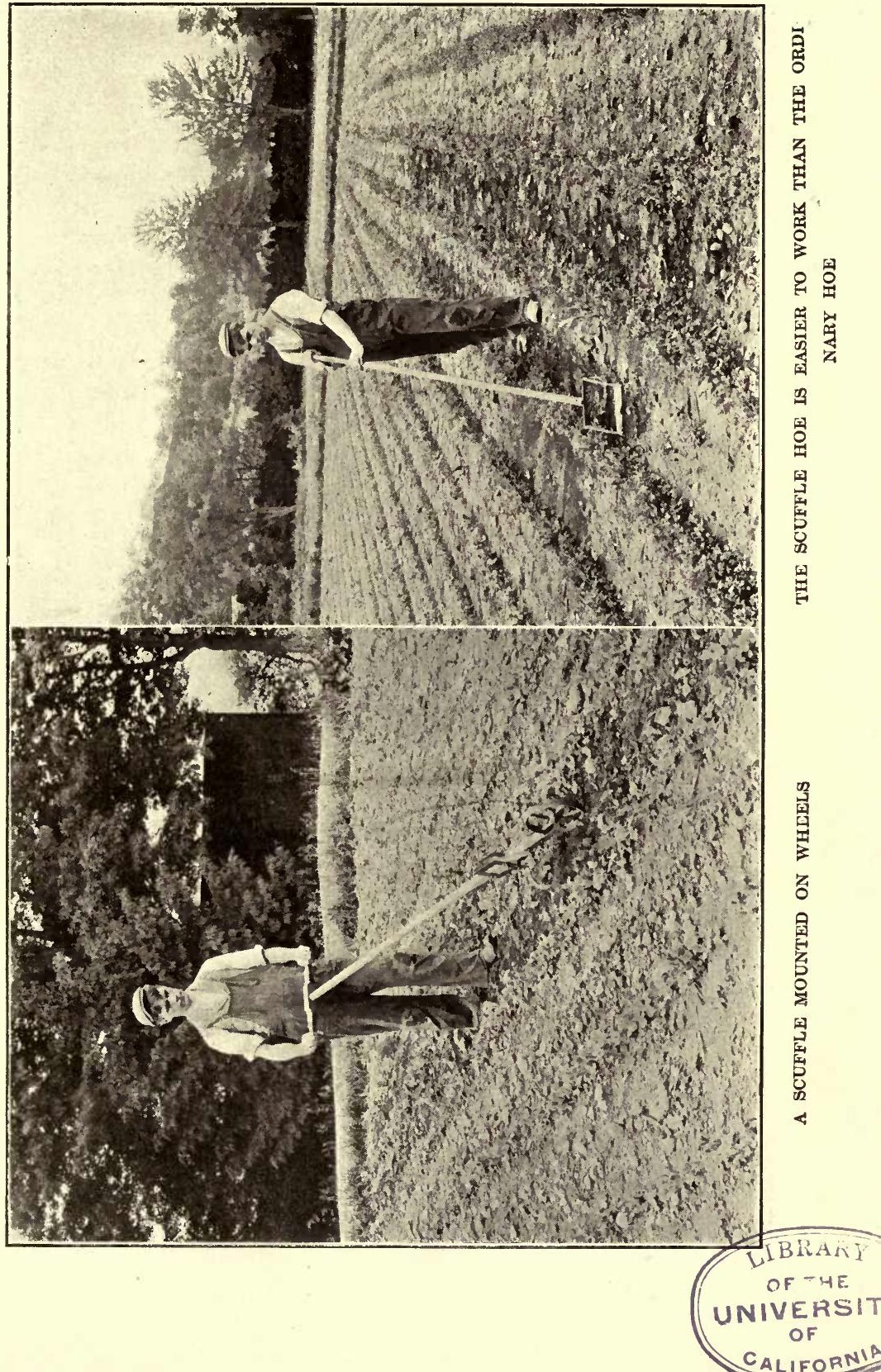




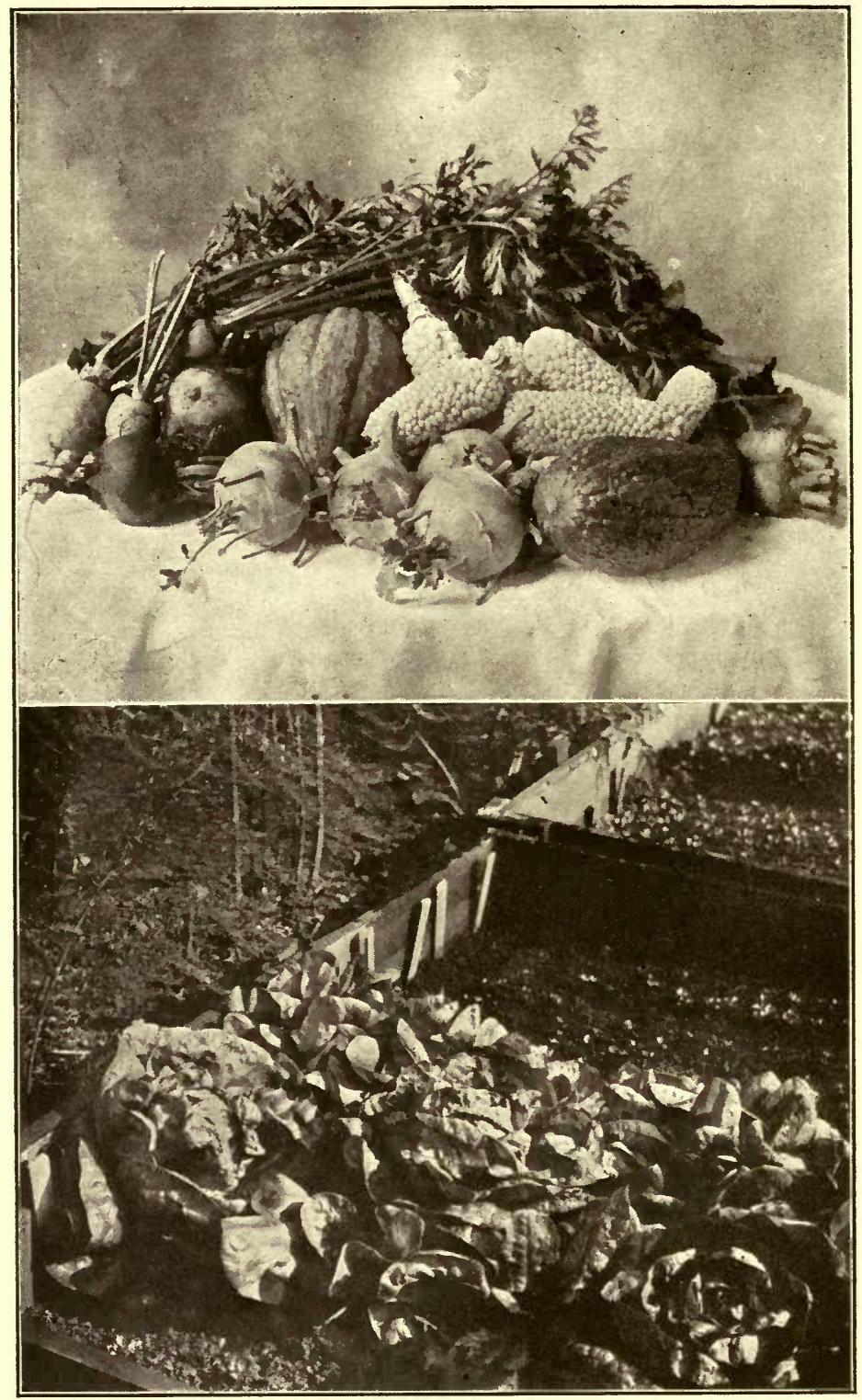

A GOOD COLLECTION OF HOME-GROWN VEGETABLES 
THE GROWING OF VARIOUS VEGETABLES

\section{CREAMED CABBAGE}

Slice the cabbage as for slaw; beat together the yolks of two eggs, one-half cup of sugar, one-half cup of vinegar, butter size of an egg, salt, and a little cayenne pepper. Put the mixture into a saucepan and stir until it boils; then stir in one cup of cream, boil, and turn over the cabbage while hot.

\section{CABBAGE SALAD}

Beat up two eggs with two tablespoonfuls of sugar, add a piece of butter the size of half an egg, a teaspoonful of mustard, a little pepper, and lastly half a cup of vinegar. Put all these ingredients in a dish over the fire and cook like a soft custard. Add half a teacup of thick, sweet cream, but when this is done use less vinegar.

\section{CAULIFLOWERS}

Are given practically the same culture as cabbages, starting the plants in the hotbed in April and planting out when danger of heavy frost is past.

Particular attention must be paid to the young plants for the first week, as they are very liable to 
be cut off by cut-worms. When this occurs, the only remedy is to replace the plants with others from the coldframe.

Spring outdoor-started plants will not give very early cauliflowers, but will come on in July and August, and are used for pickling as well as for the table. Where it is desired to grow cauliflowers for the summer use on the table, it will be necessary to start the plants very early in the hotbeds, or in the South start in the fall and winter them in coldframes, and plant out as early in spring as the ground can be worked. The wintering in coldframes hardens them, so that this early planting is possible, which is not the case with the tender greenhouse or hotbed plants. At the North, plants of the cabbage and cauliflower cannot well be kept over in coldframes.

If there is a rather wet, low spot in the garden, it may be used for the cauliflower better than for almost any other vegetable.

The cabbage worm often causes serious trouble with the cauliflowers, and as soon as the little white butterflies are seen hovering about the plants, search must be made for the eggs and these destroyed. They will be found on the underside of

$$
\text { [114] }
$$


THE GROWING OF VARIOUS VEGETABLES

the leaves - a little patch of yellow eggs - and are easily removed.

As soon as the curd, or head, is set and is as large as a teacup, the plant must be tied up by drawing the tips of the leaves together and tying them with a string. This must never be done, however, when it is wet with rain or dew. Mid-day, on a bright day, is the best time for the work. If tied up when the leaves or curd is wet, the heads will decay; if not tied up, a second growth will quickly start and ruin the heads.

Unlike cabbage, cauliflowers cannot be kept during winter, being very perishable, and must be used within a day or two of attaining perfection, or the flavour is impaired. Cauliflower is one of the most delicious of table vegetables and should come into general use; it is far more delicate in flavour than cabbage, and one of the most attractive vegetables which appears on the table.

Very good cauliflower may be raised by the ordinary culture given cabbage-cauliflowers averaging eight or nine inches across-but to grow really fine heads, a foot or fifteen inches in diameter, snowy white, and perfect, requires special culture. To this end the plants must have an abundant water 
supply during the dry months of the summer, watering every other day, and cultivating between times. Liquid manure should be given at least once a week, and twice a week will be better. With this extra care, cauliflowers may be produced that will be the envy of one's neighbours, and may contend for the blue ribbon at the county fair.

Cauliflowers do better during cool weather, and are at their best in the late days of September and October. A light frost seems to benefit rather than injure them, and tying the leaves over the curd protects them from even a severe frost, but when a frost has cut the leaves badly, the curds should be gathered and used, as decay sets in very soon after.

In watering cauliflowers, the water should be poured about the roots, never over the tops of plants which have set heads; a system of irrigation would be of much benefit to this plant.

DIRECTIONS FOR COOKING CAULIFLOWER

In preparing cauliflower for cooking, it must be very carefully washed and looked over; if worms have been present on the heads, it will be better to 
THE GROWING OF VARIOUS VEGETABLES separate the head into small segments rather than to try to cook it entire, which is the more attractive way of serving it.

\section{BOILED CAULIFLOWER}

Cook whole, or divide in segments and cook in salted water until tender. If served whole, make a dressing of cream, butter, pepper, and salt, and turn over and around the cauliflower served on a platter. If broken in pieces, drain off the water from the cauliflower and add a half teacup of cream, a small tablespoonful of butter and pepper, and salt to taste. Serve hot.

\section{FRIED CAULIFLOWER}

Boil the cauliflower until about half done; mix two tablespoonfuls of flour with the yolks of two eggs, then add enough water to make a rather thin paste; add salt to taste. The two whites are beaten till stiff and then mixed with the yolks, flour, and water. Dip each branch of the cauliflower into the mixture and fry them in hot fat. When done, take them out with a skimmer, turn into a colander, dust salt all over, and serve warm. 


\section{PICKLED CAULIFLOWER}

Break the heads into small pieces and boil ten or fifteen minutes in salt water; remove from the water and drain carefully. When cold, place in glass cans and pour over them white-wine vinegar, boiling hot, if a clear, white pickle is desired. If a mustard pickle is preferred, add a liberal supply of whole cloves, pepper, allspice, and white mustard seed, tied in a bag and scald in the vinegar; remove from the fire, and add to each quart of the vinegar two teaspoonfuls of French mustard and half a cup of white sugar. Turn this over the cauliflower in the cans, making sure that the vinegar covers the cauliflower, and seal the same as canned fruit. A few red-pepper pods added to the clear vinegar of the plain pickle adds much to its appearance.

\section{SWEET CORN}

Is one of the more tender vegetables the seed of which should not be planted until all danger of frost is passed. This, at the North, will be as late as the twentieth of May, though a chance crop my be planted by May 1st on light, warm soil. One [118] 
THE GROWING OF VARIOUS VEGETABLES

quart of seed will plant two hundred hills, which should be made three feet apart each way. The seed should be planted in slightly raised hills, dropping a number of kernels in each hill to allow for any failing to sprout; after the corn is up, these extra plants should be pulled out, leaving three plants in a hill. The extra early sorts may be planted in rows two and a half feet apart, and the hills eighteen inches apart. Plant the seed half an inch deep, and either tramp upon it or pat it down firmly with the hoe. Where the ground is not very heavily manured, a tablespoonful of phosphate may be placed in each hill with benefit.

When the corn has attained three or more feet in height, it will be well to go through the rows and pull out all side shoots and those which will not set ear, allowing the entire strength of the plant to go to the making of corn.

The green shoots removed makes excellent feed for the horse, cow, or pig, and is greatly relished by them. Corn is, of all garden vegetables, the most economical to grow, as there is absolutely no waste, such corn as may not be used for the table making the finest feed for the poultry in winter, especially for the fattening of cockerels, and the cornstalks, 
if cut before they are too dry, makes excellent fodder for stock of any kind.

Corn may be planted every two weeks, for a succession, until the middle of July.

For early corn, one must plant the extra early varieties, such as the Cory, Golden Bantum, Aristocrat, or the Early Evergreen, but for toothsome sweetness there is no corn to equal Stowell's Evergreen, and the later the season the sweeter and better it is. We are now-October rth - eating Stowell's Evergreen that is far better and sweeter than the earlier planting of the same variety, though we have had several sharp frosts - frosts that have bady cut the field corn; but the sweet corn, being somewhat protected by trees, has suffered little, if any, injury.

Corn should be cultivated thoroughly and constantly as long as it is safe to work among it; this will admit of half a dozen cultivations each way at least, and at the end of this time the ground should be in the condition that few, if any, weeds will appear. 
THE GROWING OF VARIOUS VEGETABLES

DIRECTIONS FOR COOKING CORN

TO BOIL

Corn for boiling should be perfectly fresh, as it loses its sweetness in a few hours, and must have sugar added to the water in which it is cooked to restore it. Remove the outer husks and strip back the inner, so that the silk may be removed; this should be very carefully done and the husks replaced. Put in boiling water and boil for twenty minutes and serve hot, first removing the husks. The object of leaving the husks on is that the corn, cooked in this way, is much sweeter than when the husks are removed.

\section{CORN FRITTERS}

One pint of grated corn, one-half teacup milk, one-half teacup flour, one small teaspoonful baking powder, one tablespoonful melted butter, two eggs, and one teaspoonful salt, a little pepper. Form into cone-shaped balls, roll in beaten eggs and bread crumbs, and fry a delicate brown in deep lard.

\section{CORN SOUP}

Split the grains of one dozen ears of corn and scrape from the cob. Boil the cobs in enough water [121] 
to cover them for ten minutes. Strain this water and use one quart. Add to it slowly one quart of cream, then the corn. Season and cook fifteen minutes. Milk can be used instead of cream, thickened with one tablespoonful each of butter and flour rubbed together. Serve at once.

\section{EGG-PLANT}

This is one of the few vegetables requiring special care in cultivation. The seed should be started in a warm hotbed in April, and as soon as the plants are three inches high they should be potted off into small pots and plunged back into the soil of the beds. They may be transplanted into the open ground when the weather is quite settled and the soil and nights warm, or they may be repotted into larger pots and set out in the open ground the first of June.

Egg-plants require a great deal of heat at the start, and if they receive a setback at this time, rarely recover, so that every effort should be made to keep them from being chilled, while at the same time giving them the necessary amount of ventilation. It is well in planting the seed of egg-plants [122] 
THE GROWING OF VARIOUS VEGETABLES

to reserve a portion in case the first sowing should fail and a later one need to be made.

After the plants are of a size to be planted out there is little difference in the culture accorded them and that given other vegetables, but they should not be allowed to suffer for water, and a weekly dose of liquid manure after the plants bloom will be of benefit.

When about a foot high, the earth should be drawn up about the stem in cultivating. The plants are often seriously injured by the potato-bug, which eats the stem of the blossom at the point where it curves over, seldom, to any extent, the leaves of the plant. Whenever the bug appears early in the season, the plants should be gone over daily to catch and destroy it, or they may be sprayed with Paris green, which at this stage will do no harm. The destruction of these first blossoms will make two or three weeks' difference in the maturing of the first crop and must be met energetically. These first bugs which appear lay their eggs on the underside of the leaves, and these must be looked for and destroyed and little subsequent trouble will be experienced.

Curiously enough, for a plant which starts out [123] 
in life so peculiarly sensitive to cold, the egg-plant is not hurt by light fall frost, and I have gathered and marketed very fair eggs long after the frost had destroyed tomatoes and other garden stuff.

The first eggs are always the largest, the fruit growing smaller as the season advances; especially is this true when water and liquid manure is withheld.

The best variety to raise is the Early Black Beauty or the Improved New York.

\section{DIRECTIONS FOR COOKING EGG-PLANT}

The most common way of cooking egg-plant is to fry it, the plant being cut in thin slices, a quarter of an inch through, and laid in water to which a teaspoonful of salt has been added. Leave them in the water for half an hour, but do not take from the water until ready to cook, as their exposure to the air will cause them to turn black. Have ready a beaten egg and some sifted bread crumbs. Season the egg with pepper and salt; also slightly season the crumbs. Dip the slices in the crumbs, first wiping them dry with a cloth, and then in the beaten egg, and roll once more in the [124] 
THE GROWING OF VARIOUS VEGETABLES crumbs; have ready a hot frying pan in which has been melted a tablespoonful of butter and fry a light brown; they will fry in ten minutes. Serve hot.

\section{STUFFED EGG-PLANT}

Cut the egg-plant in two, scrape out all the inside, and place it in a saucepan with a little minced ham; cover with water and boil until soft; drain off the water and add two tablespoonfuls of grated crumbs, a tablespoonful of butter, half a minced onion, salt, and pepper; stuff each half of the hull with this mixture; add a small lump of butter to each, and bake fifteen minutes. Minced veal or chicken is equally as good as ham, and many prefer it.

Egg-plants may be eaten from the time they are the size of a teacup until they are full grown and the seeds begin to harden, but it is better to let the first fruits attain full size if possible.

\section{OKRA}

This vegetable is grown for the green pods which are used in soups, to which it imparts a rich gelatinous quality, and are as easily grown as peppers, requiring about the same culture. The seed should 
not be sown until the ground is warm-about the middle of May; it should be sown rather thickly in drills, three feet apart, sowing the seed an inch deep and thinning when large enough to stand ten inches apart in the rows.

The pods must be used while young and tender, as when fully grown they are very tough, though they may still be used to flavour soups.

Keep well hoed and free from weeds.

\section{DIRECTIONS FOR COOKING OKRA}

\section{OKRA SOUP}

Fry out the fat of a slice of bacon or fat ham, drain it off, and in it fry the slices of a large onion brown; scald, peel, and cut up two quarts fresh tomatoes (canned ones will do), and cut thin one quart of okra; put them together with a little chopped parsley, in a stew kettle with about two quarts of broth of any kind; cook slowly for three hours; season with salt and pepper, and serve hot.

\section{OKRA AS A VEGETABLE}

Put the young and tender pods of long, white okra in salted boiling water in granite, porcelain, or a tin-lined saucepan, as contact with iron will [ 126$]$ 
THE GROWING OF VARIOUS VEGETABLES

blacken them; boil fifteen minutes, remove the stems, and serve with pepper, salt, butter, and, if preferred, vinegar.

\section{PEP PERS}

Are grown from seed started early in April in the hotbed or in flats in the house and planted out when all danger of frost is passed. They require rich, well-drained soil and a sunny situation. Where the supply of manure is limited, a spoonful of phosphate may be placed in each hill as the plants are set, and more be scattered about the plants and hoed or raked in unless the growth is satisfactory. Set out in rows two feet apart, setting the plants eighteen inches apart in the rows.

The culture that will produce good corn, cabbage, or tomatoes will be right for peppers, as they are of easy culture. Hen manure may be used with this plant, as it is one of the few plants which is not injured by the application of so strong a fertiliser.

The plants come into bearing in July, and if the first peppers are removed while green, the succeeding fruits will come forward more rapidly than if the peppers are allowed to ripen. 
Chinese Giant, Magnum Dulce, and Sweet Spanish Giant are the best of the large sweet peppers, the latter being a long pepper, from two to three inches wide and six to eight long; this variety is rather more shapely for stuffed mangoes than the bull-nosed varieties. The large squat peppers are excellent for table use, being prepared in various ways.

Several of the hot and pickle varieties of peppers are both useful and ornamental, the Celestial or Christmas variety being especially ornamental. These may be grown in pots on the kitchen window and the fruit enjoyed throughout the winter. They are an attractive addition to pickled cauliflowers, onions, and the like.

The Tabasco is an especially beautiful pepper, bearing its fruit in sprays of brightest red, which are extremely fiery and pungent, and the seeds may be used for making pepper vinegar instead of the cayenne.

DIRECTIONS FOR COOKING PEPPERS FRIED PEP PERS

Fried peppers form a most appetising dish and one which is a very satisfactory substitute for [ 128 ] 
THE GROWING OF VARIOUS VEGETABLES

meat. Either the green or ripe peppers may be used, the flavour of the ripe fruit being somewhat the finer, and their appearance on the table very attractive. In preparing the fruit, it is only necessary to cut in two lengthwise and flatten, first removing all seeds, or to cut in rings and fry in hot butter or good drippings - that from bacon or ham being excellent. The cooking and preparation is so quickly accomplished that it may be prepared at a moment's notice.

\section{STUFFED PEPPERS}

Are prepared by cutting a slice off the stem end and removing the seeds and central core. The peppers are then stuffed with finely minced veal or other meat, mixed with a tablespoonful of bread crumbs and a spoonful of butter, and seasoned with salt and pepper. Replace the tops and bake in a pan to which a small quantity of water or beef stock has been added until the shells are tender.

Another appetising dish is prepared by filling the cases with rice and Parmesan cheese; cooked rice is mixed with the grated cheese in the proportion of one cupful of rice to two tablespoonfuls of cheese and one of melted butter. When this has 
been seasoned to taste with salt and paprika, the pepper cases, which have been cut in two lengthwise and the seeds removed, are filled with the rice and placed in the oven, and covered for the first half hour, the cover being then removed until the rice is browned.

Pepper cases are used for serving individual salads, and are especially handy for Russian salads and similar concotions.

\section{PICKLED PEPPERS}

Select firm, sound, green peppers, and add a few red ones, as they are ornamental and look well upon the table. With a sharp knife remove the top, take out the seeds, soak over night in salt water, then fill with shredded cabbage and chopped green tomatoes, one red pepper, seeds and all, and season with salt, mustard seed, and ground cloves. Sew on the top. Boil vinegar sufficient to cover them with a cup of brown sugar, and pour over the mangoes. Do this three mornings and seal.

\section{PEAS}

Sow peas as early as the ground can be worked in spring; old gardeners usually claim that they 
THE GROWING OF VARIOUS VEGETABLES

like to have the last snow find their peas in the ground; certain it is that peas like a cool soil, and often fail to germinate when the weather and soil is warm. The dwarf varieties are usually preferred for the private garden, but will not bear as heavily as the taller sorts; but as these require brushing, the difference in labour is by many considered to more than offset their extra productiveness. Poultry netting makes ideal support for the tall-growing sorts, and if rolled up and stood in a dry place after the peas are gathered, will last a lifetime.

The wrinkled varieties are far ahead in tender sweetness of the smooth varieties, but as they are not as hardy, they should be planted in welldrained, warm, sandy ground for the first planting.

Peas may be planted for a succession every two weeks up to the middle of June, then should be discontinued until the middle of August, when sowings of the extra-early varieties may be made for a late crop.

In planting, sow in double rows, six to eight inches apart, the rows from two to three feet apart. Plant the seed four inches deep and tread down the rows, going over the rows lightly with the lawn rake when all the seeds are in. This deep plant- 
ing prevents mildew, and the seed is less apt to be disturbed by moles.

American Wonder and Nott's Excelsior are of the best of the wrinkled peas, Nott's Excelsior being a rather freer bearer, owing to possessing more top. American Wonder is but one foot in height, and has not sufficient top to be a very profitable pea except for the home garden; but as peas are one of the few vegetables which may be grown in successive crops on the same ground, the plants may be pulled up as soon as through bearing and another planting of seeds made in the same place.

Champion of England is an excellent late pea of the wrinkled sort and of fine flavour; it requires brushing or should be given wire-netting support.

The main crop of peas, which are grown through the warmer months, may be planted to advantage on a heavier soil; they should be kept cultivated and free from weeds and the earth drawn up against the vines a couple of times before maturing. This is all the culture required, peas being one of the easiest vegetables to grow. 
THE GROWING OF VARIOUS VEGETABLES

\section{DIRECTIONS FOR COOKING PEAS}

It is customary with most cooks to cook peas in considerable water, and when done to turn off the surplus water and add butter, pepper, and salt. The flavour of the peas and the sweetness will be better retained, however, if only sufficient water to cook them is used, so that it may not be necessary to discard any of it. If the pods are washed very clean and are then cooked until tender and the water strained from them and used to cook the peas, all the sweetness and flavour will be retained. After cooking, add half a cup of cream, a lump of butter, and salt to taste. Salt should never be put to the peas until nearly or quite done, as it has a tendency to harden them.

\section{PEAS AS AN ENTRÉE}

Cut out with a cookie-cutter a round of bread from an ordinary slice of bread; cut two rings with a doughnut cutter; dip them in melted butter and toast them a delicate brown in the oven or fry daintily in deep fat, drying on a wire sieve; fill the cavities with tender young peas cooked in a delicate cream sauce. 
Peas as an entrée may also be served in cups made of boiled turnips, the turnips being first boiled whole and then removed from the fire, the centres scooped out, mashed, and served as a separate dish; the peas, boiled and dressed with a white sauce, or simply with butter, pepper, salt, and cream, and dusted with bread crumbs and a bit of butter, being returned to the oven for a moment to heat and slightly brown.

\section{TOMATOES}

Start tomatoes by sowing seed in a hotbed in spring, or start them in flats in the house and plant them in the open ground when all danger of frost is passed. They require well-manured soil, and when there is a limited supply of fertiliser, it will be well to put two or three spadefuls in each hill, spreading it over a couple of square feet of surface, as the tomato makes considerable root growth. Plant in rows, four feet apart each way if no support is to be given, three feet if the plants are to be grown on racks or trellises. There is a wire-tomato support on the market that is admirable and quite within the reach of the small private garden. I am of the opinion, however, that tomatoes grown on 
THE GROWING OF VARIOUS VEGETABLES

the ground produce more fruit than when grown on racks, for this reason: as soon as the plants have attained much size, they become recumbent, lying on the ground, and wherever a joint of a branch touches the ground, it immediately makes roots and so begins to draw nourishment from the soil, and is for this reason better able to produce an abundant crop than the plant grown upright on a frame with but one supporting root.

Keep the plants well cultivated and free from weeds. As soon as the plant begins to blossom pinch off the ends of the shoots beyond the flowers that fruit may set early. This will materially hasten the ripening of the first fruit set.

In the fall, at the approach of hard frost, the green tomatoes may be gathered and placed on racks in a warm, sunny position, where they will continue to ripen for some time, or the plants may be dug up, the roots wrapped in burlap, and hung in a warm, sunny place, where the fruit will ripen very well; I have kept them in the barn until November in this way. Or use may be made of an empty hotbed, in which the green tomatoes are placed on racks or on a bed of straw, and so continue to enjoy them far beyond their usual season. 
For the private garden the Stone tomato is one of the very best, being smooth, round, large, and prolific, and exceptionally free from spot and with very little seed; it is not as early a ripener, however, as some of the varieties favoured by market gardeners. Sparks Earliana is an extra-early sort, and is more hardy in plant than the Stone, and a few plants of this variety may be set out to advance the season, using the Stone or other variety for the main crop. Dwarf varieties, like Dwarf Champion and Dwarf Stone are very desirable in gardens of limited space, as they may be planted in close rows or can be supported to a single small stake.

\section{DIRECTIONS FOR COOKING TOMATOES}

The simplest and most popular way of serving tomatoes is raw, and there are one or two points which make for perfection in the process. In scalding the fruit for the removal of the skin, moderately hot water should be avoided, as it is necessary to leave the fruit in it so long that the tomato becomes warm. Boiling water, which will instantly remove or loosen the skin, should be used, and the fruit removed as quickly as possible. I have seen 
THE GROWING OF VARIOUS VEGETABLES

cooks place a number of tomatoes in a pan, pour hot water over them, and proceed to peel them out of the water, leaving the unpeeled ones soaking and warming until the last was reached. Tomatoes served raw should be brought to the table as firm and cold as possible. They should never be dressed before serving, but the various condiments passed that each person may season them to please their fancy.

\section{STEWED TOMATOES}

Peel and remove the seeds from fresh, ripe tomatoes (as many as required), cut into small pieces, and season with salt, pepper, and a piece of butter; stew until done, and, before taking from the fire, add bread crumbs sufficient to thicken slightly, add a dash of cayenne. and let boil up once. Serve hot.

\section{STEWED TOMATOES WITH ONIONS}

Peel and slice three or four onions and place in the frying pan with a little butter or good dripping; cover and cook until tender; have ready some peeled and sliced tomatoes, add to the onions, and cook until done; season with butter, pepper, and salt. 


\section{STUFFED TOMATOES}

Scald and peel as many tomatoes as required; cut a small piece from the top of each and remove the seeds; fill the cavity thus formed with wellseasoned bread crumbs; place a small piece of butter on the top of each and bake until brown. A little water should be placed in the pan to prevent the tomatoes burning or sticking to the dish.

\section{SCALLOPED TOMATOES}

Peel and slice ripe tomatoes; place a layer in a baking-dish and cover with bread or cracker crumbs, a dash of pepper and salt, and bits of butter; add another layer of tomatoes and bread crumbs and continue with alternate layers of tomatoes, crumbs, and seasoning until the dish is full, the last layer being of the crumbs, with a liberal sprinkling of butter. Bake one hour.

\section{MACARONI WITH TOMATOES}

Break one half pound of macaroni into short pieces and boil in salted water until tender; take from the water and blanch by turning cold water over it; return to the stew-pan and add one half 
THE GROWING OF VARIOUS VEGETABLES cupful of sweet cream, one third of a cupful of butter, pepper, and salt; let simmer for a short time; have ready in another stew-pan one pint of stewed tomatoes; add the macaroni and serve hot in a covered dish.

\section{TOMATO SOUP}

Place over the fire a quart of peeled tomatoes, add a pinch of soda, and stew them soft. Strain to remove the seeds. Set it over the fire again and add a quart of hot, boiled milk, or a pint of cream and one of milk; season with salt and pepper, a piece of butter the size of an egg, and three tablespoonfuls of rolled crackers, and serve hot. Canned tomatoes may be used instead of fresh ones.

\section{FRIED GREEN TOMATOES}

These may be prepared in a number of ways: by slicing and laying in salt and water until some of the water is drawn from them and then dipping in flour and frying in hot drippings until tender; by covering with boiling water and set on the back of the range, where they will keep hot, but not boil, until yellow, then drained, dipped in flour, and fried. They are also excellent fried with onions, 


\section{THE VEGETABLE GARDEN}

but as the onions take much longer to cook than the tomatoes, they should be put on the fire in advance of the tomatoes until partially cooked, when the sliced tomatoes should be added, and both cooked until a delicate brown. Tomatoes are almost equal to egg-plant when nicely cooked, and should be more generally used, as green tomatoes are one of the most plentiful vegetables in the market. 


\section{CHAPTER TEN}

\section{ROOT VEGETABLES}

R оот vegetables form an important part of the garden's supply, and differ somewhat from those vegetables which produce heads, pods, or edible foliage in that they, as a general thing, mature later, some of the varieties, like parsnips and salsify, remaining in the earth until the following spring, when they are at their best. Others, like the beet and radish, are among the earliest available vegetables for the table-radishes being ready to use in from three to four weeks after sowing and beets for greens in a little longer time. The preparation of the ground for root crops should be deep and thorough, and ploughing is preferable to spading. All weed roots which are not thoroughly buried by the plough and show above ground after dragging should be pulled out by hand and consigned to the compost heap. The ground should be disc-harrowed, dragged, and raked to as fine a 
condition as possible. I like to have the ground lie a few days after being prepared before planting, in order that it may settle somewhat, and if a rain follows the preparation, all the better. Land moist from rain will not need to be tramped down over the seed, as will be absolutely necessary in the case of dry soil.

As a general thing, root crops should not succeed each other, but be rotated with vine or leaf crops. Root crops leave nothing in the soil and take largely from it. Vines and other forms of vegetables leave a large proportion of the growth to be returned to the soil, and are, for this reason, less exhaustive of fertility. Of course this is not of as much moment on the limited area of the kitchen garden, whose fertility is easily maintained by the application of animal fertilisers and the humus from a compost heap, which the débris of a town lot will maintain, but, in acreage planting, it is of great importance.

\section{BEETS}

Sow beet seeds as early in the spring as the ground may be worked up fine and mellow. Light, wellenriched soil suits them best. The seed should be 
sown in drills, one foot apart, sowing the seed an inch deep and treading down the rows. When the plants are large enough, thin out to stand four to six inches apart in the rows; keep them free from weeds and the soil soft and mellow by frequent cultivation. If wanted for greens, sowings of seed may be made every two weeks up to the middle of August, or, if but an early crop of greens is wished, the ground may be used for late peas when the beets are out of the way.

DIRECTIONS FOR COOKING BEETS

\section{BEET GREENS}

For this delicious dish of greens the young beets are used from a half-inch in diameter up to an inch or a little larger. They should be perfectly fresh, and in dressing them, about three inches of the top should be left on. Boil in salted water until tender, and dress with butter, pepper and salt, and serve hot, passing the vinegar with them.

\section{BAKED BEETS}

Baked beets retain their sugary, delicate flavour if they are baked instead of boiled. Turn them fre- 
quently while in the oven, using a knife or wooden spoon as the puncture made by a fork allows the juice to run out. When done, remove the skin and serve with butter, salt, and pepper.

\section{BOILED BEETS}

Select small-sized, smooth roots. They should be carefully washed, but not cut before boiling, as the juice will escape and the sweetness of the vegetable be impaired, leaving it hard and white. Put them into boiling water and boil until tender, which requires from one to two hours, even longer in winter. Do not probe them, but press with the finger to ascertain if sufficiently done. When done, take them up and place in a pan of cold water, and slip off the outside. Cut them in thin slices and season with salt, pepper, butter, and, if preferred, a little sharp vinegar, or pass the vinegar with them.

\section{STEWED BEETS}

Boil the beets, then scrape and slice them. Put them in a stew-pan, with a piece of butter rolled in flour, some boiled onion and parsley, chopped fine, and a little vinegar, salt, and pepper. Set the pan on the fire and stew for half an hour. 
The vinegar may be omitted and served at the table if preferred.

\section{CARROTS}

Are one of the economic vegetables, being not only exceedingly wholesome and toothsome, but, like the sweet corn, possess the advantage of being edible in root and top, the green tops being much relished by cows and horses, and the peelings and any surplus roots forming a most valuable addition to the winter ration of horse and cow. The juice of the yellow carrot, when expressed by grating the raw root and pressing the juice through a cloth, makes an excellent and harmless colour for butter, giving it the much-prized golden tint of early grass butter in the spring.

A good story is told of a mother who took an anemic daughter to a famous physician noted for his bluffness and brevity. A brief inspection, a briefer "claret," and a wave of the hand dismissed patient and subject. A month or six weeks later the mother returned accompanied by a blooming daughter, and at the physician's nod of approval, the mother, becoming loquacious, explained that she "gave them to her three times a day cooked 
and raw." "Raw!" exclaimed the physician in amazement. When it transpired that his brief directions of claret had been understood as carrots, and they had been liberally supplied with the result of perfect recovery, whether through the medium of faith or the medicinal qualities of the vegetable, remained a matter of individual experiment, but it is an item in favour of the carrots that they are of no uncertain tonic value to animals.

To grow carrots in perfection requires a rich, deep, sandy loam, thoroughly prepared and deeply cultivated. For an early crop, the seed should be sown in April or May in drills, one foot to fifteen inches apart, scattering the seeds as thinly and evenly in the rows as possible and tramping them down. For a late crop, the seed may be sown as late as July 1st. As soon as the plants are large enough, they should be thinned to stand four inches apart in the rows and must be kept clear of weeds and well cultivated. A little nitrate of soda drilled into the soil along the rows will greatly hasten the growth, or the nitrate may be applied with a watering pot by dissolving it in water. Phosphate worked into the rows before sowing the seed is a help to rapid growth when the animal 
fertiliser is limited, but is not necessary in well-fertilised land. For table use, the varieties known as bunching carrots, of which the yellow Danvers Intermediate is the best, should be selected. These are a very smooth, attractive sort, and, if well cultivated and thinned sufficiently, will grow to large size and prove profitable for stock as well as for the table, as even when large they are never coarse.

\section{DIRECTIONS FOR COOKING CARROTS}

The simplest and best-liked method of cooking carrots is to peel or scrape till perfectly clean, then cut in dice, and cook until tender in salted water; remove from the fire, drain, and return to the fire, adding sufficient sweet cream to cover, a tablespoonful of butter, and salt and pepper to taste. Or, two tablespoonfuls of butter rolled in flour, add enough cream to cover and allow them to come to a boil, and serve hot.

Carrots are also served mashed like potatoes, in which case they are cooked whole and mashed with a piece of butter, salt and pepper, and piled in a heap on a platter and served very hot.

A delicious substitute for plum pudding is made [147] 
from a cupful of mashed carrots, one cupful of mashed potatoes, one cupful of flour, one cupful of suet chopped fine, one cupful of molasses, one cupful of currants, and one cupful of raisins. Boil in a pudding-bag, allowing room for it to swell, three hours, and serve with a creamed or hard sauce as preferred.

As a vegetable ingredient to consommé the carrot is invaluable, and it forms an important ingredient in beef-ragouts. To prepare the latter, secure a tender, juicy-stewing piece of beef having some fat attached. Cut in squares two or three inches in diameter and place in the skillet, with a little butter or dripping, and fry to a good brown; remove from the pan, and to the butter add a tablespoonful of flour; cook a few moments and add two cupfuls of warm water, several medium or small onions whole, or large onions sliced, two or more carrots sliced crosswise, and sufficient potatoes for the meal; add the meat and cook until done, and serve very hot on a large platter.

If the meat is likely to take longer to cook than the vegetables, return it to the pan or kettle and cook until partly done, when the vegetables may be added. 
If the amount is large it will be better, after browning the meat and preparing the gravy, to place the whole in an iron or granite pot to cook. When this is done, the pot should be made hot before adding the ragout. This is a delicious and appetising dish for those who like a boiled dinner. The addition of a head of celery, cut into inch lengths, much improves the flavour, or a small quantity of celery seed may be substituted for the celery when the latter is not in season.

\section{ONIONS}

The most practical manner of growing onions in the kitchen garden is by the use of sets, which may be set out early in spring in shallow drills twelve inches apart and the sets four inches apart in the drills. The ground must be deeply dug and thoroughly pulverised, and when the onions are up so they can be seen, hand weeding through the rows will be necessary. The hand-cultivator may be used to keep the space between the rows free from weeds.

Care must be taken not to allow the mature onions to form seed, as this will render them unfit for food, the seed stalk forming a woody centre 
in the onion, which resists all efforts to cook tender. By watching the plants and breaking off all blossom stalks as they form, the onions will remain fit for use when stored for the winter.

There are no onions, however, so tender and delicate for table use as those grown from seed, which may be sown in the open ground early in March or April and thinned out to stand three or four inches apart in the rows. Or they may at first be thinned to stand from one to two inches apart, and as soon as large enough for the table, use as young, green onions; every other onion may be removed, allowing the remainder to mature for winter use.

A method of culture we have found very satisfactory is to sow seed in drills in August in very finely prepared ground, which must be kept well cultivated and free of weeds. A mulch of straw or other coarse litter as protection during winter should be given after the setting in of cold weather, and this should be removed in spring. Seed sown at that season gives an abundance of early onions of the tenderest and best quality, and the entire crop may be gathered in time for another sowing of seed in the following August. Onions succeed 
well when grown year after year on the same ground, and when the bed is well cared for one or two years, it gets in excellent tilth and is easily kept free from weeds.

By sowing onion seed in frames and transplanting in April, onions of immense size may be produced, and the labour is not much greater than that required by planting in the open ground, thinning, and giving the necessary preliminary weeding. In setting the young onions, which are very small and tender, a shallow trench is dug and the plants laid against the side of it at intervals of four inches, the earth being then filled in and pressed down against them with the hoe. For this form of onion culture, the Prizetaker type of onion is the best. This onion compares very favourably with the Bermuda onion, being of a pale yellow colour, white flesh, mild flavour, and immense size.

For general family use there is no onion to compare with the White Portugal or Silver Skin, while for pickling, the white Barletta is an exceedingly satisfactory sort. One ounce of seed will plant one hundred feet of drill. 
DIRECTIONS FOR COOKING ONIONS

May seem superfluous to the experienced cook, but there are occasional points which may be new even to an old and experienced housekeeper; it may not be generally known, for instance, that cooking fried onions in milk before frying them renders them far more appetising and delicate. This is an operation that must be undertaken with a light hand and quick eye, as onions cooked in milk burn very easily.

In preparing onions for this manner of frying, they are first peeled and sliced as in ordinary frying and then placed in the sauté-pan with enough water to cover, and cooked for a few moments, when the water should be turned off and replaced with an equal amount of milk and allowed to cook till tender, when they are drained from the milk and fried a delicate brown in hot butter.

\section{STUFFED SPANISH ONIONS}

These are a delicate and tasty form of serving this odourous vegetable. To prepare, use the large Bermuda or Prizetaker onions. Peel the onions and scoop out from the top a portion of the centre. [152] 
Parboil five minutes and turn upside down to drain. Make a stuffing of the chopped onion taken from the centres, softened bread crumbs, salt, pepper, and a generous amount of butter. Fill the onions heaping full and sprinkle the top with buttered crumbs. Cover and cook till tender (about an hour) in a pan containing a small quantity of water. Let them brown a very little before taking from the oven.

\section{PARSNIPS}

Which so welcomely supplement the late winter or early spring bill of fare, are one of the easily raised root vegetables, requiring little room for culture and yielding bountifully for the space and time devoted to them. Like the carrot, they are an ornamental feature of the garden and may be grown to edge rows or beds of other vegetables if desired; they should occupy a prominent position in the garden, as their growth is lower than most other garden crops, and the beauty of the fern-like leaves makes them attractive at all times. They have not the bright colour of the parsnip, being much darker in foliage, but they offset that vegetable and contrast beautifully with the red foliage of the beets. 
They are one of the earliest vegetables to be started in spring, and so are out of the way before the main crops must be gotten into the ground, which is a distinct advantage. The seed should be sown in drills, like the carrot, making the drills a little farther apart-about fifteen inches-and dropping the seed as evenly and sparsely in the rows as possible. The seed should be planted about one-half of an inch deep and the earth pressed down above it. The soil should be rich and deep and the after cultivation thorough and constant. As soon as the seed has germinated and the little plants large enough to distinguish, all weeds should be removed from between and each side of the rows, the cultivator taking care of those between the rows. When the plants are three or four inches high, thin out to stand six inches apart in the row. The plants pulled up may be used to plant additional rows or to fill in any vacant places in the present rows.

While the quality of the roots are much improved by leaving in the ground over winter, enough for immediate use may be stored in damp sand or earth in the cellar, or they may be dug and piled in pits in the ground and covered with a [154] 


\section{ROOT VEGETABLES}

mound of earth and boards to shed rain, but the cellar will be found more convenient, as in case of severe weather it will be found almost as difficult to get into the heaps as to dig the roots from the open ground.

The best variety to plant is the Large Sugar or Hollow Crown, and one ounce of seed will plant one hundred feet of drill.

\section{DIRECTIONS FOR COOKING PARSNIPS}

\section{BOILED PARSNIPS}

Wash, scrape, and split them. Put them in a pot of boiling water; add a little salt and boil till quite tender, which will be in from two or three hours, according to their size. Dry them in a cloth when done and pour melted butter or white sauce over them in the dish. Serve them with any sort of boiled meat or with salt codfish.

Parsnips are very good baked or stewed with meat.

\section{FRIED PARSNIPS}

Boil tender in salted water; scrape, cut into long slices, dredge with flour; fry in hot lard or drippings, or in butter and lard mixed, until quite brown. Drain on a wire sieve and serve.

[ 155 ] 
STEWED PARSNIPS

After washing and scraping the parsnips, cut into slices about half an inch thick. Put them in a saucepan of boiling water containing just enough to barely cover them; add a tablespoonful of butter, pepper and salt, and cover closely. Cook them until the water has cooked away, watching carefully and stirring often to prevent burning, until they are soft. When they are done, they will be of a creamy, light straw-colour and deliciously sweet, retaining all the goodness of the vegetable.

\section{PARSNIP FRITTERS}

Boil four or five parsnips; when tender, take off the skins and mash them fine; add to them a teaspoonful of wheat flour and a beaten egg; put a tablespoonful of lard or beef drippings in a fryingpan over the fire, add to it a saltspoonful of salt. When boiling hot, put in the parsnips which have been moulded into small cakes with a spoon; when one side is a delicate brown, turn the other; when both sides are done, put them on a dish, and a very little of the fat in which they were fried poured over them, and serve hot. These resemble very 
closely the taste of the salsify or vegetable oyster, and by many will be preferred.

Or the parsnips, flour, and egg may be shaped in the hands into small cones and fried to a delicate brown in hot fat. Dipping first in beaten egg and then in fine bread crumbs will make a more elaborate and attractive dish.

\section{POTATOES}

There is probably no crop grown that the husbandman approaches with so little hesitation as the potato. But that this confidence is often misplaced is evidenced by the mass of poor and even unsightly potatoes which crowd our markets. It is not an uncommon practice to devote the refuse of the potato bins to the spring planting; yet no vegetable is more susceptible of improvement by judicious selection of seed than the potato. The selection of seed potatoes should be made, not the last thing before planting, but at the time of the gathering of the crop in the fall, providing, of course, that one wishes to grow the same kind of potatoes a second year and that the quality of the present crop justifies the selection of potatoes for seed therefrom.

$$
\text { [157] }
$$


In selecting potatoes from seed, the choice should be from those hills which have produced best, both as to size of tubers and the number of tubers in a hill rather than from the finest potatoes, both as to size and symmetry. In the former selection you get pedigree and precedent and may anticipate a perpetuation of the good qualities in the succeeding year's crop. All scabby or misshapen tubers should be rejected, nor should seed be used from a crop that has given scabby tubers, though the tubers selected may be free from this defect. Where scabby tubers exist, the cause should be distinctly recognised, whether the fault is in the seed, in the soil, or in the presence of too green manure. Potatoes should not be planted on land newly fertilised with fresh manure. Where the land has had many successive croppings and must be manured heavily in order to restore sufficient fertility for the production of a crop, the fertilising should be done the preceding autumn, or, if that is impossible, as early in the spring as possible-February being far better than March. Preferably the manuring should precede fall ploughing. Sod land is best for the growing of potatoes, and if this has been manured the previous fall, it should be in good con- 
dition for growing a good crop of smooth potatoes. Do not plant potatoes on land which produced scabby the previous year.

Early potatoes may be planted as soon as the ground can be put in condition in the spring, but for the main or winter crop, late planting is usually more satisfactory. For one thing, these laterplanted potatoes are less troubled with the potato beetle and fewer cultivations are required to keep down the weeds. No one should undertake the growing of potatoes unless they have sufficient energy to keep down the weeds, as they require little hand work, and one or two hoeings will fit them for work with horse or hand-cultivator. Potatoes should never be banked or hilled up at the beginning of the season; when this is done at the start, it is practicably impossible to keep control of the weeds. It is better to cultivate on the level, either planting far enough apart in the rows to allow of running the cultivator each way, or they may be planted in rows three feet apart and a foot apart in the rows, and covering from three to four inches deep according to the nature of the soil; three inches if the soil is heavy and cold, but four inches in light, sandy soil. 
Phosphates are very valuable fertilisers for potatoes and produce very much smoother tubers than where it is not applied. The most economical method of using is to scatter a tablespoonful in each hill, distributing it over a foot or two of surface. Flower of sulphur in the hills will entirely prevent the presence of scab in the potatoes and is a more satisfactory method than the previous treatment of the seed by corrosive sublimate, formaldehyde, or other poisons.

In the case of the potato beetle and its ravages, one should use the ounce of prevention and watch for the first appearance of the mature beetle and its eggs. Where there is but a small planting of potatoes, it will be practicable to handpick the vine, killing all bugs and removing all eggs, which will be found, a yellow mass, on the underside of the leaves. If these are entirely removed at their first appearance, little further trouble will be experienced, unless a careless neighbour also grows potatoes, in which case one's best efforts may prove abortive.

Once the beetles have gained a footing, the only remedy is Paris green, either as a dust, mixed with plaster in the proportion of a teaspoonful of the [160] 
poison to a quart of lime, sifted from a sifting-box with quite small holes, over the plants when wet with dew or rain, or with a solution of the poisonabout a teaspoonful to three gallons of water. This may be used by means of a brush-broom dipped in the solution and shaken over the plants or by means of a spraying pump; in the latter case a much stronger solution may be used, as the spray is so fine a very small quantity of liquid is deposited. Should rain follow the spraying, it will be necessary to repeat as soon as the weather clears.

Potatoes should be dug as soon as the tubers are ripe and the tops dead. Left in the ground, especially in wet weather, they are liable to start new growth, which injures them. Late potatoes, however, may be left longer, but must be dug before the ground freezes. A bright day is best for digging the tubers, and if possible the ground should be dry in order that the earth may not adhere to the tubers and so that they may be picked up and stored as soon as possible after digging. Potatoes should not be allowed to lie uncovered, as this turns them green, but should be covered with anything available-old carpets, sacking, straw, or fodder-anything which will exclude light. 
There are many excellent varieties of potatoes, but it must be remembered that there is as great a difference in the flavour of potatoes as any other vegetable, and what may be entirely acceptable and palatable to one may prove very unsatisfactory to another, but it is universally agreed that a mealy, white-fleshed potato is the ideal one. A potato free from black spots and hollows, and one which will keep well into the following spring, is also desirable. For these last qualities there is probably no better potato grown than the Adirondack, it keeping well until the middle of June and cooking mealy and white up to planting time. It is exceptionally free from spot or blemish, but, unfortunately, is sadly lacking in flavour, being especially unsatisfactory when fried. It is a profitable potato to grow for market, however, as its excellent keeping quality makes it a favourite of the dealers. Vick's Perfection and Carmen No. 2 have given excellent satisfaction in my garden, the flesh being white, mealy, and of most excellent flavour. Early Rose and Early Ohio are both excellent potatoes for the market or home garden, and there are many other good varieties, each locality having its favourite. When in doubt as to which variety to plant, it will be well to pro[162] 
cure a peck of two or more kinds and test them by cooking in several different ways.

\section{DIRECTIONS FOR COOKING POTATOES}

It may seem superfluous to give recipes for cooking so staple an article of food as the potato; yet it must be conceded that their appetising and tasteful preparation is by no means universal. Even a good boiled potato-its simplest form-is rare, and fried potatoes, at their best, are conspicuous by their absence. It may not be a matter of general information that in the spring, when the quality of potatoes has deteriorated, they are liable to show dark spots at the eyes when boiled. This may be prevented by the addition of a cupful of milk to the water in which they are boiled.

\section{THE PERFECT FRIED POTATO}

The frying and serving of potatoes is quite as particular an operation as serving baked potatoes, which all know must be eaten the moment they are done. Fried potatoes should never go on the fire until within a few moments of the time of serving a meal. Never set them on the back of the range until time to cook them, letting them slowly dry. 
up until the outsides are hard and tough. Rather should they be cut in dice or sliced as preferred, and the frying-pan placed on the stove until hot, when sufficient butter or drippings for frying, together with salt and pepper to taste, should be put in and allowed to get hot, when the potatoes should be added and cooked a good brown as quickly as possible. Cooked in this way, they will be crisp, but not hard and tough, and should be served immediately on a hot dish.

To have the fried potato at its best, one should boil medium-sized, new potatoes and remove them from the water as soon as done, allowing the steam to pass off, so that they may be dry and mealy, when they should be cut in dice and fried at once in hot butter or drippings. They should not be allowed to grow cold between the operation of boiling and frying and should be served at once on hot dishes.

\section{POTATO SOUFFLE}

This makes an excellent lunch or supper dish and is suitable for company teas. To two cupfuls of cold mashed potatoes add half a cupful of milk, a pinch of salt, a tablespoonful of butter, two tablespoonfuls of flour, and two eggs, beaten to a froth. 
Mix the whole until thoroughly light; put into a baking-dish, spread a little butter over the top, and bake a golden brown. The quality depends upon very thoroughly beating the eggs, so that the potato will remain light, like sponge cake.

\section{POTATO PUFFS}

Prepare the potatoes as for souffle. While hot, shape in balls about the size of an egg; have a tin sheet well buttered and place the balls on it. As soon as all are done, brush over with beaten egg; brown in the oven. When done, slip a knife under them and slide upon a hot platter. Garnish with parsley and serve immediately.

\section{LYONNAISE POTATOES}

Place in a frying-pan one onion sliced fine and a tablespoonful of butter and a tablespoonful of finely cut parsley. Cook until the onion is tender. Remove the onion and add the potatoes, which should have previously been prepared by cutting into dice. Cover the pan and allow the potatoes to heat through but not cook or brown.

Remove the lid and add a teacupful, or less, of cream and allow it to boil up but not cook, and [ 165 ] 
serve at once in a hot baker or tureen. The secret of success with creamed potatoes is not to allow them to cook in the cream.

\section{SCALLOPED POTATOES}

Slice raw potatoes and lay in water till ready to use. Place a slice of salt pork in the bottom of a baking-dish. Wipe the potatoes dry and place a layer over the pork; season with salt and pepper and continue to add potatoes and seasoning in alternate layers until the dish is full. Cover the top with slices of very thin salt pork and place in the oven and bake until the potatoes are done. Cold boiled potatoes may be substituted if desired, and require less time to cook.

SCALLOPED POTATOES (KENTUCKY STYLE)

Peel and slice raw potatoes thin, the same as for frying. Butter an earthen dish, put in a layer of potatoes and season with salt, pepper, butter, and a bit of onion, chopped fine (if liked). Sprinkle over a little flour. Now put another layer of potatoes and seasoning and continue placing alternate layers of potatoes and seasoning until the dish is full. Just before placing in the oven pour over from a [ 166 ] 
pint to a quart of hot milk (according to the quantity of potatoes used). Bake three-quarters of an hour. Cold boiled potatoes may be used instead of raw if preferred.

\section{FRENCH-FRIED POTATOES}

Peel and slice in sections, as apples are cut for pies, laying them in water until needed. Heat a small shallow kettle of lard to the smoking point, but be careful that it does not scorch. Dry the potatoes thoroughly and drop in the hot lard until a delicate brown. They should puff up very light and plump. Remove from the fire and drain on brown wrapping paper before a bright fire. Sprinkle lightly with salt and if that flavour is preferred a little celery-salt also and serve at once on a hot dish. These are delicious and entirely suitable for company at breakfasts, lunches, or teas.

\section{POTATO CROQUETS}

Take two cupfuls of cold mashed potatoes, season with a pinch of salt, pepper, and a tablespoonful of butter (also a pinch of celery-salt, if liked). Beat up the whites of two eggs and work all together [ 167 ] 
thoroughly; make into small balls about the size of walnuts; dip in the beaten yolks of eggs (which should be seasoned with salt and pepper) and roll in fine cracker or bread crumbs. Fry in deep fat until a delicate brown and drain on a wire sieve and serve very hot on a folded napkin laid on a hot dish.

\section{POTATO FILLETS}

Pare and slice the potatoes thin; cut them in long strips or fillets about a quarter of an inch square and as long as the potatoes will admit. Keep them in cold water until wanted, then wipe dry and drop into deep lard at the smoking point, and cook until a fine, delicate brown. Some cooks remove them from the fat and drain when partly done, allowing the fat to heat up again when the potatoes are returned to the fat and fried until done, but if the potatoes are wiped dry and the lard at the proper temperature and a hot fire under the kettle, this is seldom necessary. Drain before a hot fire on a wire sieve or brown wrapping paper, sprinkle with salt, and, if liked, a very little dust of celery-salt, and serve on a hot dish.

Saratoga, string, and similar potatoes are prepared in the same way, the only difference being 
in the manner of cutting and the fact that Saratoga and similar thin potatoes are equally good cold and may be prepared in quantities and kept in a dry place to be used as needed. If wished warm, a few moments in a hot oven will render them very palatable.

RADISHES

Require a light, rich soil in a warm position, where quick growth may be made, as upon this depends the tender crispness which makes this vegetable so toothsome. Pure sand, well enriched with phosphates, will grow exceedingly fine radishes, and after the plants are up a little, nitrate of soda, applied along the rows, will much hasten their growth. Nitrate is of so quick action that it should not be applied until the plants are up and growing; then it is a most valuable fertiliser and stimulant.

For very early use, the seed may be sown in hotbeds or in window frames and a second crop sown in the open ground, in a sunny, sheltered position, in April.

The seed may be sown at intervals of two or three weeks up to the first of September. Sow in thoroughly prepared ground in shallow drills ten inches apart and thin to stand two inches apart in 
the rows. Where vines are planted along the fence, the intervening space may be planted to radishes, and I have found it a good plan to keep a packet of seed handy, and drop a seed wherever a radish is pulled; in this way there is a perpetual supply of the freshest and most tender of roots.

The ground should be kept free of weeds and well cultivated. It will be necessary to use the trowel here to break up the soil about the radishes, using the small hand-cultivator along the sides of the rows, or when grown along the fence, all the work may be easily done by means of the trowel. The early three weeks' radishes-such as French Breakfast - are the most desirable to plant, and the oval scarlet, tipped with white, the most attractive form on the table. In preparing them for the table, the small leaves should be retained, as they add much to the appearance of the radish and are an altogether attractive and artistic addition to the breakfast or luncheon table.

In planting melons in hills, if the land is very rich, a row of radishes may be planted around the outer edge of the hills, and will have matured and been used before the room is needed by the melons; in fact radishes are one of the few vegetables which 
may be stuck in wherever the soil is rich and the space is not needed for other crops.

\section{SALSIFY OR VEGETABLE OYSTER}

Salsify requires the same culture as carrots and parsnips. Sow early in spring in drills fifteen inches apart, scattering the seed an inch deep and treading down the rows. Thin to stand four to six inches apart in the rows and keep clear of weeds and the soil well worked and mellow. Salsify may be used in the fall or left in the ground over winter, being used early in spring, when it first appears in market. A supply for the winter may be dug and kept in boxes of moist earth or sand in the cellar if desired. When left in the ground, it should be dug before growth begins in the spring. It succeeds best in a light, mellow soil. The Mammoth Sandwich Island is the best variety. to grow, Long White is also a good variety.

\section{DIRECTIONS FOR COOKING SALSIFY}

The most common method of cooking salsify is in soup, for which purpose the roots are washed, scraped, and cut into slices a quarter of an inch 
thick. Put to cook in two quarts of water. When cooked tender, add to the water a lump of butter the size of an egg, salt and pepper to taste, a cupful of rich cream, and half a cupful of cracker crumbs; serve hot. The quantity of water and number of salsify roots will depend, of course, on the amount of soup required, and the amount of seasoning and other additions will be decided by the quantity of soup. In cooking salsify in any manner, it must be remembered that exposure to the air causes it to turn very dark, so that the roots should be kept in water until ready to cook.

\section{FRIED SALSIFY}

Stew the salsify as usual until very tender and mash it very fine. Beat up an egg and add a teacupful of milk, a little flour, butter, and seasoning of pepper and salt. Make into little cakes and fry to a light brown color in boiling lard, first rolling them in beaten eggs (which are lightly seasoned) and fine bread crumbs.

\section{TURNIPS}

Are usually grown as a catch crop to follow after some other crop which has failed to prosper or has 
matured and been gathered. For winter use, they need not be sown before the middle of July or the first of August. Any good garden soil will grow the turnip, as it is not particular as to soil or location. For garden culture, the seed should be sown in shallow drills fifteen inches apart and the plants thinned to stand four to six inches apart in the row. Keep clean from weeds and the earth loose and mellow.

Take up the roots in the fall, but not before some frost, as they will be sweeter than if dug earlier. They may be grown as a catch crop to follow early peas, cabbage, or any vegetable that is gotten out of the way before the first of August. For early summer use, sow the seed as soon as the ground can be worked in spring.

\section{DIRECTIONS FOR COOKING TURNIPS}

Turnips are less watery if cooked whole, selecting medium-sized tubers and cooking in salted water until tender, when they should be taken from the water with a skimmer and placed in the oven a few moments to steam dry, then mashed, seasoned with butter, pepper and salt, and sent to the table in a hot dish. 


\section{TURNIP CUPS WITH PEAS}

Steam small white turnips until tender. When done, remove from the fire and hollow out the centres, cutting the tops in scallops. Fill with peas cooked with a cream dressing made of two tablespoonfuls of butter cooked with two tablespoonfuls of flour, one cupful of milk, and one teaspoonful of salt. Or if cream may be used, one spoonful of butter will be sufficient. Serve very hot on a platter garnished with parsley. 


\section{CHAPTER ELEVEN}

\section{VINE VEGETABLES AND FRUITS}

\section{Though limited in number, the fruits or vege-}

tables produced by plants of a viny nature comprise some of the most important and interesting of the garden's productions. The culture differs somewhat from that given other plants and is limited to a shorter period of active operations. All vine growths are exceedingly tender when young, and for this reason cannot be gotten into the ground until all danger of frost is past and the soil is warm. The seeds of this class of plants-especially of melons in variety - are very sensitive to wet or cold and prone to decay if conditions are not quite right. It is often, for this reason, necessary to repeat the planting twice or oftener before a good stand of plants is obtained. No seed should go into the ground at the North before the twentieth of May, and in many instances the first of June will give better results. Where very early fruit is desired, 
seed may be started in the house or hotbed by cutting sods from a meadow or other place and cutting them in squares about five inches in diameter and packing them closely together in a warm hotbed. The grass, if long, should be sheared away and the sods set grass-side down. On each of these pieces of sod five or six seeds of melons or squash may be planted, covered with two inches of rich, fine soil or manure, and when the seeds have germinated, all but three of the best may be removed. When the weather is favourable, these pieces of sod may be planted out in the open ground in hills prepared as for seed. Great care must be taken in handling the sods, as there is no plant grown in the garden so sensitive to disturbance in transplanting as the musk-melon. Cucumbers and squash are less sensitive, but even these will stand little disturbance and handling. Old strawberry baskets are sometimes used for this purpose, being placed in the hotbed close together and filled with rich soil well pressed into them; when transplanted, basket and all is removed to the field. Do not set them in the open until after June 1st.

A warm, sunny situation suits all vine plants, and a light, moist, sandy soil, heavily enriched with 
well-decayed manure, is necessary for their successful culture.

The ground should be very thoroughly prepared by deep ploughing and repeated dragging and raking. The seeds should be planted in hills four feet apart for cucumbers and six for muskmelons, while eight feet apart will give none too much room for squashes and water-melons. Two or three spadefuls of manure should be incorporated in each hill, which should be raised a little above the surface of the ground. The object in planting in these raised hills is that water may not settle about the plants should excessive rainfall follow the planting. In dry seasons level planting would be all right, but seeds planted on the level in a wet season will be quite certain to decay, and even plants which have come up will damp off under these conditions. Planting on elevated hills is a measure of protection which may be supplemented by covering the hills with a frame of wood or a light box with the bottom knocked out and replaced with a pane of glass; given this protection, the plants will come through a wet spell fairly well. In the small home garden the use of frames is a very practical and satisfactory measure, as 
after the plants have become started and the weather sufficiently warm, the glass may be replaced with a screen of window netting and the plants protected from the squash-bug or beetle, which creates such havoc in the melon patch.

These frames, if removed and stored in a dry place as soon as the need for them is over, will last for years. They should not be left on the hills after the vines have made enough growth to escape from them, and in the early stage of growth, while the glass is in use, it should be removed during the hottest part of the day and netting used to prevent burning, and to allow the plants the advantage of fresh air.

As soon as the plants have made a foot or less of growth the ends of all the branches should be pinched back. This encourages the plants to branch freely and will also result in the first blossoms formed setting fruit which will ripen much in advance of fruit on unpruned vines. It is claimed by some that the first blossoms set on the vines are sterile and would bear no fruit, but this is not my opinion, nor does experience justify any such theory, as I invariably find that when the vines are pinched back they produce from three to five [ 178 ] 
melons close to the root, which are always several days or weeks earlier than those on the remainder of the vines. I note this of the melons especially, squashes giving one or two fruits at the base of the plant.

Where ground is at a premium and one only desires to grow sufficient fruit for the private table, very satisfactory results may be obtained by growing the melons and cucumbers on netting. The hen park-fence affords an excellent opportunity for this form of culture, and I find that the hens do not disturb the vines in the least.

I do not think the vines produce quite so freely as on the ground, but the fruit matures quite as well, and the labour of caring for and gathering it is so much less than when grown on the ground, and the fruit so much more attractive in appearance, that the method has much to commend it. Cucumbers especially do well, and the fresh, bright appearance is in marked contrast to that of the ground-grown fruit. There is no labour connected with the growing of vegetables so trying as that of gathering pickles; the difficulty of getting about among the vines and the stooping position necessary to their gathering make it exceedingly [ 179 ] 
wearisome. Where they are grown on the ground, it will be well to curtail the growth sufficiently by frequent pinchings back or directing the running vines, to allow room to pass between the hills without treading on the vines, which seriously injures them and stops their bearing.

Cultivation should begin about the hills as soon as the plants are above ground, and earlier if the soil becomes hard or caked. Some twelve or fifteen seeds should have been planted in each hill. This allows for those which decay or for any reason fail to start and furnish food for the bugs, which are quite sure to appear unless the plants are protected by frames. When the plants have gotten their rough leaves and the bugs have left them, all but three plants should be removed and these encouraged to grow by the application of a little nitrate of soda worked into the hills about the plants in the proportion of a tablespoonful to a hill. Hen manure is also an excellent dressing for this purpose.

If the trowel or light hoe is used about the plants in the hills and for a little distance out, no weeds will gain a foothold there, and the hand-cultivator will take care of the ground between the hills. Cul[180] 
tivation should be continued as long as there is room enough between the hills for the cultivator to pass and should be followed by the rake to produce a clean surface and a dust mulch. When the cultivator can no longer be used, there will still be work for the narrow rake or hoe, and this should be used as long as possible. After the vines cover the ground they should not be disturbed further until the fruit begins to ripen.

In very dry and dusty spells of weather the vines may be watered with advantage, especially if the watering may be done with a hose, so as to thoroughly cleanse the vine, and liquid manure may occasionally be given with advantage.

\section{CUCUMBERS}

When wanted for pickles the cucumbers should be gathered as soon as they are large enough. It is better not to gather both pickles and cucumbers for the table from the same vine, as the maturing of the fruit decreases the production of young fruit. Often, however, there will be enough pickles overlooked in gathering to supply an average family with cucumbers for the table. It is always best to gather the tiny pickles first, depending for large 
pickles for use in making mixed pickles, pickled lilly, mangoes, and the like on the later fruit, as this keeps the vines in better bearing condition. Any fruit which has grown too large to use or has begun to ripen should be at once removed, as the production of seed will greatly exhaust the vine, and there is no economy in saving more than two or three for seed.

The fruits grown on vines trained on wire netting are so easily gathered and so easily found that the picking is apt to be much cleaner than where the vines are grown on the ground.

For growing on netting, the best variety is the Japanese Climbing cucumber. This is a fine, large variety of a rich dark green, and very shapely. It is a prolific bearer, and I find the flavour superior to any previously grown and it is exceedingly crisp and firm. It is equally good as a pickle or table variety, and if $I$ were restricted to one variety, I should prefer this. As it is I usually grow this on the netting and some good pickling variety on the ground. For a good all-around cucumber the white spine varieties are satisfactory, and for pickles, the Chicago Pickling, of which Snow's Fancy Pickling is an improved sort, is [182] 


\section{VINE VEGETABLES AND FRUITS}

very popular with pickle factories and market men.

A FEW CUCUMBER AND PICKLE RECIPES

Pare and cut cucumbers into small cubes till you have a cupful; add one teaspoonful each of salt, minced onion, and parsley; one tablespoonful each of tarragon vinegar and lemon juice. Drain on colander or wire sieve half an hour. Put on ice. Just before serving add one and one-half cups of stiffly whipped cream.

\section{HALIBUT IN CUCUMBERS}

Cook the halibut till tender in court bouillontwo quarts of water-add a few slices each of carrot, onion, and celery; two or three cloves and peppercorns; a bit each of mace, bay leaf, and parsley, a little salt, and lemon juice.

Drain, and when cool remove skin and bone and pick the fish apart in fine flakes. Make a rich white sauce in the regular way, adding from a quarter to a half teaspoonful of curry powder to every two cupfuls of sauce, according to taste. Pare, cut in halves, and parboil in bouillon the required number of cucumbers. Scoop out the inside of each half, [183] 
fill with the creamed fish, cover with prepared crumbs, to which add one-third cupful of butter to every cupful of dried bread crumbs, and bake about half an hour or less, till the cucumbers are soft, but not till they lose shape. Serve with a lemon point on each plate.

\section{TO SERVE CUCUMBERS RAW}

Place them in ice-water until very cold. Peel and slice very thin; sprinkle with salt and place in an earthen dish, which should be tilted on one end to allow the water to drain away from the fruit. Place in the ice-box until ready to serve. Drain free of moisture and serve in salad bowl with a dressing of pepper and vinegar. If liked young, green onions may be sliced and served with the cucumbers. Prepared thus, they are perfectly digestible, and may be eaten by any one.

\section{CUCUMBEr à LA CRÊME}

Peel and cut into slices lengthwise some fine cucumbers. Boil them until soft; salt to taste, and serve with a delicate cream sauce. 
CUCUMBER PICKLES

Select medium-sized small cucumbers. For one peck, make a brine which will bear up an egg; heat it boiling hot and pour it over the cucumbers; let them stand twenty-four hours, then wipe them dry. Heat some vinegar boiling hot and let stand again twenty-four hours. Now change the vinegar, putting on the fresh vinegar, adding to it one gill of brown sugar, one-half gill of white mustard-seed, a teaspoonful of cloves, and the same of cinnamon sticks, a piece of alum the size of a hickory nut, and a tablespoonful of celery-seed; heat it all boiling hot and pour over the cucumbers. Seal up in quart cans.

TO PUT DOWN CUCUMBERS A FEW AT A TIME

When gathered from the vines put in a crock or firkin layers of cucumbers and rock salt alternately, enough salt to make sufficient brine to cover them; no water; cover with a cloth; keep them under the brine with a heavy board; take off the cloth and rinse it every time you put in fresh cucumbers, as a scum will rise and settle upon it. Use plenty of salt and the pickles will keep a year.

[185] 


\section{THE VEGETABLE GARDEN}

To prepare pickles for use, soak in hot water and keep in a warm place until they are fresh enough, then pour spiced vinegar over them and let them stand over night, then pour that off, and put on fresh.

\section{SWEET CUCUMBER PICKLES}

Take ripe cucumbers, pare them, and cut out the seeds; cut in strips or fancy shape and soak in weak brine for twenty-four hours, then put them in vinegar and water and soak for twenty-four hours longer. Then put them in sweetened vinegar, the same as for any sweet pickle, and cook until tender. Take to a quart of vinegar three pounds of brown sugar, a tablespoonful of ground cinnamon and a few cloves tied in a cloth, and boil together and turn over the cucumbers.

\section{MUSK - MELONS}

Have been so greatly improved in the past few years that they possess a quality and flavour unknown a few years ago. To those who like a greenfleshed melon-and they are the sweetest, finestflavoured melons grown-the Rocky Ford is the melon of melons. This is a small melon, averaging 
about five inches in length, oval in shape, beautifully netted, and of delicious flavour. It is eminently suited to growing on netting, as its small size makes it of easy support and the fruit will not separate from the stem until ripe, so that a brief inspection of the vines will determine which fruit is ready to use without any preliminary handling.

For a yellow-fleshed melon of a large, showy kind there is nothing superior to the Irondequoit. The fruit is nearly round, finely netted, and of a handsome yellow colour. It is a melon which sells better than most of the varieties in the market, and on the table well sustains its reputation for quality. I grow these two melons exclusively in my own garden, experience with other varieties demonstrating the truth that there is nothing superior in the melon line.

Water-melons are not worth while growing here in the North. Kleckley's Sweet and Cole's Early are good varieties for the Northern garden, both being of good size, very sweet, and good bearers.

\section{WATER-MELON OR MUSK-MELON PICKLES}

Cut the fruit into desired size and put in a stone jar and pour over it enough scalding vinegar to 
cover. Heat the vinegar three successive days and pour over fruit. Then weigh the fruit, and to every five pounds add three pounds of white sugar, one quart vinegar, and cloves, cinnamon, and allspice to suit. Boil all together until fruit is tender. Put the fruit in jars, boil down the syrup until there is just enough to cover, and pour over scalding hot.

\section{PICKLED MANGOES}

Let the mangoes, or young musk-melons, lie in salted water strong enough to bear an egg for two weeks, then soak them in pure water for two days, changing the water two or three times; then remove the seeds and put the mangoes in a kettle, first a layer of mangoes and then a layer of grape leaves and then mangoes, and so on, until all are in, covering the mangoes with leaves. Add a lump of alum as large as a hickory nut, pour vinegar over them, and boil them ten or fifteen minutes; remove the leaves and let the pickles stand in this vinegar for a week; then stuff them with the following mixture: One pound of ginger, soaked in brine for a day or two and cut in slices, one ounce of black pepper, one of mace, one of allspice, one of tumeric, half a pound of garlic, soaked in brine [ 188 ] 
for a day or two and then dried, one pint of grated horse-radish, one of black mustard-seed, and one of white mustard-seed. Bruise all the spices and mix with a teacupful of pure olive oil. To each mango add one teaspoonful of brown sugar; cut one solid head of cabbage fine, add one pint of small onions, a few small cucumbers, and green tomatoes. Lay them in brine for a day and night, then drain them well, and add the imperfect mangoes, chopped fine, and the spices; mix thoroughly; stuff the mangoes and tie them; put them in a stone jar and pour over them the best cider vinegar. Set them in a bright, dry place till they are canned. In a month add three pounds of brown sugar. If this is not enough add more to taste. This is for four dozen mangoes.

\section{SQUASHES}

Squash are such rank growing vegetables that they are especially benefited by liberal pinching back, and this should be done as soon as the vines are a few inches long and continued at intervals until cultivation ceases. There is little difference in the cultivation accorded the summer and winter squash. The varieties known as bush squash, however, are 
planted much closer together-from three to four feet, giving room enough for these. Where one has a convenient compost heap, sufficient summer squash may be grown on it to supply the needs of the table. They make a pleasing addition to the summer bill of fare, and some of them are good winter keepers.

For a winter squash there are no better varieties than the old-fashioned Hubbard and the Golden Hubbard, the latter being a much more prolific bearer and ripening its fruit much in advance of the warted Hubbard. I do not think it is quite so good a keeper as the Hubbard; these we have had in perfection until mid-March, but so much depends upon the manner of handling the squash after harvesting that that must be taken into consideration in comparing any two varieties.

Any variety of squash must be gathered before they are injured by frost, but unless the shell is so hard as to resist the thumb nail, they will not prove good winter keepers, nor will they cook very dry and mealy, as a good squash should. Such squash should be used at once if for table use, but they will be much relished by the poultry should they be unfit for household use, and should be stored 
VINE VEGETABLES AND FRUITS

in as dry a place as possible and kept for that purpose.

\section{TOOTHSOME WAYS OF COOKING SQUASH}

The green or summer squash is best when the rind has begun to turn yellow, as it is then less watery and insipid than when younger. Wash them, cut them in large pieces, and take out the seeds. Steam for three-quarters of an hour, or until quite tender. When done, place on a piece of cheese-cloth over a colander and press with a potato-masher or spoon till smooth; then take the ends of the cheese-cloth and twist them until all the moisture possible is extracted from the squash.

Put in a stew-pan and season with butter, pepper and salt, and set it on the range, stirring frequently, until quite dry, taking care that it does not burn. Or it may be set in the oven until dry, when it should be served in a hot dish.

\section{BAKED WINTER SQUASH}

Winter squash should never be cooked in water, as its quality depends upon the mealy dryness of the vegetable. Break into large pieces, remove the seed, and place in a dripping-pan, first sprinkling

[191] 
lightly with sugar, and place in the oven to bake for about an hour, or until done. When done, peel and mash like mashed potatoes, seasoning with butter, pepper, and salt, or serve in the shells, to be eaten like sweet potatoes.

Squash retains its sweetness much better this way than when boiled and is far dryer. The next best thing to baking is steaming, the squash being broken into pieces, the shell removed or not, as preferred, and steamed till done, when it is mashed and seasoned and placed in the oven a few moments to dry out.

\section{PUMPKIN PIE}

One quart of steamed or baked pumpkin or squash pressed through a sieve, nine eggs, whites and yolks beaten separately, two quarts of milk, one teaspoonful of mace, one teaspoonful of cinnamon, and the same of nutmeg. One and onehalf cupfuls of white or very light-brown sugar. Beat all well together and bake in a crust without a cover.

\section{SQUASH PIE}

One pint of steamed, dry squash, one cupful of brown sugar, three eggs, two tablespoonfuls of [192] 


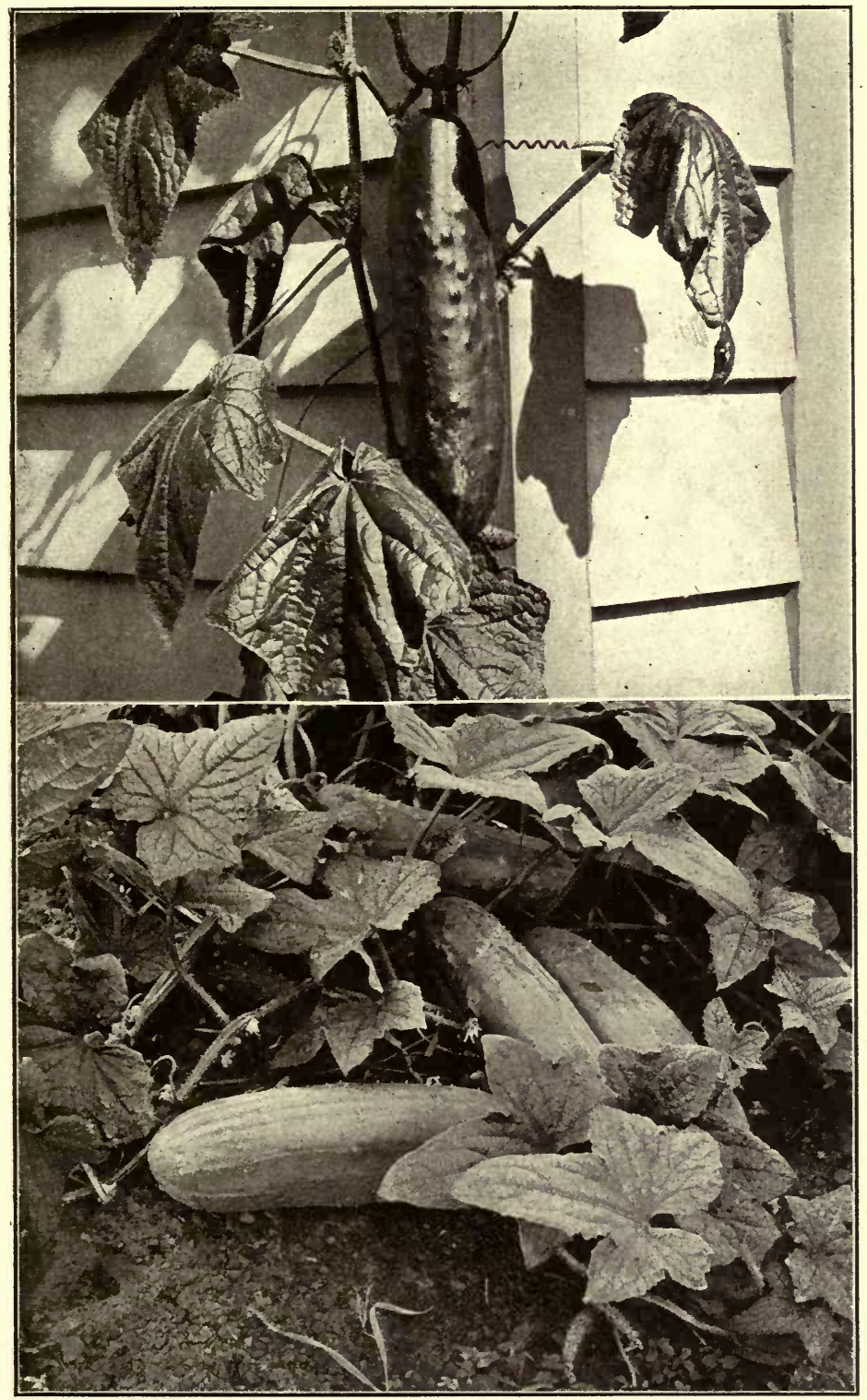

JAPANESE CLIMBING CUCUMBER NEARLY SIX FEET FROM THE GROOND 


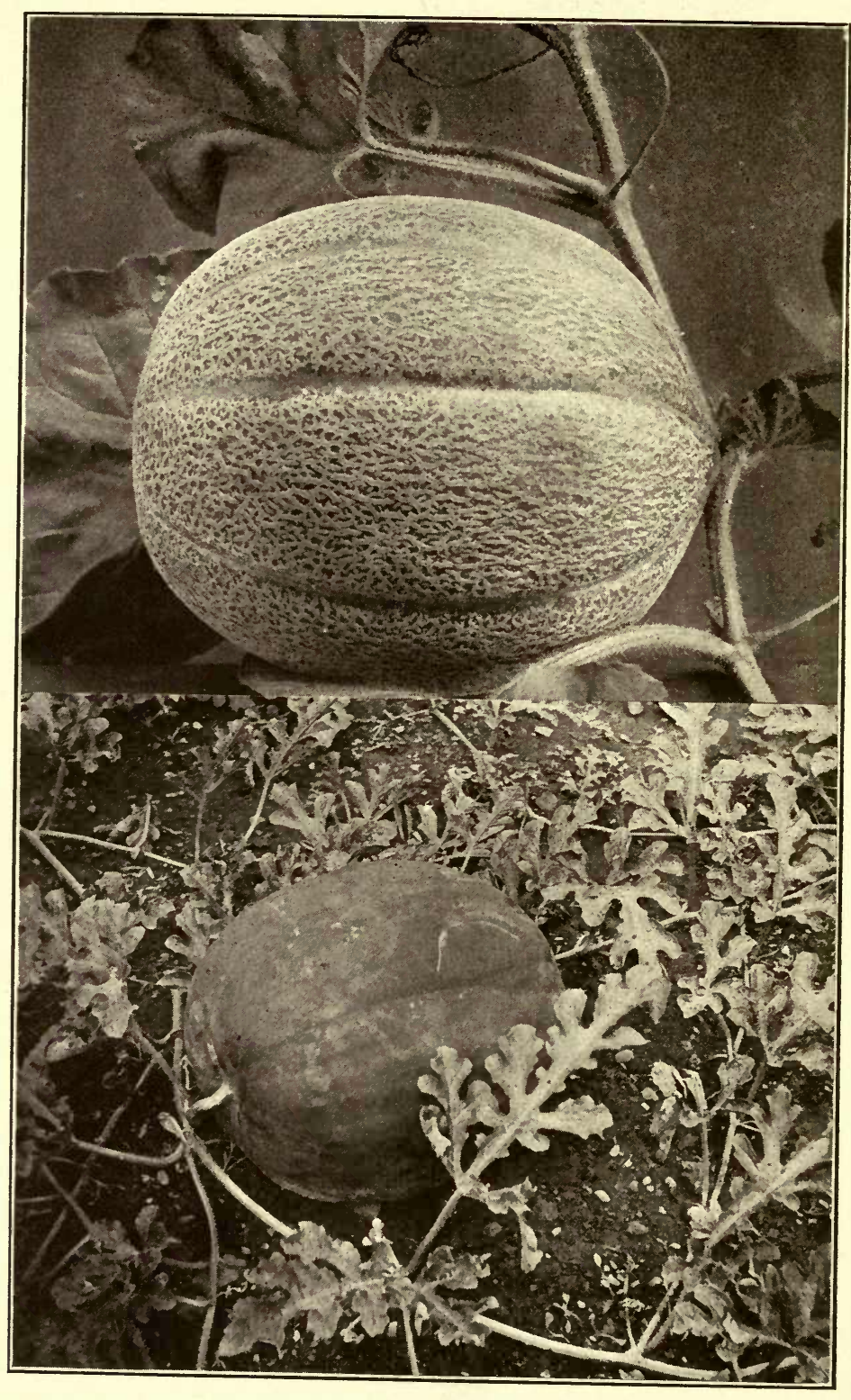

A PERFECTLY GROWN MUSKMELON 
molasses, one tablespoonful of melted butter, one tablespoonful of ginger, one teaspoonful of cinnamon, a pinch of salt, and one pint of milk. This makes two ordinary pies or one large deep one.

\section{SQUASH SOUFFLÉ PIE}

Cook four tablespoonfuls of flour in one-half cup of butter until smooth, add gradually one and one-quarter cupfuls of rich milk, three-quarters of a cupful of sugar, one-half cupful of molasses, and two cupfuls of sifted squash. Cook until the boiling point is reached, then cool a little and stir gradually into the beaten yolks of six eggs, season with cinnamon, and fold into the mixture the beaten whites of four eggs. Turn into tins covered with rich pastry that has baked fifteen minutes, and return to the oven to finish baking the crust and to cook the souffle for about twenty minutes.

When cool, cover with a meringue made of the two remaining whites and set in the oven to brown slightly. Baked in patty tins, these are very nice for luncheons and Sunday night suppers. 


\section{CHAPTER TWELVE}

GRENS AND SALAD VEGETABLES

THE plants which are grown for their leaves which are eaten either cooked or raw form a healthful and important part of the garden's offerings. It is a question if any of the cooked vegetables afford so marked a relief from the winter bill of fare as does the dish of dandelion or other greens, which may be gathered wild by the dweller in country or village. Unfortunately, these wild things of the fields and woods are not so available to the dweller in towns and cities, but there are many cultivated vegetables which are very palatable substitutes for these and may be grown in the limited area of the back-yard garden. In the cities materials for salads may be obtained throughout the year; this is especially true of lettuce and celery salad, which is in the market most of the year. 
GREENS AND SALAD VEGETABLES

WATER-CRESS

This is prized for salads and sandwiches, and grows wild along the margins of streams and about springs. Similar conditions may be supplied for a small patch of it by planting it about a hydrant from which water is allowed to trickle. Good soil, supplemented with a liberal addition of leaf-mould from the compost, should be supplied, and in this the cress seed may be sown in shallow drills a few inches apart. The only culture it will require after once getting started will be to keep it free from weeds.

Upland cress, which is more frequently grown in the home garden, is grown in shallow drills in beds, setting the rows a few inches apart and thinning the plants somewhat by using plants from too congested parts of the drills. Repeated sowings should be made at intervals, as the upland cress quickly forms seed and is no longer useful for the table. The Upland Cress and the Extra Curled or Peppergrass are the varieties commonly grown, while the Erfurt Water Cress is the variety favoured for this sort.

Very dainty sandwiches are made by buttering [195] 
lightly slices of very thin bread, with the crust removed, salting slightly and placing sprigs of the cress between the slices. Only the newest, most tender leaves should be used for this purpose. Cress is also served as an appetiser, to be eaten with the fingers, accompanied with salt.

\section{CORN SALAD}

This unique and comparatively little known salad plant is much liked by some. It is sown early in spring in drills one foot apart. It is one of the quickgrowing vegetables, maturing in about six to eight weeks. For winter and early spring use, sown in drills in August and September. It should be protected over winter by a light mulch of straw or litter.

\section{ENDIVE}

Is one of the best and most wholesome salads for fall and winter use. Sow in shallow drills in April for early use, or for late use, sowings may be made in June or July. When two or three inches high, thin out to stand about a foot apart in the rows. The plants which are removed may be used to set other rows or to fill in any vacant places in the present rows. They should have mellow and very 
GREENS AND SALAD VEGETABLES

rich soil, as all salad vegetables require to make a quick growth in order that the leaves may be crisp and tender.

When they have nearly gotten their growth, the plants should be blanched by bringing the outer leaves together above the heart and tying with yarn raffia or bits of cloth strips, or anything which will not bruise the leaves. The tying must be done in dry weather, a clear, sunshiny day being best, or, like the cauliflower, the inner part of the plants will mildew or decay. Some growers cover the plants with boards or canvas, much as is done in the case of celery. It takes from three to four weeks to blanch the plants. Like all vegetables, it is necessary to keep the rows clear of weeds and well cultivated. Going through the rows before a good rain, which has been preceded by a prolonged spell of dry weather, should always be done if possible, as this puts the soil in condition to absorb and retain the moisture and fits it for another dry spell, should one follow.

ENDIVE SALAD

The plants for this should be nicely blanched and crisp. It is the most wholesome of all salads. [ 197 ] 
Take two plants, cut away the roots, remove the dark-green leaves, and pick off all the rest; wash and drain well and add a few chives; dress with mayonnaise dressing.

\section{KALE}

Kale is cultivated the same as cabbage. It may be sown from May to June, one ounce of seed planting two hundred feet of drill. For early spring use, sow in September and protect during winter. A light frost improves kale, in this respect it being much like turnips and cauliflowers.

\section{LETTUCE}

Lettuce requires a rich, mellow soil, the richer the better, as all plants of this character, in which the leaves are the edible part, depend upon the rapidity of their growth for their peculiar crispness and toothsomeness. For early plants, sow the seed in the hotbed in March or April, or in flats in the house, and transplant to a sheltered border with a sunny southern exposure as soon as the plants are large enough and the ground outside in a suitable condition. For later use, the seed may be sown in the open ground at any time in April or May and 
continued for a succession at intervals throughout the summer until August. The plants should be thinned out to eight or ten inches apart in the rows if fine heads are wanted. The rows should be kept free from weeds and the soil loose and open at all times. In dry spells water should be flowed over the ground, and an occasional watering of liquid manure will be of benefit. By picking the outer leaves the inner ones will continue to develop, and in this way a very small patch be made to furnish a considerable amount of lettuce.

Lettuce is a useful crop for following other vegetables or for filling in vacant places left by the maturing of other plants or the failure of seeds to germinate. The hotbed may be devoted to the growing of radishes and lettuce as soon as the plants started therein have been transferred to the open ground. When used for this purpose, it will be well to provide a shade of light cotton cloth to cover the frames in the heat of the day, as the sun's rays are liable to prove too strong in the vicinity of the hotbed, which is selected for its sun and warmth.

A few hills of lettuce may be started around the melons and squashes and will become of size to use 
before the vines need the room. Like the radish, the lettuce is one of the plants which may be stuck in anywhere.

There are so many good varieties of lettuce that one hesitates to make a selection. For my own personal use I have always preferred those sorts which show a tint of bronze on the leaves, the Early Prize Head being a most delicious variety. The Black Seeded Simpson is a fine home variety of the light green type, and the Grand Rapids Forcing Lettuce an excellent sort for early growing in hotbed or frames. All Season lettuce is a very popular sort at the North, forming large compact heads which much resemble a flat-head cabbage.

\section{SOME WAYS OF USING LETTUCE}

Everything used in the concoction of a salad should be of the best and freshest material. The vegetables fresh and crisp, the oil of the purest or butter of the freshest, and the flavour of the vinegar beyond reproach.

Lettuce salad is one of the simplest and most available of salads, and lends itself to many combinations with other vegetables, fish, and meats. A 
salmon or lobster salad without its crisp, underlying leaf of lettuce is a disappointment in appearance and in taste.

Vinegar used with lettuce should be much weaker than for other vegetables, a too sour vinegar quite spoiling the flavour of the lettuce. One of the simplest and most satisfactory ways in which to serve lettuce is undressed, but very fresh and crisp in a well-chilled salad bowl. Accompanying it should be served, carefully shelled, chilled, hard-boiled eggs, and sugar and vinegar passed. This makes a salad of the freshest and simplest.

\section{LETTUCE SALAD}

Take three hard-boiled eggs and salt and mustard to taste, make it fine; make a paste by adding a dessertspoonful of olive oil or melted butter; mix thoroughly, and then dilute by adding gradually a teacupful of vinegar, and pour over the lettuce. Garnish by slicing another egg and laying over the lettuce.

\section{MUSTARD}

Is one of the most satisfactory vegetables used for greens. It is also used in combination with cress

[201] 
as a salad. The seed of both the black and white mustard is quite universally used in pickles of various kinds.

For salad use, it is sown thickly in shallow drills about six inches apart, forming beds of the drills. It should be sown at intervals during the summer to assure a succession of new and tender growth. For early spring use, it may be sown in frames or boxes, where it can be kept from severe cold. Keep free from weeds and cultivate sufficiently to keep the soil open and soft.

In using mustard for salads or greens only the leaves are used, and these should be carefully washed and looked over that no grit or insects may be included in the cooking. Cook like spinach in an open vessel until done, drain through a colander, pressing free from moisture, and serve seasoned with salt, pepper, and melted butter.

\section{SPIN ACH}

Is one of our most important vegetables, and should be found growing in every garden. The culture is simple: the chief point to bear in mind is that it requires very rich soil; it can scarcely be too rich, as upon its rapid growth depends its suc- 
culence and tenderness. For spring and summer use the seed is sown in shallow drills, a foot apart and one inch deep, as early as the ground can be worked in the spring and every two weeks thereafter for a succession. For winter and early spring use, sow in well-worked and manured ground in September, covering the plants from frost with straw at the approach of severe weather.

The Round-seeded Savoy is one of the best varieties for summer use, but the new Victoria is said to stand the warm weather somewhat better and to be in many respects an ideal spinach. The New Zealand variety is a larger-growing variety, and is usually planted in hills three feet apart each way. One ounce of seed will plant a hundred feet of drill. Keep free from weeds and well cultivated, watering freely in dry weather.

\section{DIRECTIONS FOR COOKING SPINACH}

In cooking spinach for greens only the tender parts should be used, and these should be carefully washed through several waters to entirely free them from sand or any insects which may have found lodgment. Drain and put to cook in boiling water. Fifteen to twenty minutes is usu- 
ally sufficient time in which to cook spinach. Be careful to remove all scum which raises. When it is quite tender, take it up and drain it well by laying on a piece of cheese-cloth over a colander and pressing out all water with a spoon or potato masher. Further pressure by twisting the cheesecloth will remove any remaining moisture, after which it should be returned to the saucepan -with a piece of butter and pepper and salt to taste. Set it on the range and let it stew five minutes, stirring all the time. Serve on a hot vegetable dish, formed into a mound and garnished with sliced hardboiled eggs. In order that the spinach may retain its fine green colour, the vessel in which it is cooked should not be covered.

\section{CREAM OF SPINACH SOUP}

One-half peck of spinach washed and cooked in a cup of boiling water with one teaspoonful of salt for five minutes in a porcelain kettle; chop it and rub through a sieve. While it is being pressed through a sieve add to it one pint of chicken stock. Let a quart of milk come to a boil in a double kettle, add one teaspoonful of grated onion, a blade of mace, and a bay leaf. Rub smooth three table- 


\section{GREENS AND SALAD VEGETABLES}

spoonfuls of flour and two of butter and stir them into the boiling milk; continue to stir until it is thick and smooth, add the spinach and rub through a purée sieve, return to the double boiler and bring to the boiling point, and serve in a hot tureen.

\section{SPINACH BALLS}

Pound to a paste in a mortar the yolks of two hard-boiled eggs and rub smooth with the yolk of one raw egg; season with salt, a drop of tabasco, and a very little melted butter. Mix with one cup of cold cooked spinach, drained and pressed as dry as possible. Make into small balls, roll in flour, and fry in a basket a few at a time. 


\section{CHAPTER THIRTEEN \\ PERENNIAL VEGETABLES}

$\mathrm{T}_{\mathrm{HE}}$ list of perennial vegetables commonly grown in the kitchen garden is not large, but it includes some of the most indispensable vegetables of the kitchen cuisine. They come into use so early in the spring that they provide fresh vegetables at a time when the palate is most jaded from a winter diet and bridge over the period of waiting for the new planting to become productive.

\section{ASPARAGUS}

Is the most palatable of our spring vegetables and comes into cutting in May. The usual way of starting an asparagus bed is by setting out the roots, which are obtained of the florist or market gardener; but very excellent, though somewhat slower, results follow the planting of seed. In growing the asparagus from seed, the usual way is to plant the seed in drills in rows one foot apart in thor[206] 
oughly pulverized and well-manured ground. The plants must be kept entirely free from weeds, and to achieve this it will be necessary to do considerable hand work, pulling out the weeds from between the plants and loosening up the soil with the fingers. The young asparagus plants are very slender and fragile, and thus close culture and weeding is essential. As soon as the plants are a few inches high, they should be thinned out to stand six inches apart, and from that on be cultivated sufficiently to keep the soil mellow and entirely free from weeds.

The second spring the young plants may be transplanted into permanent beds, which should be so located as not to be in the way of the cultivation of other parts of the garden. It will be found that setting the rows far enough apart to cultivate between will greatly advance the culture and lessen the care.

The ground for the permanent beds should be very rich or specially prepared. The rows should, if they are to be cultivated by the hand-cultivator, be not less than eighteen inches apart and the plants set a foot apart in the rows; this will enable the gardener to cultivate each way of the plants and [207] 
will produce fuller stools of asparagus and larger shoots than if the plants are set closer together.

In preparing the ground for the plants, it should be trenched to a depth of eighteen or twenty inches, several inches of rich manure worked into the bottom of the trench, and the plants set in this. Sufficient earth should be filled in about the roots to cover them three inches deep, more soil to be added in cultivating after the plants are set. Place the roots in a natural position, rounding up the soil somewhat under the crown and spreading out the roots; press down the earth firmly about them and level all off gradually in cultivating.

Thorough culture may be given the first year, or resort may be had to a mulch of straw, marsh hay, or lawn clippings, which will greatly reduce the care of the beds, and if sufficient material is used, keep the beds in quite satisfactory condition.

As soon as the plants have become old enough to bear berries I prefer to cut the fruiting tops before the seed shall have ripened and burn them, replacing with other litter; but this should not be done till the tops have quite matured. I find that allowing the old plants to seed will, in a short time, produce a crop of young plants which, unless re[208] 


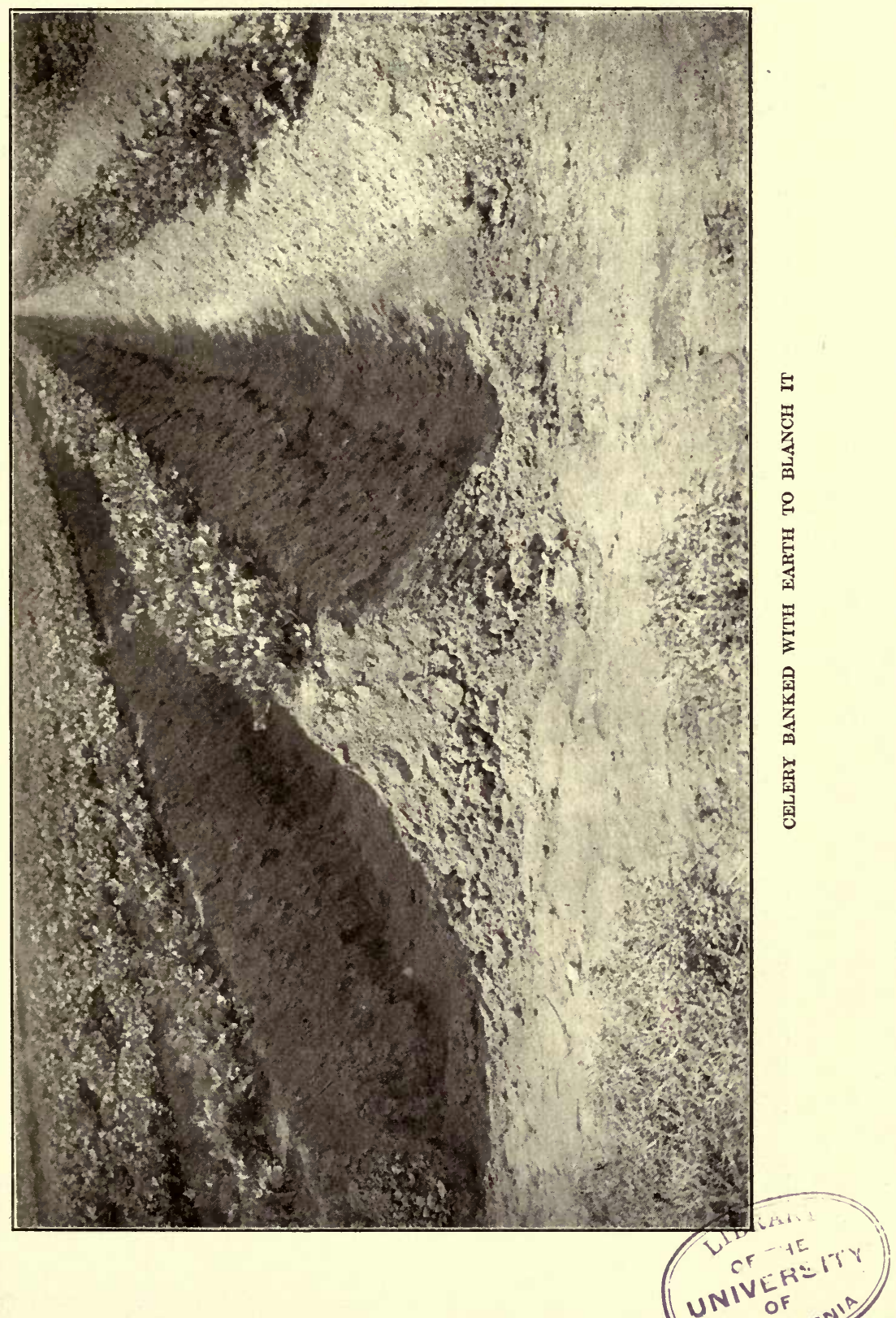




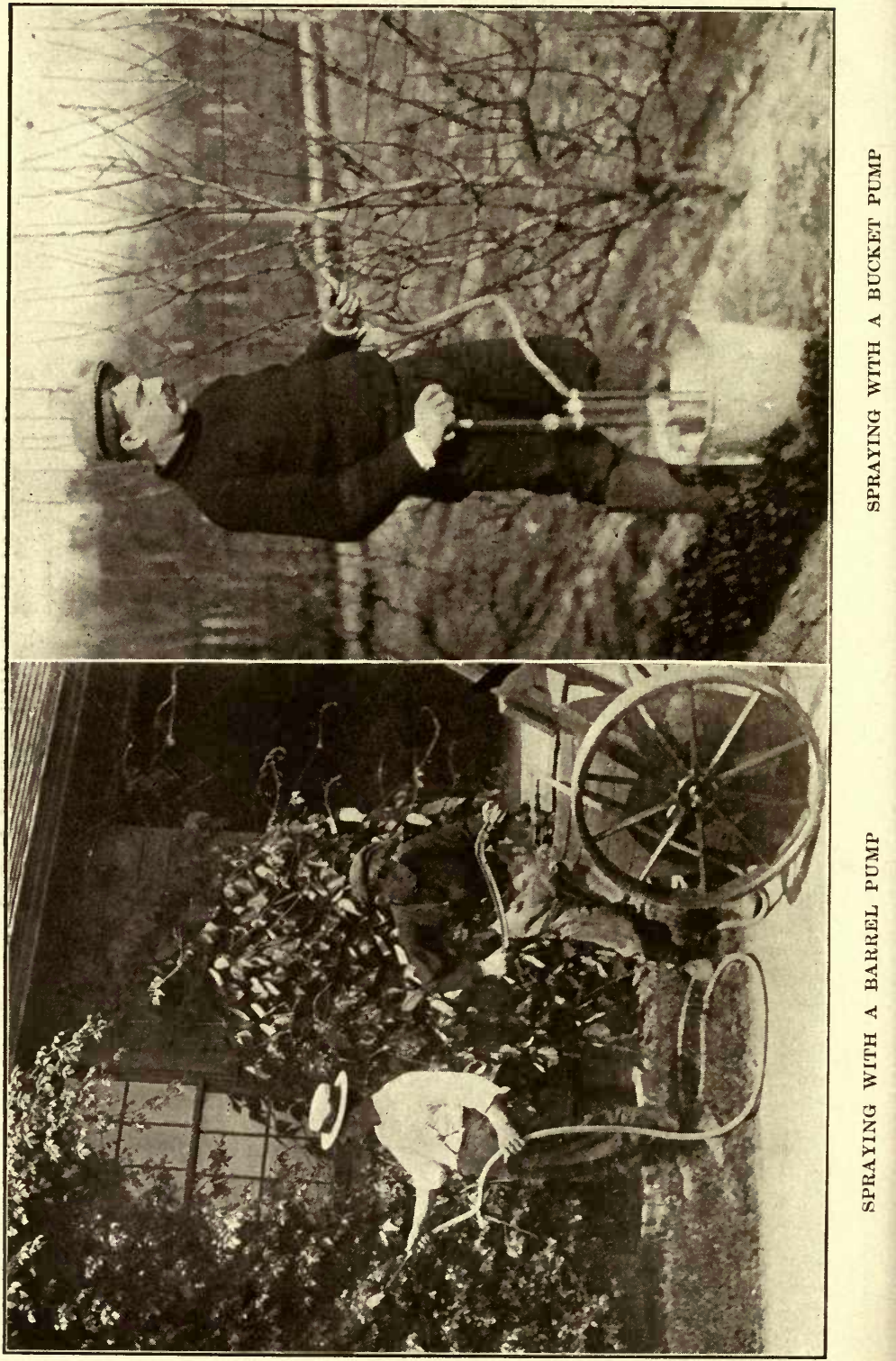


lentlessly treated as weeds, choke out the old plants, and are troublesome to destroy and altogether undesirable.

Cutting for use may begin the second season, but should not be carried to the extent that would be practised on an old bed, and should be discontinued while yet the roots are throwing large, healthy shoots. In cutting asparagus for use, it should be cut just below the surface, never very much under it, as all that grows below the surface is tough and unfit for use. Where the bed is not producing sufficient for use at first, it may be gathered from day to day and placed upright in a dish of water until sufficient has accumulated for use. It will, in this way, make considerable growth and the flavour will not be very much impaired.

As soon as the bed has come into bearing it should have all the rough litter removed very early in the spring and a liberal top dressing of wood ashes and fresh manure spread over it. Nitrate of soda and other commercial fertilisers may be applied at this time or deferred until the roughest of the manure is removed preparatory to cutting. Salt is often applied in the proportion of six hundred pounds per acre, or about four pounds to the [209] 
square rod, but it is not a plant food and only serves as a weed killer for a very short time. If one wishes very early asparagus, one should plant it in rows running east and west and with a sunny southern exposure and protected on the north by a high wall or building. A rough board frame around the beds, covered with sash, may be provided and this well banked with rough litter during winter. In February this is removed and the frames filled with fresh manure, which should also be banked about the outside of the frames. Part of the inside manure will need to be removed as soon as growth begins and the sashes lifted during the warmer part of the day to admit air. As soon as the weather becomes warm the sash and frames may be removed and the beds given the usual treatment.

Asparagus is successfully forced in warm cellars by lifting clumps of roots in the fall and placing them on the floor of the cellar, as is done with rhubarb. It is, of course, necessary that the plants become frozen for some time before forcing and that the cellar be warm and dark, or that light should be shut away from the immediate vicinity of the plants by turning boxes or barrels over 
them. A position back of a furnace offers a favour-, able position, as it is usually out of the way, warm, and not too light. Here, on the cement bottom of the cellar, a bed of rough boards or a big shallow box, adapted to the purpose, may be prepared, and the roots, which must be lifted before the ground freezes, but left outside to freeze, covered with loose earth until some time in November or December, when they are set closely together therein. Sufficient earth should be added to cover the crowns of the plants, and this may be well enriched with manure. It should be kept moist, for it will be remembered that the asparagus is a plant of the spring, when the earth teems with moisture. If the cellar is at all light, it will be necessary to cover the beds with a frame of wood, covered with canvas, old carpet, or anything convenient, or even a heavy mulching of straw. This is not actually necessary after growth has begun and the shoots are breaking ground. Additional heat may be provided by placing a lantern under the frame and covering the beds with a piece of old carpet, but this must not be retained long enough to engender mould or mustiness. 
SOME OF THE WAYS OF COOKING ASPARAGUS

\section{CREAM OF ASPARAGUS}

Cook twelve stalks of asparagus in one quart of water, add two sprays of parsley, three leaves of mint, and two small green onions. When the asparagus is tender, rub all through a sieve, mashing and rubbing through as much as possible. Return to the fire, add a teaspoonful of celery-salt, a teaspoonful of paprika, and one pint of hot milk. When it comes to a boil, draw back from the stove and add the yolks of two eggs, beaten with half a cup of cream. Have a tablespoonful of finely chopped parsley in the soup tureen and pour over the hot soup and serve at once. A tablespoonful of flour, rubbed smooth in a tablespoonful of butter, may be substituted for the eggs and cream. If a rich, creamy consistency is desired, place a half cupful of whipped cream in the tureen before adding the soup.

\section{ASPARAGUS SOUP}

Boil slowly for forty minutes one bunch of asparagus, which has been cut into inch pieces, in [212] 
one pint of water. At the end of this time remove the tips and press the remainder through a colander. Place a quart of milk in a double boiler, and when it boils stir into it two tablespoonfuls of flour and one heaping tablespoonful of butter rubbed together until smooth. Stir until smooth and thick; then add the asparagus which was pressed through the colander, season with salt and pepper, heat, then add the asparagus tips, and serve at once very hot.

\section{ASPARAGUS TIPS IN CROUSTADES}

These are nice served with broiled lamb chops, with fried chickens, or as an entrée. The croustades are nicer if prepared from round loaves of bread, made by baking in a tin can or in a Quakercrimped bread-pan, but square slices of bread, three or four inches square, may be used. Trim the slices of bread, which should be free from crusts, two inches thick. Remove from the centre of each as much of the crumb as possible, leaving a small square or round box; fry a golden brown in a kettle of hot fat, or butter inside and out, and brown in a quick oven. Fill the centres with asparagus tips dressed with a delicate cream sauce. 
ASPARAGUS CREAM OMELETTE

Stir one heaping tablespoonful of butter and the same amount of flour together. Set the saucepan over the fire, and when well blended add one cup of milk; stir until smooth; add a teaspoonful of chopped parsley; remove from the fire and cool. Beat three eggs separately, the whites to a stiff froth; add the yolks to the cold sauce, with a teaspoonful of salt and a dash of cayenne. Add also one cup of asparagus tips and the stiffly beaten whites. Put a tablespoonful of butter in a hot frying-pan. When it is brown, pour in the mixture, break it in pieces with a fork to allow the uncooked portion to run down. When it is set, place in a hot oven for five minutes, double over, and serve.

ASPARAGUS LOAF WITH YELLOW BECHAMEL SAUCE

Butter thoroughly a charlotte mould of quart size and line it with well-drained, cooked asparagus tips. Cook two tablespoonfuls of flour and two tablespoonfuls of butter together, add a teaspoonful of salt, a dash of cayenne, and a cup of cream; gradually allow it to boil five minutes, remove from 
the fire, and add one cup of cooked asparagus tips and four eggs thoroughly beaten. Turn the mixture carefully into the decorated mould, set the mould in a pan of hot water, and cook in a moderate oven about thirty minutes, or until the centre is firm. Turn the loaf onto a hot platter, arrange about it little triangular pieces of bread that have been dipped in beaten eggs and milk and browned in hot butter. Pour around the sauce and serve at once.

\section{YELLOW BECHAMEL SAUCE}

Mix two tablespoonfuls of flour and two of butter, cook until it begins to bubble, add gradually half a cup of hot stock and half a cup of milk. When sauce boils, set in a dish of hot water and stir in the beaten yolks of two eggs, half a cup of cooked asparagus tips, a teaspoonful of salt, a dash of cayenne, and a tablespoonful of lemon juice. In place of stock, the water in which the asparagus was cooked may be used.

\section{ASPARAGUS ON TOAST}

Scrape the stems of the asparagus lightly, but very clean; throw them into cold water, and when all are ready, tie them in bunches of equal size, 
cutting the large ends off neatly and evenly, and stand upright in a deep saucepan of boiling, salted water, which should not cover the tips, but allow these to steam done, so that they may not be overcooked by cooking as long as the tougher parts. Have ready several slices of bread toasted a delicate brown; dip these quickly in the water in which the asparagus was boiled and dish the vegetables upon it, the points all turned the same way, and send to table with a white sauce or melted butter. In cooking asparagus, it should be removed from the water the moment it is done in order that the colour and flavour may be at its best.

\section{STEWED ASPARAGUS}

Prepare as for asparagus on toast; remove from the water and remove the strings. Return to the saucepan and pour over a half cup of good cream, and, if liked, a spoonful of flour rubbed smooth in a little of the cream. Some prefer the asparagus dressed in this way and with the asparagus cut in inch lengths. Prepared this way, it is excellent on toast. 


\section{RHUBARB}

Is much appreciated by many in the early days of spring, and has certainly much to recommend it as a tonic and appetiser. There are few gardens in which a root or two of rhubarb will not be found growing, so accommodating is it as to environment and conditions, but it is, at the same time, a plant which will well repay liberal culture. It should be given a permanent position in a warm, sunny place, and the ground should be very deeply dug, as the plants make an immense root growth, and the hole in which it is set should be dug eighteen inches or two feet deep, and all poor soil at the bottom should be removed and the excavation filled in with old manure and good, mellow soil. On this the roots of the rhubarb should be set, the crown only a little below the surface of the ground. The ground should slope away from the plants to insure good drainage in the winter. Cultivation in the early spring should be given, but will not be necessary throughout the summer if a mulch is placed over the ground on each side of the plant. The great overhanging leaves are quite effectual discouragers of weeds, and few, if any, 
will grow in the immediate neighbourhood of the root.

A heavy mulch of rough litter should be applied about the plants in the fall, and in the spring half barrels or boxes may be turned over the plants and fresh manure packed about them; this will much advance the growth of the plants. Later, as the weather grows warm, this may be removed and the plants allowed to make a natural growth, but the use of the barrels acts as a forcing house for early stalks.

Rhubarb is easily forced in a warm cellar. The roots should be dug before the ground freezes and left outside, lightly covered with soil and brought into the cellar after they have been severely frozen. For the best results, however, this should not be done until about Christmas time, it will force better then. A dark, warm cellar is necessary, and where there is a heating plant, the furnace room will afford an excellent location for their forcing, or roots may be placed on the ground under the hot water or steam pipes, where they run under the floors of rooms under which there is no cellar. If a strip or two of wood is nailed to the floor above the pipes, to which a heavy piece of duck or canvas can be [218] 
secured to extend down to the earth beneath, it. will form an enclosure for the plants, which will retain heat and shut out light effectually. It will also be a convenient place in which to attend to them if the pipes are near the cellar wall. The soil in which the plants are set should cover the crowns several inches and should be kept moist - not wetand any suspicion of mould or mustiness should be counteracted by airing as needed. Rhubarb grown in this way is very tender and delicate. Old rhubarb plants in the garden or field should be dug up, divided, and plants with only two or three buds be replanted in very rich soil every three or four years. No insects are injurious to the rhubarb.

\section{RHUBARB PIE AND OTHER DELICACIES}

Skin the stalks, cut them into small pieces and wash and put them in a stew-pan with no more water than adheres to them; when cooked, mash them fine and put in a small piece of butter; when cool, sweeten to taste; if liked, add a little lemonpeel, cinnamon, or nutmeg; line your plate with thin crust, put in the filling, cover with crust, and bake in a quick oven; sift sugar over it when served. The improved varieties, when grown rap- 
idly, are so tender and delicate that the stalks need not be peeled.

Another way of making rhubarb pie is as follows:

Cut the large stalks off where the leaves commence, strip off the outside skin, then cut the stalks in pieces half an inch long; line a pie-plate with rather thick paste, put a layer of the rhubarb nearly an inch deep (for a quart bowl of cut rhubarb allow a large teacupful of sugar); strew it over with a saltspoonful of salt and a little nutmeg grated; shake over a little flour, cover with a rich pie-crust, cut a slit in the centre, trim off the edge with a sharp knife, and bake in a quick oven until the pie loosens from the dish. Rhubarb pies made in this way are altogether superior to those made with fruit which has previously been stewed.

\section{RHUBARB MERINGUE PIE}

Prepare the rhubarb as for the preceding pie, but do not use a top crust. Place in the oven and bake until done; take from the oven and let stand for a few moments, cover with a meringue made of the beaten white of an egg and one tablespoon[220] 
ful of sugar, and return to a slow oven until it turns a golden brown.

\section{RHUBARB SAUCE}

Peel and cut the rhubarb into inch pieces and place in a dish, cover with sugar, but no water, and place in the oven and bake until tender. This is far finer than to stew the rhubarb on the stove with water. One tablespoonful of gelatin dissolved in water and added to one quart of rhubarb will produce a most attractive dish when moulded and turned out in a glass dish for serving.

\section{HORSE-RADISH}

May be grown in any out-of-the-way corner, but seems to prefer a rather low, damp place. It is one of the most easily propagated of plants, as it thrives best when most disturbed. A small piece of the root stuck in the ground will quickly strike and commence to grow. It is not necessary that the crown of the plant should be used, a piece broken some distance below the crown doing equally as well and often better. It is for this reason difficult to eradicate once it has become established. Last year, in extending the boundaries of my flower garden, 
a patch of horse-radish was encountered which was, as far as possible, dug up; but the following spring it appeared as thrifty as ever, and although it was cut at frequent intervals-making the cutting as deep in the ground as practicable-it was still in a most flourishing condition when fall came, when another attempt was made to eradicate it, and all this new growth was produced from the broken ends of the roots left in the ground each time.

This persistence in growth makes it convenient for use, as a few roots may be dug up and placed in a crock of water and will continue to grow and furnish a pungent relish for weeks. It is only necessary to see that the water is changed occasionally, so that it does not become slimy, and horse-radish will be at hand for immediate use without the trouble of going to the garden and digging it up each time it is wanted. It is one of the easiest of vegetables for winter forcing, as a few roots can be taken up and placed in a box of moist earth in a light cellar and will continue to grow all winter.

This ease of culture and survival under unfavourable circumstances indicate that it will spread rapidly, but this does not seem to be one of its faults, as a patch of it increases its boundaries but 
slowly, and there is little fear of its overrunning the garden to any extent. The leaves are of much use in sickness as a blister, and the plant itself highly ornamental.

Horse-radish, when grated for the table, should be mixed with white-wine vinegar, never with cider vinegar, as this gives it an unpleasant, dirty colour.

\section{PARSLEY}

Is one of the most useful of our perennial vegetables; it enters into all forms of savory cooking, either as a seasoning or as a garnish. It is almost as appetising as cress for a sandwich, and gives an air to the plainest dish when used as a garnish. Strangely enough, its use seems little known outside the cities, and is regarded rather as a curiosity than a necessity by many. It is easily established in any spare nook, or may be used to border beds of flowers or vegetables.

The usual manner of starting a bed of parsley is by sowing the seed; the plants may be transplanted, but will not do as well as the seed-grown plants. The ancients held that parsley should never be sown but transplanted, as they claimed that the seed had to make a journey to Hades before it [223] 
could again appear above ground, and, indeed, the tardiness with which it germinates would almost seem to bear out that idea.

The ground should be thoroughly prepared by spading and enriching, and the seed should be sown as early in the spring as the ground can be worked, as after the ground becomes at all warm or dry, the seed will not germinate. It may be sown broadcast or in drills a foot apart, covering the seed about half an inch deep, pressing the soil down firmly. When the plants are up, thin out to stand six inches apart in the rows. Keep clear of weeds and well cultivated. In using the parsley, the leaves are picked and the crown of the plant left undisturbed. If allowed to go to seed it injures the plant for garnishing, but a few plants should be allowed to seed, as it propagates itself in this way and insures a succession of young and tender plants. A light covering of brush or evergreen boughs during winter will be of benefit. A few plants may be lifted and wintered in a light window of the cellar or in a kitchen window and will furnish leaves for garnishing throughout the winter.

Dried parsley is much used with other pot herbs in soups, and is easily prepared by picking the [224] 
leaves and enclosing them in paper bags and hanging them in a dry, airy place to dry. Parsley was much esteemed by the ancients, who believed it prevented intoxication by absorbing the fumes of wine. It was much used, therefore, as wreaths and chaplets at their feasts and drinking bouts. It was parsley which Hercules selected for his first garlands of victory, and as the ancients utilised the plants in their merrymaking and rejoicing, so, too, it was brought into use in their funeral decorations, sprigs of the herb being strewn over their dead. 


\section{CHAPTER FOURTEEN}

STORING VEGETABLES IN WINTER

$V_{\text {Egetables, which have been grown to perfection }}$ during the summer months and gathered while at their best, will deteriorate rapidly unless proper care is exercised in storing them away for the winter. Many of the methods employed by market gardeners and on farms where large quantities of fruit and vegetables are grown, and must be stored for sale at a time when they will bring a price much in advance of that which will. prevail in the fall and early winter, are not practicable in the small home garden.

Any dry, frost-proof cellar will keep potatoes in good condition providing the precaution is observed of airing the cellar regularly and persistently. The most common mistake in storing fruit and vegetables in the cellar of the house is in the direction of too much heat and too little air. It is rarely that the cellar windows require to be closed 
before December, but in many cases they will be hermetically sealed at the approach of the first hard frost. This is not only bad for the contents of the cellar, but far worse for the people who dwell above the cellar. Where there is a heating plant in the cellar it is essential that there should be vegetable rooms separate from that devoted to furnace or boiler, and where this does not exist, an end of the cellar, at least, should be partitioned off for the purpose, though it may be but by a rough board partition; this as well as anything will shut out heat. Such a room should include one or more of the cellar windows, and preferably those on the sunny side of the house.

For the storing of potatoes there is no better arrangement than bins made long and narrow and with partitions through the centres, making compartments which will hold from one to three bushels of potatoes. There should be a number of large auger holes in the bottom of each and the bins should be elevated on some sort of supports to a foot or more from the floor. It must be remembered that cold falls and that the bottom of the cellar is much the coldest part of it, and where there is danger of frost, the floor of the cellar is 
the very poorest place in which to place anything that is to be kept from frost.

Potatoes should be dug on a bright day, when the soil is dry, so that the earth will shake off easily. Vegetables should never be washed before putting away for the winter, as they will not keep as well if they have been wet. Potatoes should never lie for any time exposed to the light, as this will cause them to turn green, and when they are placed in the cellar, should be kept covered with canvas, carpet, or newspapers, but carpet is best.

By the middle of winter it will be necessary to look the potato bins over carefully and to remove any tubers which may have begun to decay. One decaying tuber will produce thousands of fungus spores, which will contaminate the entire contents of the bins if not promptly removed. By the first of March, or even in February, the potatoes will have begun to sprout; especially will this be the case if the cellar is too warm and at all damp. They must then be gone over and all the sprouts rubbed off by hand.

If the cellar is quite dry, a portion of the potato bins may be reserved for the onions, which require a cool, dry place to be kept dormant in. No great [228] 
amount of these will be stored for the winter use of a small family, and such of these as begin growth before being used may be planted out in the garden early in spring and will soon furnish messes of green onions for the table.

Squashes are one of the most difficult of vegetables to keep, as they are very susceptible to cold and moisture and must be kept warm and dry. An upstair room or garret will often be found an excellent place of storage. A room where a chimney passes through will often furnish sufficient heat, and if the squash are packed in barrels of dry leaves, excelsior, or buckwheat chaff, they will winter all right. Or they may, if few, be simply piled on the floor near the chimney and covered well with rugs, carpets, or something warm, and will usually come through all right.

Beets, parsnips, carrots, and turnips, on the contrary, need to be kept somewhat moist, and should be buried in damp earth, sand, or leaves. If one has a room in the cellar with earth walls and floors - what is known as a Michigan cellar-it will be an ideal place for these vegetables, and they may be simply piled in heaps on the floor and sufficient earth to cover thrown over them. This is the sim[229] 
plest form of winter storage for these vegetables. The earth is right at hand and needs neither to be carried out nor brought in. In storing the beets and carrots, I usually leave the tops on and pile one layer on the floor, the tops all one way, and place over them a layer of earth, then another layer of vegetables and more earth, and so on, until the lot is coviered. The presence of the tops make uncovering the roots less difficult, and I think helps to retain a certain amount of freshness in the vegetable. Turnips are always prepared by removing all but about an inch of the tops and piling the earth over them. Treated in this way, they will all keep fresh and crisp until spring. Slightly moistened leaves make admirable covering for vegetables and are much cleaner than soil and more easily used.

Celery should be planted in boxes of damp sand or earth, drawing the earth up about the stems, as in the garden. Stored in this way, at a temperature of about $33^{\circ}$, it will keep fresh and crisp for a long time and be well blanched. Cauliflowers which have failed to mature their heads in the fall may be taken up and planted in shallow boxes of soil in the lightest part of the cellar and watered oc[230] 
STORING VEGETABLES IN WINTER

casionally and will then mature their heads and be a welcome addition to the winter bill of fare.

Dry beans should be stored in a dry place-an upstair closet or cupboard-until wanted. They are not injured by freezing, and if more convenient, may be left in the barn till wanted. Salsify may be stored in damp sand, leaves, or soil, and a winter's supply of parsnips may have the same treatment, the main crop being left in the ground to be dug early in spring ere yet they have started to grow. Light is not necessary to plants stored in earth in the cellar, but sufficient air should be admitted to the cellar to prevent any musty or mouldy odours or taste being communicated to the vegetables.

Where the cellar affords little or no room for storage, enough for immediate use may be placed in boxes of earth or sand and the remainder cached in the garden. To do this, it is only necessary to dig a shallow pit and pile the vegetables therein and bank earth over them. Only enough to cover them completely should be placed at first, but more should be added at the approach of severe weather and the whole covered with boards to shed rain. Placing straw over the vegetables before ad- 
ding the dirt makes them a little easier to unearth when wanted, but does not make them keep any better. Of course, if the heap is a large one, it will be necessary to provide ventilation, and this may be done by placing a length or two of old stovepipe in the centre of the heap and letting one end extend outside, where it should be masked with enough straw to shut out the cold but not to impede ventilation. Cabbages are very successfully kept by storing heads downward in a trench in which straw has been placed for a few inches in the bottom and covered up with earth above the tips of the roots and the ridge covered with boards to shed rain. A hotbed makes a very good place for storing cabbage, as it can be gotten into readily at any time during the winter. The earth should be removed as for fitting the bed in the spring; a layer of clean straw placed down on the bottom. The cabbages which have been pulled-not cutare placed head down on this and the heads covered with earth; the remainder of the pit should be filled with straw or leaves to keep out the cold and the sash placed in position. Stored in this way, it is only necessary to reach down into the litter and pull out a head as wanted. 


\section{CHAPTER FIFTEEN}

THE GARDEN'S ENEMIES

The price of a good garden and orchard is a never-ceasing warfare on insect pests and plantdiseases.

But some will say, "What's the use of my keeping up the fight when my neighbour next door doesn't do anything, and insects and diseases of all kinds breed on his premises and then come over to mine?"

It is true that the work is made much more difficult without the co-operation of your neighbours, as it will have to be done continually and without much real satisfaction, but my advice is to keep up your efforts. Your neighbour may come to see his folly, but if he doesn't, laws will soon be enacted, I believe, compelling owners to spray and care for infected trees and shrubs.

Spraying merely frees us for the time being; it does not eradicate the pests entirely. If it did, we [233 ] 
shouldn't have any pests, because, no matter how much behind the times a person might be, he would make one supreme effort, and spray, to rid his garden of bugs and disease. We must spray continually, and all our efforts will only keep the insects in check. This can be accomplished best by killing as many of the bugs as possible before they breed.

The various pests may be expected to appear about as follows:

AprIL.-Aphis or green plant-lice and asparagus beetle.

May.-Aphis, Colorado potato beetle, fleabeetle, cut-worms.

JuNE.-Cabbage worms, Harlequin or fire-bug, root maggot on cabbage and cauliflower, club root, corn ear-worm, striped beetle on cucumbers, melons, and squashes, onion maggot, thrips.

JuLy.-Bean anthracnose, celery rust, squash bug, melon blight and mildew, tomato fruit worm.

August.-Asparagus rust, celery caterpillar, mildew on peas, potato blight, potato scab, squash borer.

The following is a list of the more common vege[234] 
tables and the insects and plant diseases attacking them, with remedies or preventives:

Asparagus.-Beetles.-Keep beds closely cut in spring and protect the stalks with poison, preferably arsenate of lead.

Rust.-Spray thoroughly a few times in July and August with diluted Bordeaux. Set plants on good land, and keep them in vigorous condition.

Bean.-Anthracnose.-Spray with Bordeaux mixture when the first true leaf appears, making a second and third application when it is necessary to keep the foliage covered.

Bean Beetle.-Kill grubs on under side of leaves with kerosene emulsion ( 1 to 8 ) or spray with arsenate of lead.

Bean Weevil.-Fumigate beans for twenty-four hours in a tight vessel, using one tablespoonful of carbon bisulphide to the bushel.

Flea Beetles.-Spray with poisoned Bordeaux mixture.

BEET.-Leaf Spot.-Spray with Bordeaux mixture when four or five leaves have expanded, and repeat two or three times at intervals of ten to fourteen days.

Cut-rorms.-Use poisoned baits, and prevent [235] 
attack by early fall ploughing, harrowing, or disking.

Cabbage and Cauliflower.-Aphis.-Spray with kerosene emulsion, or a whale-oil-soap solution, when numerous, and repeat if necessary.

Cabbage Worm.- Spray with a poisoned resinlime mixture, if plants have not headed; otherwise use hellebore or kerosene emulsion.

Club Root.-Large clubs or knobs on roots. Dig up and destroy all infested plants, and give soil a heavy dressing of lime. Never plant either of these vegetables on land known to be infected.

Cut-worms. - Protect stems with bands of paper or use poisoned bait.

Harlequin Cabbage Bug.-Sow mustard early as a catch crop and destroy the bugs thereon with kerosene, or resort to hand-picking.

Root Maggot.-Protect plants with paper collars, or wet the surrounding soil with emulsion composed of one pound of soap, one gallon of boiling water, and one pint of crude carbolic acid diluted with thirty parts of water.

CELERY.-Blight.-Make fortnightly applications of Bordeaux mixture until plants are onehalf or two-thirds grown, then use an ammoniacal [236 ] 
copper carbonate solution every ten to fifteen days, if the weather is rainy.

Celery Worm. - A pea-green worm with black bands. Hand-pick and spray with Paris green or arsenate of lead.

ConN.-Earrorm.-A small worm which eats out the tip of the ear. Poison them by dropping dry Paris green in the axils of the leaves when plants are young. Plough deeply in fall and leave the land rough, so that frost can work through it thoroughly.

Cucumber. - Aphis. - Spray with kerosene emulsion or whale-oil soap as soon as they are noticed.

Striped Beetle.-A small black- and whitestriped beetle which is very active. Protect plants when young by screens, and dust them when wet with dew with ashes or lime. Spray with Bordeaux mixture containing arsenate of lead every two weeks to keep foliage well covered.

Squash Bug.-A dark-brown beetle which sucks the plant's juices. Hand-pick and destroy any eggs found on leaves. In the fall put down small boards or shingles, under which bugs will collect at night; gather and destroy.

\section{[237]}


Blight or Milderw.-Leaves become spotted or covered with down. Spray every two weeks with Bordeaux mixture.

Onion. - Blight. - Spray with two-thirds strength Bordeaux mixture at ten-day intervals.

Maggot.-Wet the surrounding soil with carbolic-soap wash, or remove the soil about the plants in the morning, replacing at night, so as to allow some drying of soil about the maggots.

Pea.-Aphis.-Spray with kerosene emulsion, or a whale-oil-soap solution, when it is necessary.

Weevil.-Same as for bean weevil.

Milderw.-White growth on stems and leaves. Spray with Bordeaux mixture containing resin wash to make it stick.

Potato.-Colorado Beetle.-Spray with Paris green or arsenate of lead every two weeks. To save time, add the poison to Bordeaux mixture when spraying for blight.

Flea Beetle.-Keep plants well covered with Bordeaux mixture.

Blight.-Spray every two weeks with Bordeaux mixture.

Scab.-Soak uncut tubers one and one-half hours in a solution of $1 / 2$ ounce of corrosive subli[238] 
mate to 8 gallons of water, or for two hours in a solution of one pint of formaldehyde to 15 gallons of water.

Squash.-Squash Borer.-Slit infested stem, and destroy the borer, covering the injured part with earth. Employ early trap vines.

Squash Bug.-Trap bugs under shingles laid about vines, destroying them every morning, and crush egg clusters. See, also, Cucumber.

Sweet Potato--Black Rot.-Select clean tubers, roll in sulphur, and, if possible, plant in soil free from infection.

Flea Beetles, Tortoise Beetles. - Dip young plants in arsenate of lead mixture, and spray ten days later, if necessary.

Tomato.-Leaf Blight.-Spray with Bordeaux mixture at seven- to ten-day intervals.

Flea Bectle.-Spray with poisoned Bordeaux mixture as needed.

Rot.-Treatment same as for leaf blight, though usually unsatisfactory.

Tomato Worm. - Hand-picking; spray with poison.

Other Vegetables.-Cut-worms.-Protect base of plant stems with strips of paper reaching just [239] 
below the surface. Use poisoned bait, or dig out and destroy.

\section{POISON FORMULAS}

Many .of the remedies advocated may be secured ready-made at the seed stores for use in the small garden. These ready-made mixtures are much more convenient for the amateur than the mixing of them from the raw materials. It is often necessary, however, to use considerable quantities and special combinations.

\section{Combined Insecticides and Fungicides}

Poisoned Bordeaux.-Mix 4 ounces of 'Paris green, or 1 pound of arsenate of lead with $\mathbf{5 0}$ gallons of Bordeaux mixture (see formula under Fungicides). This is the standard remedy for leafeating insects and fungous diseases.

\section{Insecticides}

Paris Green.-Use 1 pound, with an equal weight of thoroughly slaked lime, in 100 to $\mathbf{3 0 0}$ gallons of water. Keep well stirred while spraying.

Arsenate of Lead.-Use the prepared paste form, at the rate of about $\mathbf{1}$ pound to $\mathbf{5 0}$ gallons of [240] 
water, or it may be made by dissolving 11 ounces of acetate of lead (sugar of lead) in 4 quarts of water, in a wooden pail, and 4 ounces of arsenate of soda (50 per cent purity) in 2 quarts of water in another wooden pail. The process can be hastened by using warm water. Pour the solutions in from 25 to 50 gallons of water, mix, and the insecticide is ready for use.

Adhesive Poison.-Put 1 pint of fish oil, or any cheap animal oil except tallow, 5 pounds of resin, and 1 gallon of water in an iron kettle, and heat till the resin is softened, then add 1 pound of concentrated lye, in solution made as for hard soap; stir thoroughly, add 4 gallons of water, and boil about two hours, or until the mixture unites with cold water, making a clear amber-coloured liquid, and dilute to 5 gallons. Mix 1 gallon of this solution with 16 of water and three gallons of milk of lime, or thin whitewash; add thereto $1 / 4$ pound of Paris green or other arsenical poison. Recommended for spraying cabbage and other crops that have foliage to which it is difficult to make the insecticide adhere.

Poisoned BaIts.-Dip fresh clover, lettuce, or other attractive leaves in strongly poisoned water 
and distribute in infested localities. Twenty pounds dry middlings and 1 pound of Paris green, well mixed, is an attractive bait. A mash composed of 1 pound of Paris green to 50 pounds of bran, and sweetened with cheap sugar or molasses, is very attractive to grasshoppers. Paris green 1 part, salt 2 parts, and horse droppings (preferably fresh) 35 to 40 parts by measure, thoroughly mixed with enough water to make a soft though not sloppy paste, is a valuable grasshopper poison.

Kerosene Emulsion.-Dissolve $1 / 2$ pound of soap in 1 gallon of boiling water, add 2 gallons of kerosene, and force through a pump repeatedly for five to ten minutes; dilute four to twenty-five times before applying. In lime regions, where the water is hard, use a sour-milk emulsion, made by thoroughly mixing 2 gallons of kerosene and 1 gallon of milk, as described above.

WHALE-OIL-SOAP Solution.-Apply at the rate of $11 / 2$ to 2 pounds to a gallon of water in the winter, and for summer use employ at least 4 gallons of water to each pound of soap.

Ivory-soAp Solution. - Dissolve a five-cent cake in 8 gallons of water. Good for house plants.

Helcebore.-Mix thoroughly 1 ounce of fresh [242] 
white hellebore with 3 gallons of water. Use on fruits.

Tobacco Dust.-This waste from tobacco factories may be used freely in trenches around trees with roots infested with aphids.

Carbolic-soap WAsh.-Thin 1 gallon of soft soap with an equal amount of hot water, and stir in 1 pint of crude carbolic acid ( $1 / 2$ pint refined) and allow this to set over night, then dilute with 8 gallons of water. Or dissolve 1 gallon of soft soap in 6 gallons of a saturated solution of washing soda. Add 1 pint of crude carbolic acid and mix thoroughly. Slake enough lime in 4 gallons of water so that a thick whitewash will result, then add $1 / 2$ pound of Paris green and mix the whole together. Recommended for borers.

\section{Fungiciues}

Normal or 1.6 Per Cent Bordeaux MixTURE.-Dissolve 6 pounds of copper sulphate, by hanging it in a bag of coarse cloth in an earthen or wooden vessel containing 4 to 6 gallons of water, and then dilute with 25 gallons. Slake 4 pounds of lime diluting to 25 gallons and mix by pouring the two solutions into a third vessel. 
The amount of copper sulphate should be reduced to 4 pounds for peaches and Japanese plums, and some have used but 2 pounds each of copper sulphate and lime to $\mathbf{5 0}$ gallons, with excellent results. Employ the weaker formula whenever the normal proves too strong.

Ammoniacal Copper Carbonate.-Make a paste of 5 ounces of copper carbonate with a little water, and dilute 3 pints of ammonia (26 Beaumé) with 7 or 8 volumes of water. Add the paste to the diluted ammonia, stirring till dissolved, and add enough water to make 45 gallons. Allow it to settle and use only the clear blue liquid. This mixture loses strength on standing.

Potassium-sulphide Solution.-Dissolve 1/2 to 1 ounce of potassium sulphide (liver of sulphur) to 1 gallon of water.

Copper-sulphate Solution.-Dissolve 1 pound of copper sulphate (blue vitriol) in 15 to 25 gallons of water. Never apply this to the foliage. Use only before the buds break. For peaches and nectarines, dilute with 25 gallons of water.

Formalin.-Dilute 1 pound (1 pint) with 50 gallons of water, sprinkle on grain, stirring thoroughly and leave in piles for several hours for grain [244 ] 
smut. Use 1 pound to 30 gallons of water and soak seed potatoes therein for about 2 hours, for potato scab.

There are many kinds of apparatus for spraying, such as power-sprayers, barrel-pumps, bucketsprayers, and hand-sprayers, and they usually come fitted with proper nozzles. Where the work must be done by one person, the air-pressure sprayers are the best, as the machine can be charged, and all attention can be directed to the spraying. The 5 -gallon size is best for the small garden.

Another very good sprayer for the amateur with a small garden is a bucket spray-pump. These are the cheapest pumps on the market. Some sell for as low as two dollars, but I wouldn't advise any one's buying the cheapest. Pay from four to five dollars, and get a good one, with all the working parts of brass, which, with good care, will last a number of years. This style of sprayer comes with a short hose, which is convenient for spraying low shrubs and vegetables; but, if you have a few trees to spray, it will be necessary to buy an extra twenty-five feet of hose. To spray the tops of them, tie the nozzle on the end of a rake handle, and stand on a step-ladder to reach the highest parts. 
For this work you will need two persons-one to pump and the other to direct the spray.

Another form of spray-pump is the knapsacksprayer. The idea of it is very good, but they are never tight, and the motion of walking slops the liquid over the one doing the work. When using one of these, it is necessary to wear a rubber coat. If you are on friendly terms with your neighbours, and your garden and grounds are not large enough to warrant your investing in a sprayer by yourself, why not buy a good barrel-sprayer on shares? This will necessitate your giving each other a hand in the spraying, but the work can be done in much less time, and more effectively.

No matter what kind of a sprayer you have, always clean it thoroughly after using it, as some of the chemicals used in spraying, if allowed to remain in the pump, will destroy it in a short time. 
CHAPTER SIXTEEN

FALL WORK IN THE GARDEN

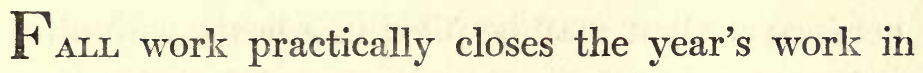
the garden, while, at the same time, it may be said to be introductory and initiative to the beginning of another season's work, as it clears the way for the first operations of the spring, and, if thoroughly done, simplifies it in a marked degree.

The first thing in order will be to clear away all rubbish that may have accumulated during the summer, and pile it on the compost heap, or if it is of a character not likely to be infested with the larvi of insects, to use it as a winter mulch about the trunks of fruit trees, about the rhubarb rows, or as a winter protection for the asparagus bed. If, however, the rubbish be in the nature of weeds, in which seeds exist, the best course will be to rake it into a light, dry pile and burn it. The resulting ashes will be of benefit to the garden.

The presence of sod along fence rows and about [247] 
the roots of trees is objectionable, and the fall is a good time to get rid of it, as after the fall rains have thoroughly soaked the ground, it is easily lifted and may be used to protect the beds of tearoses, wrapping a chunk of sod-grass-side outabout the roots of each plant, forming a cone, and securing it with a stout piece of binder twine if necessary. Or it may be piled in a heap, with alternating layers of cow manure, and left to decay until spring, when it may be used to enrich the rose or peony beds or other plants requiring fertilising. Again, it may be left where dug, simply turning it grass-side down about the trees or vines from which it was removed, until spring, when, if sufficiently decayed, it may be worked into the soil.

The fall is a good time in which to prepare for a very early crop of peas by trenching the ground where they are to be planted, filling in a generous quantity of well-rotted manure and placing the necessary amount of earth above this to receive the seed, leaving that portion which will be placed over the seed in a ridge along the trenches. The action of the frost will keep it loose and mellow, and as soon as the ground has dried sufficiently in the [248] 
spring the seed may be gotten into the ground with the least possible delay and labour.

It is possible that at this season there will remain a number of cabbage and cauliflower plants, especially the latter, which have failed to make heads. These may be lifted and planted in coldframes, or even protected where they are by banking the earth about the stems and protecting the tops with straw, and used for very early planting in the spring. Or if a few rough boards can be run along one side of them where they stand to form a shelter from the west wind and a little litter of corn fodder thrown over them to form a shed, they will usually come through all right.

If a similar protection is given the parsley bed, using evergreen boughs, if procurable, for the shelter on the leaward side, parsley can usually be had all winter.

Every effort should be made at this season to get rid of all insect pests which hibernate in any form; a few hours spent in this work will be well repaid. The cut-worm, which is the first pest to appear and cause trouble in the spring, hibernates in the worm form usually and may be discovered along the edges of the sod land under boards and [249] 
other rubbish which lie close to the ground; he does not go far in the earth at this time of year, and a light scraping of the surface of the ground will unearth him in numbers; wherever found, he should be killed at once. Most of the borers change into smooth, brown chrysalids in the fall, and are found in the ground not far from the surface. Fall ploughing and spading is of much benefit, as it destroys considerable numbers of these pests. The cabbage butterfly lays its eggs and hatches out the succulent green worm, which, arriving at an adult stage, spins itself a silken chrysalid which is transmitted into a hard, paper-like shell, which will be found attached to the underside of the window sills, house siding, and other favourable places, the worms sometimes travelling considerable distances to find favourable winter quarters, the shelter they require being of the slightest, a quarter of an inch of projecting wood seeming to meet all requirements.

The tomato worm enters the ground to a considerable depth before changing into the large brown chrysalid, with its curious-shaped handle, which is the case for its equally curious tongue. In studying these worms at close range, it was always 
one of the difficulties in their rearing to give them boxes of earth of sufficient depth to induce them to change at the right time. They would enter the earth and penetrate to the bottom and return again and again to the surface, each time more irritable and uneasy, until finally Nature proved too much for them and they were compelled to accept conditions as they found them. It is a very fascinating study-this of the moths and butterflies-when one can watch them through the four changeswinged creature, infinitesimal egg, the curious, often beautiful, worm, and its still more curious shell and cradle through which it braves the storm of winter as it waits for the resurrection of the spring. The worms lose much of their repulsiveness when studied at close range, and in captivity soon come to know one and to show none of the signs of irritation displayed by the wild worms, or the tame ones in the presence of strangers.

Many gardeners make a practice of hauling manure to the garden in the fall, that it may leach into the soil during the winter and be ready to turn under in the spring; this is of doubtful value, as much of the substance of the manure is lost. A better plan would be to pile the manure 
under shelter, where it would be protected from the action of the elements, and to fork it over often during the winter to prevent heating, and then to draw it on the land early in spring while yet the ground is frozen enough to get on to it easily. In a small garden plot it is seldom, if ever, necessary to use much rough manure, and it will be well to fork out all the cornstalks and coarse material and pile them in a heap to burn, or better compost them, as they are nothing but a nuisance in a garden.

In February the wood ashes which may have accumulated during winter may be spread on the asparagus beds and along the rhubarb rows, and, if there are enough, about the fruit trees and berry bushes.

If one has a few choice fruit trees it will be time well spent to give them a coat of whitewash at the approach of severe weather and again at intervals during the winter, making at least three applications, the last to precede the cold waves of February and March, according to locality. This will protect the trees by preventing the absorption of sun heat and enable them to withstand the rigours of the winter. 
A heavy mulch about the roots of the fruit trees in any section where there is a light or no snowfall will be of the greatest benefit.

It is a good plan to place the manure directly on the ground in the fall or early winter under the trees; it is also an excellent time to secure it and so have it in readiness for early spring use, and if there is no convenient place in which to store it, it may still be engaged and its time of delivery fixed, always remembering that old manure is what is wanted and that that will be found at the bottom of the pile, and it should be clearly stipulated that this is what is to be delivered.

If any seeds have been saved from the garden, these should be sorted out and stored in properly labelled bags or boxes against the time they will be wanted in the spring. In addition to the label the packets should always bear the date of their saving, as seeds are often carried over from year to year, and, not being dated, quite old seeds, unfit for planting, often comes to be used much to the hindrance and loss of the gardener. While seeds are little affected by frost, I prefer to store them in a dry, frost-proof place if possible, and it is especially important that they be kept out of the reach 
of mice, which much enjoy a banquet of melon, squash, or pumpkin seeds and do not disdain less succulent morsels.

The long winter evenings and any stormy days which find one at leisure may profitably be spent in getting ready for spring work, by putting all the tools in first-class order, painting them when necessary, oiling and sharpening them to a working edge. Racks for tomatoes may be manufactured quickly and cheaply by using three or four stakes with pointed ends and a couple of iron or wooden barrel hoops. These are nailed to the top of the stakes and to a point nine or ten inches below and are set over the plants as soon as they begin to make growth. Boxes for covering the melon hills may also be prepared and the frame for the hotbeds, if one is not already supplied with that convenience. Stakes for marking rows of vegetables will be little work to prepare and will save time in the hurry of planting.

Many of the racks and trellises used about the garden during the summer will serve for another season if taken up and stored in a dry place over winter; especially will this be the case if any metal or wire parts are concerned. Fences and walks [254] 
should be given attention and put in condition to stand the weather. Gates are prone to sag on the hinges and posts to work loose under the force of a winter's gale, and an hour's work in this portion of the yard may save a day's work during the busy time of spring.

And last, but not least, it will be a good plan to make a brief but orderly record of the season's work, noting down all failures and their cause, recording all new information which has been gained, such as the amount of time it requires for the various seeds to germinate, the length of time it takes for the different vegetables to come into bearing, the proportion of seed which germinated, the causes, as far as known, for any seed to fail to grow, the quality of the several varieties of vegetables, and any data as to better varieties grown in a neighbour's or market gardener's grounds.

All this data will be of value in starting the next season's garden, and will be always available and reliable, which is seldom the case where the memory alone takes charge of these items.

The record may also give account of the expenditures and receipts, though, as far as this goes, it is sometimes more comfortable not to look too

[255 ] 


\section{THE VEGETABLE GARDEN}

closely into the details when gardening for pleasure or for the privilege of eating one's own vegetables. One must sacrifice something in learning to garden, just as the young housewife sacrifices her eggs and butter and flour in learning to cook; it is the resultant knowledge, after all, which counts, and if the work is done in one's spare time, with little labour hired, the balance cannot be far on the wrong side. 


\section{N D E X}

Ammoniacal copper carbonate, 244. Anthracnose, 234, 235.

Aphis, 234, 237.

Arsenate of lead, 240.

Artichoke, 70.

Ashes, 46.

Asparagus, 23, 206, 235.

beetle, 234 .

cooking, 212.

forcing, 210.

Bait, poisoned, 95, 241.

Bean, 23, 26, 104, 231, 235.

Beans, lima, 105.

recipe for cooking, 107.

Beetle, asparagus, 234, 235. bean, 235 .

flea, 234, 235, 239.

potato, 234, 238.

striped, 180, 237.

Beets, 23, 50, 78, 142, 235.

cooking, 143.

Berries, 28.

Blight, celery, 236.

cucumber, 238.

melon, 234.

potato, 234.

Bone, 38.

Bordeaux mixture, 235, 240, 243.

Borer, 234, 239, 250.

Cabbage, 10, 14, 15, 23, 27, 50, 65, $70,78,85,95,109,232,234$, 236, 249.

recipe for cooking, 111.
Cabbage, to prevent cracking, 110. worm, 234, 250.

Carbolic soap wash, 243.

Carbon bisulphide, 235.

Carrots, 10, 23, 145, 229. cooking, 147.

Cauliflower, 10, 14, 23, 27, 65, 70, 95, 113, 236, 249. cooking, 116.

Celery, 15, 50, 230, 236, 237.

Club root, 234, 236.

Coldframe, 48, 53, 70, 249.

Compost heap, 247.

Concrete, 59.

Copper carbonate, ammoniacal, 244. sulphate solution, 244.

Corn, 8, 10, 23, 78, 118, 237.

cooking, 121.

ear-worm, 234, 237.

salad, 26, 196.

Cress, serving, 195.

upland, 195.

water, 195.

Cucumber, 5, 24, 25, 26, 78, 176, 179, $181,234,237$.

pickles, 185.

serving, 183.

Cultivation, 91.

Cultivator, horse, 98.

Currants, 5.

Cutworms, 94, 234, 235, 239, 249.

Damping off, 68.

Diseases, 233. 
Egg plant, 64, 65, 85, 122. cooking, 124.

Endive, 26, 196. salad, 197.

Enemies, garden, 233.

Fall work, 247.

Fertiliser, 26, 29, 209. amount to apply, 35, 42 .

Fire bug, 234.

Flea beetle, 234, 239.

Formalin, 244.

Fungicides, 243.

Fungus, 235.

Garden, planning the, 22. site of, 12.

Gardening, coöperative, 9.

Gooseberry, 5.

Grape, 5.

Harlequin bug, 234, 236.

Hellebore, 242.

Herbicide, 6.

Hoe, 99. wheel, 96.

Horseradish, 221.

Hotbed, 47, 53. manure for, 59.

Humus, 14, 29.

Insecticides, 235, 240.

Insects, 233.

Irrigation, 18.

Ivory soap, 242.

Kale, 198.

Kerosene emulsion, 242.

Leaf blight, 239. spot, 235.
Lettuce, 23, 26, 50, 70, 73, 78, 198. serving, 200.

Lime, 44.

Maggot, 234, 236, 238.

Mangoes, pickled, 188.

Manure, 30, 59. green, 31 .

Melon, 5, 10, 24, 25, 26, 78, 176, 186, 234.

pickle, 187.

Mildew, 234, 238.

Mulch, 89, 91, 150, 181, 208, 247, 253.

Mustard, 26, 201.

Nitrogen, 34, 35.

Okra, 125.

Onion, 10, 18, 26, 50, 78, 149, 238. cooking, 152. maggot, 234. transplanting, 151.

Paris green, 5, 95, 160, 240, 242.

Parsley, 26, 223, 249.

Parsnip, 10, 153, 229. cooking, 155.

Peas, 8, 10, 23, 26, 78, 130, 238, 248. cooking, 133.

Pepper, 64, 65, 85, 127. cooking, 128.

Phosphoric acid, 38.

Plant protectors, 254.

Plants, hardening of, 84. protection for, $66,68,82,89$, 254.

Poison, 5, 6, 240. adhesive, 241. 
Poisoned bait, 95, 241.

Potash, 40.

Potassium-sulphide, 244.

Potatoes, 10, 23, 27, 40, 157, 227, 238.

cooking, 163.

Potato beetle, 160, 234.

Protection, winter, 249.

Pumpkins. 24.

Radish, 8, 23, 26, 50, 73, 169.

Recipe, asparagus loaf, 214 . omelette, 214. on toast, 215 . soup, 212.

beans, cooking, 107, 108, 109. bean salad, 108.

bechamel sauce, 215 .

beets, baked, 143.

boiled, 144 .

greens, 143.

stewed, 144.

cabbage, cooking, 111. salad, 113.

carrots, cooking, 147.

cauliflower, boiled, 117.

fried, 117.

pickled, 118.

corn, boiling, 121.

fritters, 121.

soup, 121.

cress serving, 195.

cucumber à la crême, 184.

pickles, 185.

serving, 183.

egg plant, fried, 124.

stuffed, 125.

endive salad, 197.

lettuce salad, 201.

mangoes, pickled, 188.
Recipe, melon pickle, 187. mustard as greens, 202. okra soup, 126. onion, fried, 152. stuffed, 152.

parsnip, boiled, 155. fried, 155.

fritters, 156.

stewed, 156.

peas, cooking, 133.

peppers, fried, 128.

pickled, 130.

stuffed, 129.

potato, boiled, 163.

croquets, 167.

fillets, 168.

fried, $163,167$.

lyonnaise, 165.

puffs, 164 .

scalloped, 166.

soufflé, 164.

pumpkin pie, 192.

rhubarb pie, 219.

sauce, 221.

salsify, fried, 172.

slaw, 112.

spinach balls, 205 .

boiled, 203.

cream of, 204.

squash, baked, 191.

boiled, 191.

pie, 192.

succotash, 108.

tomato, fried, 139.

scalloped, 138.

soup, 139.

stewed, 137.

stuffed, 138.

with macaroni, 138.

Records, 255. 
Rhubarb, 23, $21 \%$. cooking, 219. forcing, 218.

Rust asparagus, 234, 235. celery, 234.

Salads, 194. lettuce, 201.

Salsify, 78, 171. cooking, 171.

Scale, 234, 238.

Seeds, order early, 76. sowing, 75. stormy, 253.

Soil testing, 45.

Spade, 101.

Spinach, 26, 78, 202. cooking, 203.

Spraying, 160, 233, 235.

apparatus, 245.

Squash, 5, 23, 24, 26, 176, 189, 229, 234, 239.

bug, 237, 239. cooking, 191.

Storing vegetables, 226.

Sweet potato, 239.
Tankage, 36, 39.

Thomas slag, 38.

Thrip, 234.

Tobacco, 40. dust, 243.

Tomato, 10, 23, 27, 64, 65, 78, 93, $95,134$.

cooking, 136.

rot, 239.

worm, 234, 239, 250.

Tool shed, 17.

Tools, 96. cleaning, 254.

Transplanting, 69, 84, 151.

Trellis, 254.

Trenching, 248.

Turnips, 78, 172, 229, 230. cooking, 173.

Water-cress, 195.

Weevil, 235, 238.

Weeds, 6.

Whale oil soap, 242.

Wheel-hoe, 96.

Whitewash on fruit trees, 252.

Wood ashes, 252.

\section{THE END}

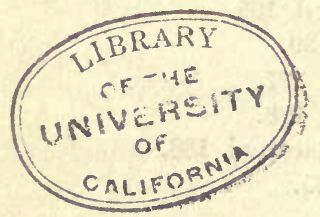



UNIVERSITY OF CALIFORNIA LIBRARY

THIS BOOK IS DUE ON THE LAST DATE STAMPED BELOW

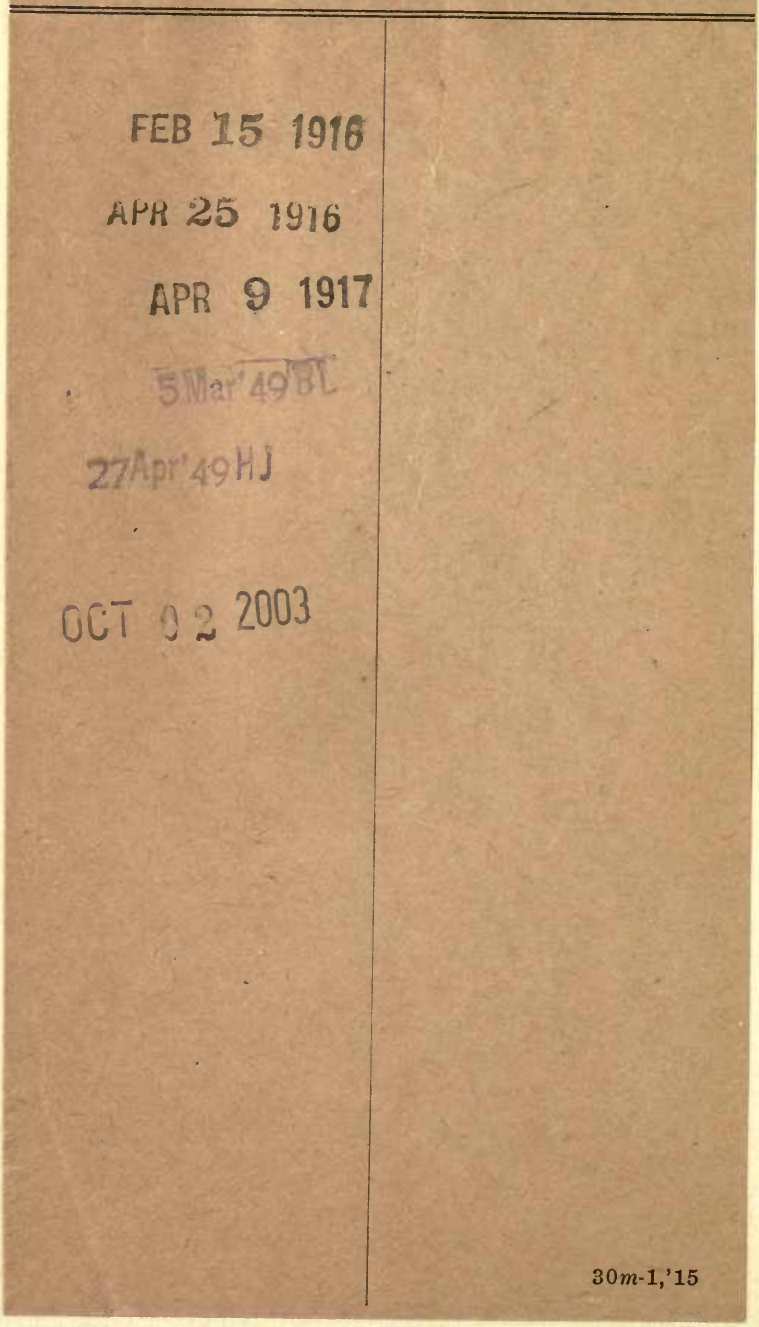



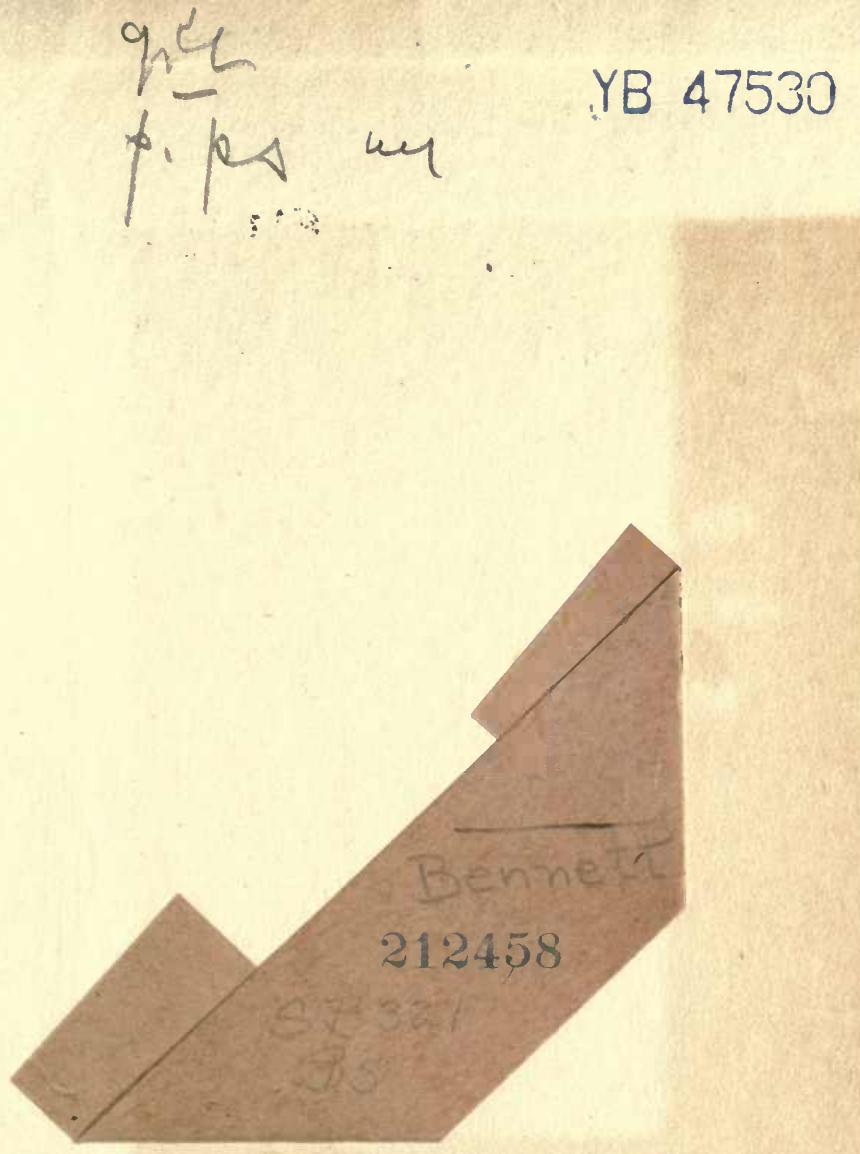
